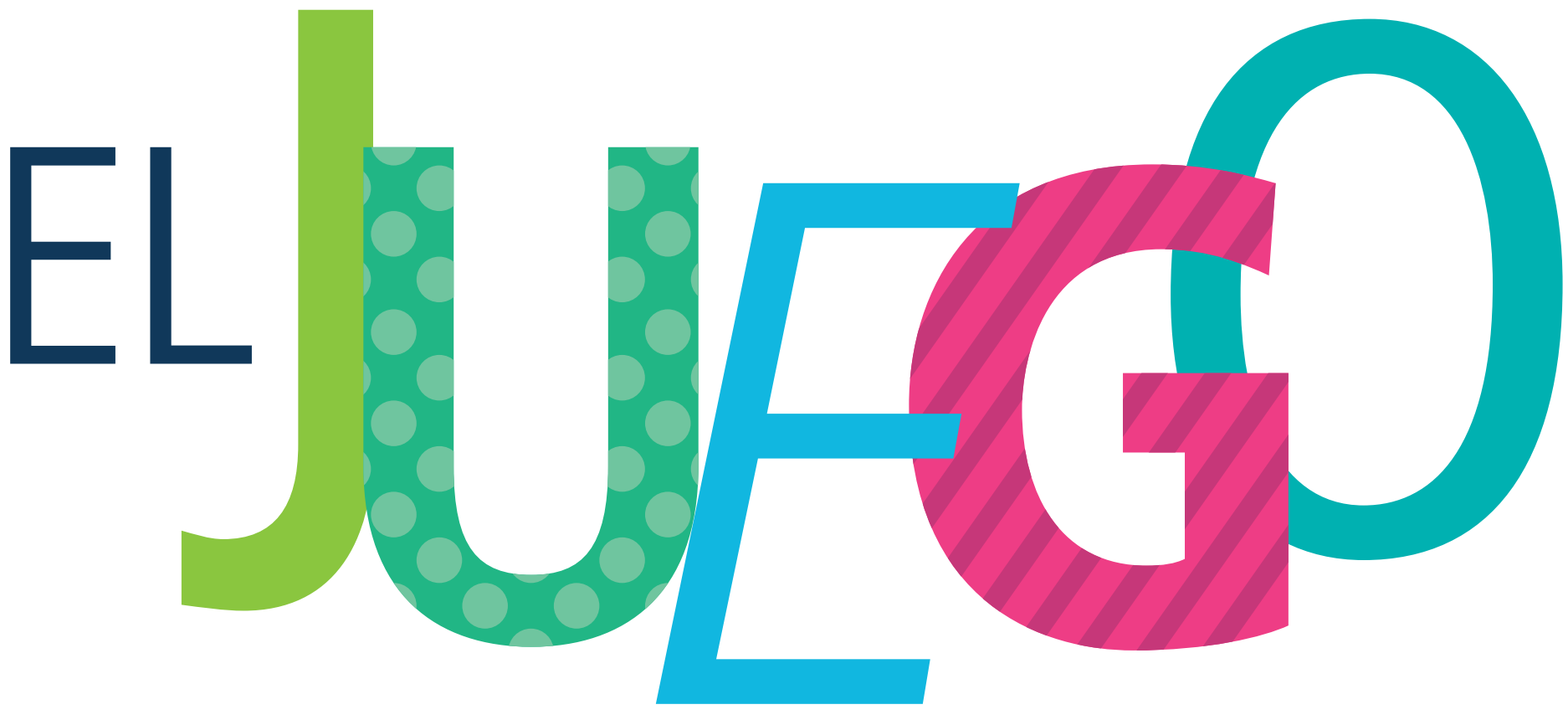

\title{
un asunto serio \\ en la formación \\ de los niños \\ y las niñas
}
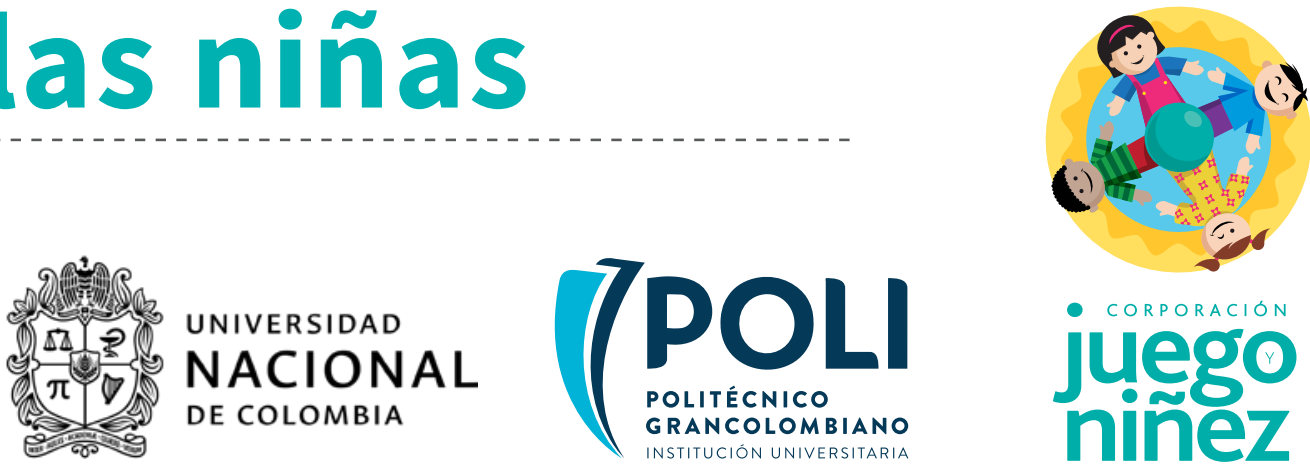



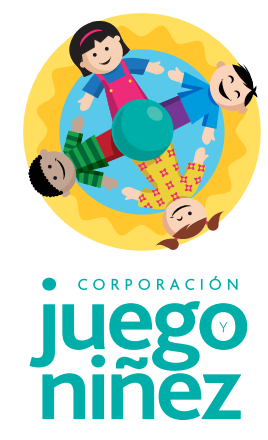

Nacimos hace 20 años en Colombia y nos hemos transformado al aprender jugando- como un asunto muy serio- con niñas, niños, adolescentes y sus abuelos; docentes, padres, gobernadores, alcaldes, empresarios y padrinos de ludotecas; Presidentes de la República y sus esposas.

Todos ellos han aportado considerablemente a que se garantice el derecho a jugar, con el objetivo de evolucionar y transformar con juego, en todo el ciclo de la vida y desde la casa, la Educación en Colombia.

Este es el VI libro que publicamos sumado a miles de páginas sin editar y el primero en Colombia y en el mundo de una investigación longitudinal centrada en juego y ludotecas, que convenimos durante 4 años con la Universidad Nacional al presentar con evidencia científica lo que significa disfrutar del tiempo en las Ludotecas NAVES ${ }^{\odot}$.

Lo ponemos en circulación desde nuestro quehacer misional cuyo propósito es hacer transformación social desde el juego en proyectos con primera infancia, niñez y adolescencia en casas, centros de desarrollo, salones de clase, hospitales, bibliotecas, parques, centros comerciales, y por supuesto espacios lúdicos y culturales como son las Ludotecas NAVES ${ }^{\circledR}$, modelo que sigue en creación con ludotecarios y educadores para cerrar las brechas de la educación en Colombia. Ludotecas que se movilizan en cada territorio a partir de lo que es la vida cotidiana de cada participante y su gran diversidad. 


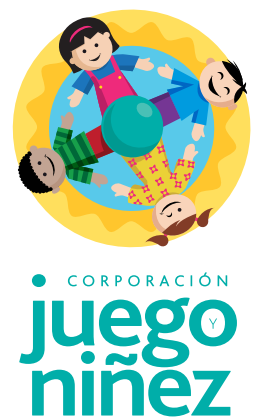

\section{Consejo de Fundadores de Corporación Juego y Niñez}

I. Ruth Camelo C.

Alejandro Rivas R.

Fernando Martelo M.

Jorge Silva L.

\section{Junta Directiva 2019}

1. Politécnico Grancolombiano: Leonardo Gil Q Rector

2. Chevron Colombia: Patricia Serrano Gerente Asuntos Corporativos América Latina

3. Coca- Cola Femsa Colombia: Silvia Barrero Directora Asuntos Corporativos

4. Nestlé de Colombia: Antonio Nuñez Presidente y Oscar Recio Vicepresidente Recursos Humanos.

5. Consuelo Carrillo: Consultora Financiera

6. Gabriel Burgos: Consultor Educación

7. Alejandro Rivas R.: Empresario Fundador

8. Fernando Martelo M.: Consultor Fundador

9. Jorge Silva L.: Gerente Colombia y Perú Amazon WS

Revisoría Fiscal: Pricewaterhouse auditores y contadores Ltda 


\section{EL JUEGO}

UN ASUNTO SERIO EN LA FORMACIÓN DE LOS NIÑOS Y LAS NIÑAS 



\section{EL JUEGO}

UN ASUNTO SERIO EN LA FORMACIÓN DE LOS NIÑOS Y LAS NIÑAS

Rita Flórez Romero

Jaime Castro Martínez

I. Ruth Camelo C.

Fernando Martelo Martínez

Irma Salazar Montenegro

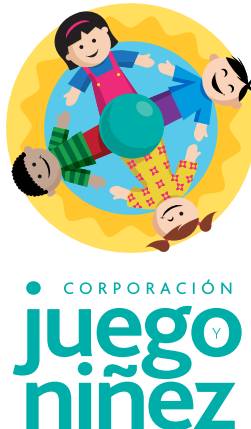




\section{POLI \\ POLITÉCNICO \\ GRANCOLOMBIANO \\ INSTITUCIÓN UNIVERSITARIA}

\section{(C) Institución Universitaria Politécnico Grancolombiano}

EL JUEGO: un asunto serio en la formación de los niños y las niñas

ISBN: 978-958-5544-22-2

E-ISBN: $978-958-5544-23-9$

Digital ISBN: $978-958-5544-24-6$

Octubre 2019

Editorial Politécnico

Grancolombiano

Calle 61 No. 7 - 66

Tel: 7455555, Ext. 1516

Bogotá, Colombia

\section{Autores}

Rita Flórez-Romero

Profesora Titular

Universidad Nacional de Colombia

\section{Jaime Castro-Martínez}

Docente Investigador

Institución Universitaria

Politécnico Grancolombiano

\section{Ruth Camelo C.}

Directora Ejecutiva

Corporación Juego y Niñez

\section{Fernando Martelo Martínez}

Presidente Consejo Fundadores

Corporación Juego y Niñez

Irma Salazar Montenegro

Gerente Técnica

Corporación Juego y Niñez

\section{Lider de publicaciones}

Eduardo Norman Acevedo

\section{Edición del Libro}

I.Ruth Camelo C. - Irma Salazar M.

Analista de Producción Editorial

Carlos Eduardo Daza Orozco

\section{Corrección de Estilo}

Hernán Dario Cadena

\section{Fotografías}

Patricia Arcos - Adriana Camelo Yuselfi Bermudez - Eliana Mejía Johana Méndez - Oscar Meneses Santiago Montaño - Irma Salazar Ricardo Salazar - Liseth Silva

Filiberto Yepes

\section{Diseño y Armada Electrónica}

Kilka Diseño Gráfico

\section{Impresión}

Xpress Estudio Gráfico

y Digital S.A.S

¿Cómo citar este libro?

Flórez-Romero, R., Castro-Martínez.

J., Camelo, R., Martelo Martínez,

F., \& Salazar Montenegro, I. (2019).

EL JUEGO: un asunto serio en la formación de los niños y las niñas (Vol. 1). Bogotá: Editorial Politécnico Grancolombiano.

\section{Creado en Colombia}

Todos los derechos reservados

No se permite la reproducción total o parcial de esta obra, ni su incorporación a un sistema informático, ni su tratamiento en cualquier forma o medio existentes o por existir, sin el permiso previo y por escrito de la Editorial de la Institución Universitaria Politécnico Grancolombiano

Para usos académicos y cientificos, la Institución Universitaria Politécnico Grancolombiano accede al licenciamiento Creative Commons del contenido de la obra con: Atribución - No comercial - Sin derivar - Compartir igual

El contenido de esta publicación se puede citar o reproducir con propósitos académicos siempre y cuando se dé la fuente o procedencia

Este libro es resultado de un proceso de investigación y ha sido evaluado por pares ciegos cumpliendo con los criterios de selectividad, temporalidad, normalidad y disponibilidad propuestos por COLCIENCIAS.
Grupos de investigación:

- Cognición y lenguaje en la infancia

- Psicología educación y cultura

Las opiniones expresadas son responsabilidad exclusiva del autor(es) y no constituye una postura institucional al respecto

La Editorial del Politécnico Grancolombiano pertenece a la Asociación de Editoriales Universitarias de Colombia (ASEUC) 


\section{Tabla de contenido}

\section{PRESENTACIÓN}

$--\cdot-\cdot-\cdot-$

¡Es hora de jugar!

CAPÍTULO 1

CAPITULO

El juego en el desarrollo infantil desde las ludotecas NAVES

20

\section{CAPÍTULO 2}

CAPITULO 2

La importancia de evaluar el impacto de las ludotecas en Colombia

CAPÍTULO 3

- - - - - - - -

Juego y ludotecas en el desarrollo de competencias ciudadanas,

emocionales y de creatividad en niños: estableciendo una línea base

CAPÍTULO 4

- - - - - - - -

El impacto de las ludotecas en el desarrollo de competencias ciudadanas, emocionales y de creatividad: hallazgos finales

CAPÍTULO 5

- - - - - - -

Conclusiones y Recomendaciones 



\section{¡Es hora de jugar!}

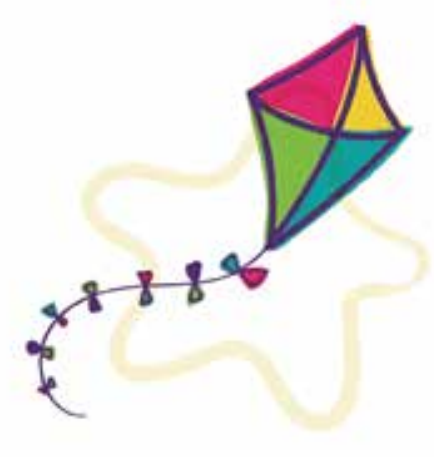

Existe una voluminosa bibliografía y testimonios de experiencias y prácticas acerca de las bondades del juego en el desarrollo humano que dicen, palabras más palabras menos, lo que afirma el presente libro -comprobado con investigación rigurosa de campo en nuestro país. 
Una lista de autores y trabajos académicos aparecerá en este libro, dándole base al marco conceptual sobre el cual se realizó esta primera investigación longitudinal en Colombia, sobre el impacto del juego jugado con Metodología Naves (niños, niñas aprendiendo,viviendo, experimentando y socializando), en seis ludotecas en seis municipios. Adicionalmente, tenemos a los autores e instituciones que vienen insistiendo cada día más en la importancia de las habilidades que se están atrofiando y que, por lo tanto, se necesitan desarrollar para vivir una vida plena en el mundo de hoy. Goleman las popularizó bajo el concepto de Inteligencia Emocional (2008), y subtituló su libro, "Por qué es más importante que el cociente intelectual". James Heckman ganó el premio Nobel de economía en el año 2000 por su trabajo, analizando datos de 40 años de estudios longitudinales en los Estados Unidos que lo llevaron a concluir que las habilidades blandas son tan o más importantes que el IQ para tener éxito en la vida, sobre todo cuando se forman desde edad temprana (Heckman, 2000). Kahneman, también premio nobel de economía, fue el primer psicólogo en ganar ese mismo premio lográndolo con sus estudios que resaltan la importancia de las emociones en el gobierno del pensamiento rápido (Sistema 1), en la toma de decisiones (Kahneman, 2012). Y esas son algunas de las habilidades que desarrolla el juego bien jugado.

Sabemos por todos ellos que el juego es:

“parte fundamental del ser humano, es una necesidad vital, que contribuye con el desarrollo de habilidades y potencialidades cognitivas, sociales, psicomotrices, emocionales, comunicativas, espirituales y estéticas; de la misma forma, transmite y transforma la cultura, permitiendo expresar, recrear y transformar la realidad de quienes lo viven, generando cambios en situaciones y comportamientos hacia la convivencia y la ciudadanía". (Salazar \& Flórez, 2019, p.62)

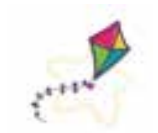


Francesco Tonucci (Fratto, 2015), nos viene diciendo, con ese tono afectuoso que le caracteriza, que el juego debe considerarse como un deber que hay que cumplir todos los días. Desde otra orilla, nos llama la atención que la Academia Americana de Pediatría esté recomendando a los pediatras recetar jornadas de juego diario. Así tal cual. En un reciente documento titulado El Poder del Juego (Yogman, Garner, Hutchinson, Hirsh-Pasek, \& Golinkoff, 2018), la academia muestra su preocupación con la disminución del tiempo que los niños dedican tanto en la escuela como en la vida hogareña a jugar a sus anchas. Y como demostración que el juego está en la agenda del día, en la versión 2019 del Foro Económico Mundial en Davos se lanzó la Real Play Coalition.

Martha Nussbaum (2014), entre sus Diez Capacidades Funcionales Humanas Centrales dedica una especialmente a la capacidad para "jugar y ser capaces de reír y disfrutar de actividades de ocio" (p.500). Y como derecho, el juego aparece en todas las legislaciones del mundo, empezando por la Declaración de los Derechos de los Niños de las Naciones Unidas.

Desde diferentes ópticas y en todos los continentes nos vienen reflexiones sobre el papel central que tiene el juego en nuestras vidas, llegándose incluso a necesitar revistas especializadas para su publicación, como por ejemplo, la American Journal of Play, que publica cuatro números al año desde 2008, y que hace parte de The Strong, el museo y biblioteca más grandes del mundo dedicados a la historia y la importancia del juego, bajo la inspiración de Brian Sutton-Smith (1924-2015), autor de La Ambigüedad del Juego (2009) y otros textos fundamentales.

Según el laureado biólogo Edward Wilson (1982), la creatividad es el rasgo que define nuestra especie y su objetivo definitivo es la autoconciencia, el poder entender quiénes somos y preguntarnos para dónde vamos. Así mismo, la evo- 
lución por selección natural de grupo estimuló la comunicación, el lenguaje, las historias y, por consiguiente, premió el desarrollo de la inteligencia emocional y el altruismo, gracias a los cuales sobrevivimos como especie. Otros han estudiado el juego en el comportamiento de los animales. Y estos son solo algunos. Algunos de los muchos y muchas que ven claramente la conexión juego - desarrollo humano - vida plena y que han encontrado inspiración en Huizinga (1972), y su clásico Hommo Ludens.

Sin embargo, no todas las corrientes pedagógicas le dan esa importancia al juego, porque ven al ser humano como un cajón vacío que se va llenando de repeticiones, de instrucciones e información. Y el juego implica libertad, exploración, imaginación, sentido de los otros jugadores, buen humor, manejo de situaciones difíciles y frustraciones, alegría de jugar. Actitud lúdica lo llaman algunos, a otros les daremos permiso de llamarlo "mamagalllismo", jugar a toda hora con las palabras y las situaciones. El mismo García Márquez, en su Proclama de los Sabios (2014/original publicado en 1994), nos lo dijo claro y directo:

\begin{abstract}
“Creemos que las condiciones están dadas como nunca para el cambio en nuestras sociedades, y que la educación será su órgano maestro. Una educación, desde la cuna hasta la tumba, inconforme y reflexiva, que nos inspire un nuevo modo de pensar y nos incite a descubrir quiénes somos en una sociedad que se quiera más a sí misma. Que aproveche al máximo nuestra creatividad inagotable y conciba una ética -y tal vez una estética- para nuestro afán desaforado y legítimo de superación personal". (p.24)
\end{abstract}

Él y los sabios recomendaron hacer de Colombia un país al alcance de los niños, porque un país así estará al alcance de todos para que todos alcancemos

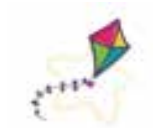


una vida plena. Un país donde la vida se viva en unos entornos que privilegian las habilidades socioemocionales y la creatividad.

Es tan importante llamar la atención sobre el asunto, que ha sido la misma OCDE (UNESCO-OCDE, 2016), la que ha tenido que preguntarse “¿Cuáles son las habilidades que impulsan el bienestar y el progreso social?" Al respecto, responde que:

“... ya es reconocida la necesidad de desarrollar un "niño completo", dotado de una serie equilibrada de habilidades cognitivas, sociales y emocionales que le permitan enfrentar mejor los desafíos del siglo XXI. Las habilidades sociales $\mathbf{y}$ emocionales no tienen un papel aislado: interactúan con las habilidades cognitivas, se estimulan unas a otras y mejoran aún más la probabilidad de que los niños consigan resultados positivos en el futuro". (p.11-12)

Y nos parece que aquí queda zanjada la cuestión.

Y de eso trata este libro. De presentar soporte con evidencia científica de lo que significa disfrutar del tiempo en las Ludotecas NAVES ${ }^{\circledR}$. Queremos que sea de gran utilidad para los que creen y cátedra de iniciación para quienes aún no lo entienden del todo.

Y no es este un tema solo teórico que puede admitir poca o mucha discusión, sino que esperamos que una vez comprendido se traduzca en acciones concretas en las poblaciones, en los colegios, en las políticas públicas que tienen que ver con desarrollo humano y social, que así deben ser todas. 
Y aquí pedimos permiso para hablar de nosotros y aclarar qué papel tenemos en todo esto. En la Corporación Juego y Niñez (CJN), tenemos esta pasión por el juego para contribuir a la vida en un mundo más lúdico y feliz, y por eso creamos en 1999 el Día de la Niñez y la Recreación, que se elevó como Ley de la República en diciembre de 2001. Todos los años mucha gente de nuestro país se prepara y dedica el mes de abril a recordarle al mundo que escuchen las voces que juegan cantando y que miren las manos que juegan pintando y pintan jugando, y participando llenan todo a su paso con su energía y buena onda.

La CJN tiene como propósito hacer transformación social desde el juego, considerado como lenguaje natural del ser humano, para lograr el desarrollo de las personas y sus comunidades. Para nosotros, los niños, niñas, adolescentes y jóvenes de Colombia se empoderan para influir en su realidad cuando fortalecen sus habilidades para la vida y su creatividad, jugando con una metodología basada en juego, científicamente probada, y por eso fue indispensable fomentar esta investigación con la Universidad Nacional de Colombia, porque la niñez en este país requiere que la dejen jugar y era necesario ratificar, con evidencia local, para convencer a los adultos que cuando jugamos nos conectamos con lo bueno, con lo mejor del ser humano. De esta manera concebimos que Colombia necesita avanzar en el desarrollo de las nuevas generaciones, y que el juego es el método ideal para su logro.

Esta fue la idea que nos motivó a crear e impulsar las ludotecas en Colombia en el año 2001. La ludoteca es un espacio de juego en donde las niñas y los niños desarrollan todo su potencial porque crean y recrean su cotidianidad, construyendo nuevos sentidos e incorporando reflexiones para generar nuevos aprendizajes, despliegan todo su potencial, viven una vida plena y mejoran su entorno. Para lograr esto es necesario formar cuidadores y propiciar entornos

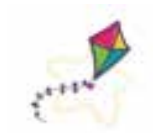


protectores de niñas, niños y adolescentes para que puedan desarrollar sus habilidades socioemocionales, su ciudadanía y su creatividad.

De este empeño nacen los y las ludotecarias, quienes vibran con la energía que tienen que canalizar todos los días. El ludotecario es un facilitador e inspirador del juego, inquieto y dinámico, quien dispone los recursos de la ludoteca para generar experiencias en las vidas de los participantes, aportando a la transformación de su ser, su hacer y su estar en el mundo.

Siempre nos han distinguido por nuestra atención al detalle, a la observación y la sistematización de experiencias y saberes, capacidad que se plasmó en la Metodología Naves ${ }^{\circledR}$ en 2008.

El trabajo de campo, y muchas veces en el campo, cerca de lo rural y lo urbano extremo, nos dio la garra suficiente para implementar un forma de administrar proyectos sociales, fundamentada en buenas prácticas gerenciales, con el acompañamiento de las personas de nuestro consejo directivo, conformado por líderes de empresas de primer nivel y del sector educativo.

Y lo más importante, la gente y el milagro del desarrollo humano y social. No poca cosa hemos aprendido de los niños y las niñas que nos han acogido y vienen a jugar con nosotros, lo que es un privilegio. $Y$ de sus familias. $Y$ de sus cuidadores. Y comprobamos a diario que también hay funcionarios que los respetan y se ocupan de sus cosas en sus corregimientos, municipios y gobernaciones.

Especial crédito debemos darle al papel que la academia colombiana ha tenido en el desarrollo de nuestras ideas, midiendo lo que hacemos en la práctica. En este caso, el Grupo de Investigación Cognición y Lenguaje en la Infancia 
y el Observatorio de Infancia, de la Universidad Nacional de Colombia, bajo la batuta de Rita Flórez-Romero y el Grupo de investigación Psicología educación y cultura con la participación del profesor Jaime Castro Martínez, investigador de la Institución Universitaria Politécnico Grancolombiano, quienes se midieron al reto de medir y probar lo que la intuición nos sugería. A ellos, nuestro reconocimiento por su dedicación e imparcialidad.

Queremos que Colombia sea un país que juegue. Un país que le sigue el juego a sus niños y niñas, adolescentes y jóvenes, porque "El juego es el recurso natural más importante en una economía creativa", tal como lo afirma Laura Seargeant Richardson (2011), Directora Creativa en la firma Argo Design, una firma global de innovación, quien ha llegado al extremo de afirmar que "en el futuro, las economías no serán impulsadas tanto por el capital financiero o incluso el capital científico, también lo serán por su capital de juego". Yo predigo que los países que toman el juego en serio, no exclusivamente nutriendo con él la educación, y a la fuerza de trabajo, sino también convirtiéndolo formalmente en un esfuerzo nacional, se destacarán y ascenderán en el orden mundial. ¿Será tan difícil de entender?

Por eso nos empeñamos en rescatar el juego para que con él los niños, niñas y adolescentes con sus familias transformen su mundo, y porque creemos en una sociedad donde haya más empatía, altruismo y en el que la gente se sienta contenta con lo que está viviendo. 


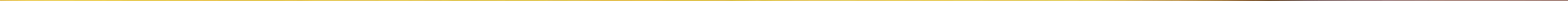


......- CAPÍTULO 1

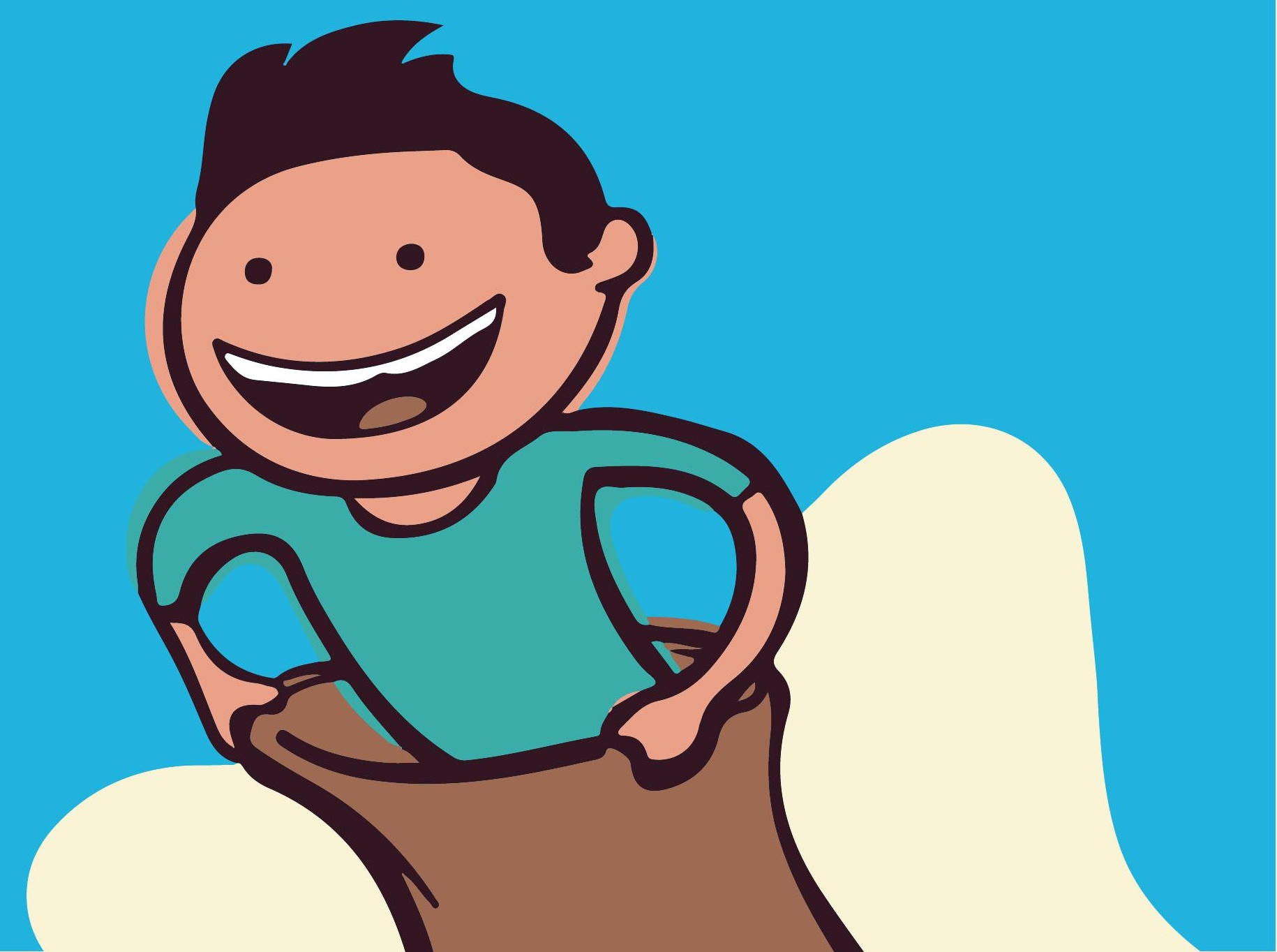




\section{El juego en el desarrollo infantil desde las ludotecas NAVES}

En este capítulo se acercará al lector

a una serie de elementos teóricos

y conceptuales respecto al lugar que ocupa el juego en el desarrollo humano $y$, en particular, en el desarrollo infantil, desde los cuales se plantea la acción metodológica de las ludotecas Naves (niños, niñas aprendiendo, viviendo,experimentando y socializando) en los diferentes contextos y territorios donde se implementan.

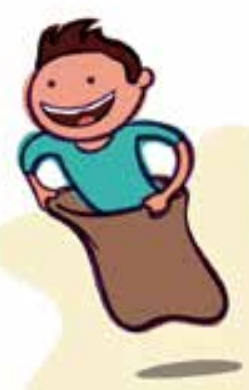


Entender el juego desde enfoques diversos implica analizar las múltiples miradas desde las cuales se establecen relaciones directas con el desarrollo y se logra entender como un elemento fundamental de la existencia humana, tal como lo plantea Eugen Fink (1993), al darle un lugar determinante en la vida del ser humano y en su desarrollo. Pero si reflexionamos un momento en eso de ser un elemento fundamental de la existencia humana, inmediatamente nos encontramos con la pregunta sobre el jugar: ¿qué definimos como juego?, ¿qué entendemos por jugar?, por qué jugamos? Son preguntas que cada uno puede responder desde su propia vivencia porque todos tenemos nuestra propia experiencia de juego: jugamos en la plaza, en el patio, en la habitación, en el barrio, en la escuela, en el hospital, en la ludoteca. Jugamos con amigos, con no amigos, con conocidos, con desconocidos, con la familia, con los lejanos. Jugamos con un juguete perfectamente elaborado o con un convencional lapicero que se convirtió desprevenidamente en juguete al dibujar sobre un papel trazos con sentido solo para quien raya. Jugamos solos cuando vamos por la calle sin pisar raya o jugamos con otros cuando esto es posible. Jugamos cuando niños tratando de inventar un nuevo modo de vivir y jugamos cuando adultos tratando de salirnos de ese modo de vivir construido. Jugamos sin un objetivo definido, pero con el más alto sentido del regocijo por la vida misma, por la alegría, por la diversión inocente o por la más elaborada pasión irreverente de disfrute y búsqueda de la felicidad.

Visto esto así, tratar de definir el juego no es una tarea fácil, por cuanto cada vez que se plantea la sola palabra "jugar" se entiende de modo diferente de acuerdo con el lugar desde el cual se hace la pregunta o el lugar desde el cual cada uno se juega su respuesta. Por ejemplo, al revisarlo desde el lugar de la educación en el imaginario común aparece como un elemento central del aprendizaje, pero al analizarlo desde un enfoque psicológico aparece como un 
factor de descarga de energía, de exploración y manifestación de la personalidad, etcétera.

La dificultad para definir el juego aumenta cuando se percibe que un mismo comportamiento puede ser visto como juego o no juego según quien lo observe o lo viva. Por ejemplo, si se para un observador externo cerca de un niño indígena que se divierte lanzando con su arco y flecha a un pequeño animal, lo ve como un juego. Para la comunidad indígena nada más es una forma de preparación para el arte de caza necesaria para la subsistencia de la tribu. Así, el lanzar una flecha con el arco, para uno, es un juego, para otros es preparación del oficio. (Kishimoto, 2011, p.14)

Visto así, tratar de definir el juego no es una tarea sencilla; sin embargo, para darle una comprensión amplia que salga del ámbito personal es preciso analizarlo desde sus múltiples facetas y desde los diversos enfoques a partir de los cuales se ha analizado a lo largo de la historia del hombre, los cuales van desde una visión antropológica, pasando por la filosófica y psicológica hasta llegar a una visión educativa del juego, lo cual permite acercarnos a un ejercicio profundo de las diferentes comprensiones sobre el juego, desde las cuales se puede establecer un panorama amplio e integral del lugar que ocupa este en el desarrollo integral de los niños y las niñas, en el desarrollo social y el desarrollo humano.

Desde el enfoque antropológico del juego, el cual lo plantea como un elemento central de la cultura y de la evolución del hombre y su cultura, se encuentra la teoría expuesta por Huizinga (1972), Caillois (1986), y Vidart (1995), quienes muestran, desde diferentes aristas, la naturaleza del juego, el entramado que teje con la cultura y las culturas, la forma en la cual es capaz de anticipar la cultura en los juegos de la infancia hasta atreverse a afirmar, como lo haría Hui-

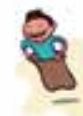


zinga, que la civilización surge del juego. Pues bien, juego y cultura se desarrollan en una estrecha relación que es permanente y que emerge desde una misma dimensión del ser humano: la dimensión lúdica. Dentro de esta dimensión, el juego, en tiempos de la antigüedad clásica, era puesto en escena y estudiado como un elemento de crianza con el cual era posible desarrollar disciplina en el niño o niña y, por lo tanto, era puesto en escena como un factor de formación en las habilidades para vivir en sociedad (valores), que estaba en íntima relación con la manera como la sociedad establecía un orden o la manera como se orientaba al ciudadano que se quería para los pueblos. Por lo tanto, existía una "interesante vinculación entre juegos, saberes y prácticas" (Enriz, 2011, p.95).

De acuerdo con Brougere (2013), el juego es una manifestación clara de las culturas en tanto muestra la manera en la cual se desarrollan desde tres aspectos centrales: primero, sobre la manera en la cual se establecen las reglas del juego, las cuales corresponden, en gran medida, a la manera como en los grupos sociales se van configurando y las formas en las cuales establecen las relaciones y las maneras de convivir; segundo, sobre las maneras en las cuales se juega esas reglas interpretándolas a partir del momento histórico en el que se dan, es decir, se juega de una manera dependiendo de la época en la cual el juego se desarrolla; y tercero, los materiales de juego (juguetes), los cuales son una muestra de las producciones de la cultura, de su momento histórico y de la manera en la cual se interpreta o se percibe la realidad. Un ejemplo de esto son las muñecas, las cuales reflejan la forma en la cual se muestran los hombres y mujeres de cada época. Desde la antropología, el juguete es un elemento muy importante en tanto muestra cómo fueron las culturas de los tiempos pasados, su vestimenta, sus objetos, sus maneras de percibirse, los colores, los materiales y las formas.

En este enfoque se deja ver una importante diferencia entre el juego y el jugar, entendiendo el juego como un esquema sociocultural que tiene significa- 
ción propia, como lo propone Mantilla (1991), y el jugar como la acción de hacer esa representación, la cual implica movimiento interno y externo del cuerpo y de la mente, en tanto hay expresión, gesto, cambio, tensión, distensión, alegría, concentración, vida. Esto nos hace adentrar en la idea de que el juego en la cultura y en la historia del hombre no está atado a otras necesidades vitales, por lo tanto, no es necesario entender el por qué y para qué jugar, sino comprender el sentido del juego en sí mismo, en su propia extensión.

Desde el enfoque psicológico, autores como Groos, Freud, Piaget y Erikson lo plantean de diversas maneras; como fenómeno de preparación a la vida adulta, como la mejor manera que expresa el principio del placer, como una manifestación de la inteligencia del niño y de la evolución de sus capacidades, como la sublimación de la energía del ser humano, como manifestación comportamental que da lugar a cambios o tránsitos en la personalidad y, en especial Winnicot (1982), lo plantea como el espacio potencial, el lugar del ser humano que no está dentro ni fuera, que no es realidad pero tampoco es ficticio totalmente, ese espacio potencial donde el ser humano es capaz de crear. Solo en el juego el niño o el adulto están en libertad de ser creadores en ese espacio potencial en el cual la confianza cumple un papel fundamental, la cual se desarrolla a partir del vínculo de seguridad establecido con la madre.

Este enfoque psicológico del juego presenta dos características comunes: por un lado, el principio de libertad del juego, pues cada jugador es libre de decidir si juega o no, o simplemente si lo hace o no, y aunque se obligue a hacerlo el jugador entra en el juego cuando, desde su propia voluntad, decide hacerlo. Una segunda característica común en este enfoque psicológico es plantearlo como una manifestación de la inteligencia, lo que está íntimamente relacionado con el desarrollo cognitivo del ser humano. Según las diversas teorías psicológicas, jugar implica un compromiso de las capacidades cognitivas, como análisis, de-

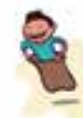


ducción, inducción, reflexión, entre otras que hacen parte determinante en el desarrollo del pensamiento y conocimiento de cada persona.

Por lo tanto, el enfoque psicológico del juego relaciona de manera directa el desarrollo del comportamiento humano con la forma en la cual se desarrolló el juego infantil; de hecho, desde este enfoque, el juego tiene el poder de mostrar lo que sucede con los niños y las niñas, su personalidad, su carácter, lo que está pasando en su vida y las formas en las cuales se está relacionando consigo mismo y los otros.

Desde un enfoque social, el juego es planteado como un moderador del comportamiento colectivo y como la mejor posibilidad para relacionarse con los otros. En este sentido, en el juego aparece la norma, la cual le confiere al juego uno de sus más innegables rasgos: no contradice su libertad y espontaneidad, pero la regula, y esto le imprime incluso un mayor grado de emoción al jugador. La regla define el contexto del juego, su tiempo, su espacio, su orden. La regla es lo que le imprime al juego el reto, la necesidad de superarlo y lograr un reto mayor. Es lo que le otorga la excitación de lo que hay que cuidar y a la vez superar. La regla es silenciosa y bulliciosa a la vez, está ahí para que no se quebrante, y si lo hace, lanza un grito de alerta que emociona al juego y al jugador. Cuando se juega con otro es la regla lo que nos iguala, hace equitativo y justo el objetivo y la forma para llegar a él. Esto es lo que va creando o configurando una relación, es decir, un campo social, un campo de relación con los otros.

Las reglas deben ser aceptadas y respetadas por todos los jugadores para que el juego pueda comenzar y seguir su desarrollo. Aquel jugador que no respete las mismas es el denominado "aguafiestas". Es preciso hacer una diferencia entre aguafiestas y tramposo. En el primer caso, se crea una ruptura 
del juego, en cambio el tramposo aparenta estar dentro del círculo mágico del juego (Tirado, 1998).

La regla le otorga un amplio sentido social al juego. Se configura una sociedad cuando se juega. Una estrecha relación en la cual los jugadores aceptan unas maneras de estar y de hacer las cosas. Unas formas de actuación que las delinea el juego mismo. Por ejemplo, no es posible jugar golosa (rayuela, peregrina, avión), de una manera distinta a la que el juego se ha acordado cultural y socialmente. Al ser un acuerdo social, quien acepta jugar acepta las reglas que el juego tiene, o las reglas que se van creando en torno al juego, aun aquellos juegos que parecieran no tenerlas, como aquellos que espontáneamente se van construyendo. Un ejemplo de esto son los juegos que hacen los niños en las habitaciones de la casa: se van creando castillos, caminos, vehículos, etc. Al irse creando, van delineando sus espacios, los cuales no pueden transgredirse: la puerta por la cual se entra al castillo es la que se definió en el juego, por lo tanto, aunque un jugar desprevenido pudiese entrar por otro lugar, aquellos que han constituido la puerta advierten que "por ahí no es"; si alguien quisiera pasar caminando un río acordado en el juego, el grupo inmediatamente advertirá el riesgo que tiene de ahogarse.

Otro elemento que vale la pena analizar sobre el enfoque social es el carácter competitivo 0, como lo diría Caillois (1986), el carácter agonal del juego. Pues bien, esta característica es lo que le exige al juego hacerse con otro o con otros, por lo tanto, el juego reconoce "la otredad", pues el rival, aunque lo sea, se necesita. Desde esta perspectiva, el juego se hermana con el deporte, con la diferencia que en el juego ganar o perder es una opción legítimamente considerada, en cambio, en el deporte, perder es la opción no esperada. En ambos casos, ganar es lo deseado y en ambos casos el rival es necesario, pues en el competir con otro u otros está parte de lo vertiginoso y divertido del juego. Si

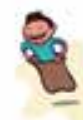


bien se puede competir consigo mismo, por ejemplo, en un juego de solitario, el saberse compitiendo con otros implica un mayor grado de compromiso con el juego mismo y un mayor grado de esfuerzo en las capacidades que se ponen en escena por parte del jugador.

El juego, desde este enfoque social, vincula a los jugadores, estrecha relaciones, desarrolla vínculos, afectos, rivalidades, cercanías. Constituye un lugar de privilegio para estar con los otros de una manera que reta las capacidades sociales y logra afirmar la personalidad de cada persona cuando está y convive con otros.

Desde el enfoque filosófico, el juego es analizado incluso en un lugar ausente del jugador. El juego es en sí mismo y hace parte no solamente de la condición humana, sino de la existencia misma. Esta compresión implica entender la inutilidad del juego, como lo plantearía Scheines (1998), el juego se agota en sí mismo, es total y no algo que espera ser completado. Es una actividad de aquí y ahora. Una isla desconectada del pasado y del futuro. El juego es todo el mundo, lo demás no existe mientras se juega.

Desde este enfoque, también se plantean las posturas de Caillois (1986), Duvignaud (1982) y Gadamer (1991, 2001), quienes plantean el juego como la ausencia de producción de un producto, la perspectiva de la nada, un movimiento constante de ida y vuelta, un constante vaivén sin un fin determinado.

El juego tiene un modo de ser propio, total, particular, en una relación analógica permanente de lo objetivo y subjetivo, en donde el verdadero sujeto del juego es el juego mismo. No requiere de un jugador para ser juego, lo que le otorga el carácter atractivo, pues es desde el ser del juego que los sujetos se sienten atraídos a jugar o a entrar en el juego como observadores. Esto se 
explica en un juego de ajedrez (bolas de cristal), en donde el juego transcurre incluso en el silencio y seriedad de quien juega. El espacio de juego tiene un propio movimiento, y si hay alguien observando el juego, este disfruta el ser de ese juego aun sin jugarlo. Tiene otro lugar que lo atrae y hace que permanezca de pie, viendo los movimientos de las fichas. Pero en este juego, también quienes juegan entran en una realidad paralela de la que ellos mismos no son conscientes y solo se interrumpe cuando la partida termina, y es cuando se retorna a la otra realidad en la que el juego no está.

Por último, desde un enfoque educativo, se plantean las maneras de entender el juego como elemento central de la función educativa, siempre que el docente lo introduzca como parte de su práctica pedagógica, comprendiéndolo como una acción desde la cual los contenidos pueden ser intencionados o no, pero vividos y experimentados.

Cuando el juego se "formaliza" en algunos espacios, especialmente en los educativos, tiende a adquirir diferentes funciones. Así, el juego es un recurso para enseñar, una actividad por la que los niños se sienten "naturalmente" atraídos, un medio para llamar la atención. El juego es el momento libre de la escuela en el recreo o en los días de lluvia, cuando la ausencia de los niños no permite iniciar contenidos nuevos. Los niños solicitan jugar y el "no jugar" se transforma en una forma de castigo para los grupos. Algunos contenidos se enseñan con juegos y a otros es imposible atravesarlos por lo lúdico. (Sarlé, 2010, p.19)

El juego constituye un modo fundamental por medio del cual los niños paulatinamente llegan a formar una representación de una actividad en la que se especifican todos los objetos, las acciones y sus interrelaciones.

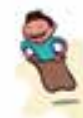


En los primeros juegos individuales, los niños ponen de manifiesto aquello que han podido abstraer de las diferentes situaciones de la vida cotidiana. Las representaciones mentales que va desarrollando el niño "constituyen un sistema de conocimientos del mundo, que funciona como un "contexto cognitivo" desde el cual el niño interpreta lo que otros hacen y dicen y construye un nuevo conocimiento" (Sarlé, 2010, p.44).

Para Pavia (2018), el contexto de la escuela es propio para el juego, en especial el tránsito para su llegada y el patio para el recreo. El acto educativo allí se materializa cuando el docente -pedagogo observa. La escuela no es solamente un establecimiento en donde se imparte enseñanza. La vieja escuela constituye aun hoy un punto privilegiado de encuentro al que los niños asisten con la renovada expectativa de cruzarse con sus pares. Pensemos también que buena parte de esos rituales de encuentro "sucede en los patios bajo la forma genérica e imprecisa de juegos" (Pavia, 2018, p.154).

Para Sátiro (De Puig \& Sátiro, 2011; Sátiro, 2006), desde la filosofía para niños, el juego es la fórmula perfecta para favorecer que los infantes desarrollen el pensamiento creativo y postulen nuevas formas para transformar su vida y la vida de otros. Es la posibilidad para comprender, a partir de preguntas, su lugar en la familia, en la comunidad, en la escuela, en el mundo. El acto creativo inicia con el juego y con él las preguntas que dan lugar a la oportunidad de reflexionar y pensar sobre sí mismo, sobre el transcurrir de la vida y en especial de la vida humana y de la manera en la cual nos construimos como seres humanos.

Este primer acercamiento al juego y al jugar nos impulsa a continuar en la siguiente parte del capítulo, relacionándolo con el desarrollo infantil y, enseguida, con el desarrollo humano, lo cual resulta congruente con uno de los plantea- 
mientos iniciales que sugiere que, en el jugar, está la vida misma y, con esta, el desarrollo del ser humano.

\section{El juego y el desarrollo infantil}

Al respecto son muchos los análisis, investigaciones, planteamientos que se han hecho desde diversos lugares y teorías; todos coinciden en incorporar el juego como factor central del desarrollo infantil, no solo como elemento que da cuenta del propio desarrollo, según lo plantearía Piaget (1991), o como una manifestación que evoluciona en la medida que evoluciona la cultura, como lo diría Brougere (2013).

En efecto, el juego está íntimamente ligado al desarrollo de los niños y las niñas, pues es la forma en la cual los niños están en el mundo: durante el baño, los niños juegan imaginando ríos bajo sus pies o haciendo volar pompas de jabón o la sola espuma con aquel que lavan su cuerpo. Cuando se alimentan en el plato abren caminos para que la cuchara transite buscando entre los alimentos la magia del juego. Al irse a la escuela tomados de la mano del adulto que lo acompaña o transitando solos por el camino, van cuidadosamente tratando de no pisar raya o pateando la piedra que fantásticamente es el juguete que permite el juego, bajo la premisa de no dejarla perder del camino. Estando en clases hacen trazos sobre la última hoja del cuaderno, jugando con los trazos, las sombras, las líneas, las curvas o dibujando al profesor y, al llegar nuevamente a casa, cualquier momento es el preciso para jugar en el cuarto, en la cocina, en la sala, en el patio o, si la seguridad lo permite, en la calle. ¡Tal cual! El juego es la forma de estar los niños en el mundo. Para ellos es la vida misma y se juegan la vida de manera permanente.

Pero frente a esta "actividad, creativa, libre y placentera que permite vivir la transformación de la realidad", como lo define la Corporación Juego y Niñez

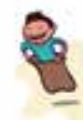




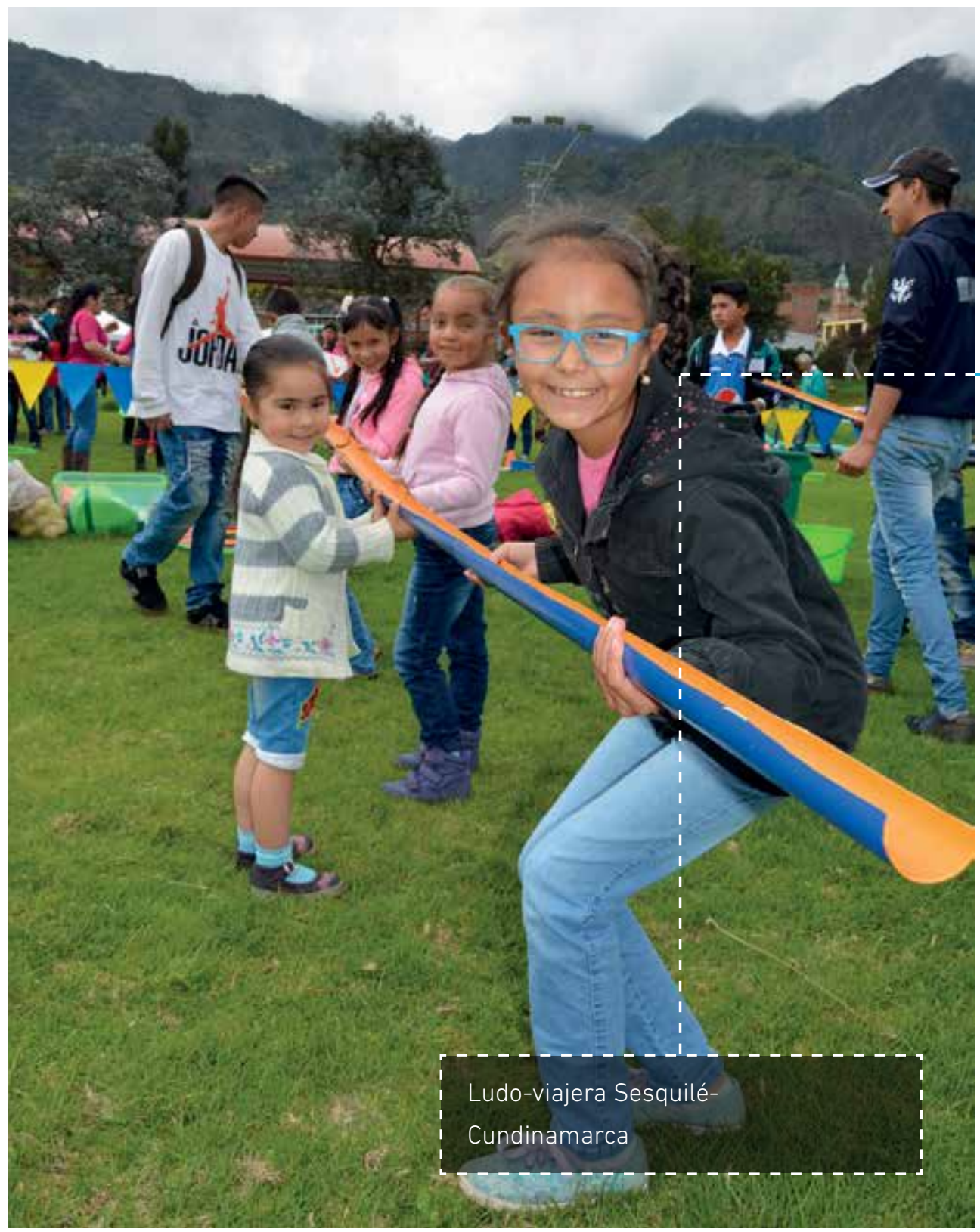


(2008), que, a ojo del adulto desprevenido y preocupado por la búsqueda permanente de la utilidad de las acciones y de ganarle tiempo a la vida, el juego es una actividad que produce divertimiento, pero que puede ser una pérdida de tiempo a no ser que aporte algo útil. Pues bien, si de eso se trata, es preciso decir que el juego, al ser una actividad presente de manera inmanente en la vida del ser humano, constituye un factor que determina o favorece el desarrollo de cada una de sus dimensiones.

Por ejemplo, el desarrollo de la dimensión corporal es posible en tanto el niño y la niña descubren, exploran, apropian y potencian su cuerpo y las capacidades que tiene de movimiento, flexibilidad, fuerza, resistencia, ubicación espacial, equilibrio, destreza, entre otras. Pues bien, estas capacidades y habilidades se desarrollan cuando se juega y en el juego se compromete el cuerpo: saltar la golosa, saltar lazo, trepar un árbol, jugar a las carreras, jugar a las estatuas, empujar carros de cartón, hacer girar el trompo, jugar una ronda, esconderse, salir corriendo en el "tin tin corre corre", y cientos de juegos de este tipo hacen que el niño y la niña conozca su cuerpo, lo explore, lo potencie y alcance el máximo potencial.

Otro ejemplo: la dimensión socioafectiva emerge en tanto el niño y la niña empiezan a desarrollar emociones y sentimientos sobre sí mismo y por los demás. Cuando comprende que se encuentra con otros que son sus cercanos en el mundo, con quienes tiene la posibilidad de construir vínculo, el cual inicia en la estrecha cercanía con la madre y que, poco a poco, se va trasladando a los apegos con objetos, juguetes y otras personas que van siendo parte de su entorno cercano. Sin embargo, es jugando cuando puede experimentar las emociones, afectos y relaciones que van a hacer parte de su desarrollo. Cuando el niño juega empieza el descubrimiento del mundo, pero al jugar con otro es cuando descubre el significado de convivir desarrollando sentimientos que van desde la alegría, la

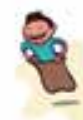


confianza, la placidez, hasta la frustración, el asombro, la ira, entre muchos otros que constituyen el amplio universo de afectos y desafectos que constituyen la dimensión socioafectiva en el ser humano. Con quienes se juega en la infancia se crea un vínculo afectivo que favorece las relaciones afirmativas y la capacidad del niño y la niña de establecer relaciones de amistad, respeto, aceptación de la diferencia y convivencia.

Respecto a la dimensión cognitiva, diremos que el juego permite la cognición, es decir, la capacidad de elaborar pensamiento a partir de la información que recibe de la realidad, a lo que se ha denominado percepción. En este sentido, la percepción permite incorporar y elaborar información, que lo hace de manera especial cuando juega. Es así como al empujar una pelota percibe la información sobre su forma y peso, y esto le permite intuir cuál es el mejor movimiento para lanzarla lejos de sí o hacerla rebotar para que vuelva a sus manos. Este pensamiento intuitivo, diría Piaget (1979), es lo que da lugar posteriormente al pensamiento operacional y luego a la abstracción. Cuando juega, el niño experimenta, se equivoca, acierta, intuye, analiza, infiere, calcula, concluye. Todas estas son capacidades de la dimensión cognitiva que comporta el pensamiento y el conocimiento.

Con relación a la dimensión comunicativa, es preciso decir que el juego es un lenguaje en sí mismo, en tanto expresa, sin el habla, lo que el niño o niña quiere comunicar, pero también, como lo plantearía Bruner (1983), el juego es la primera oportunidad y la primera actividad con la que el niño descubre que las palabras logran acciones; por ejemplo, si dice "pelota", sin necesidad de decir rodemos la pelota, el adulto entenderá que debe hacerlo y se inicia un juego en el que obtiene la acción que espera solo con nombrarse un objeto. Pero también cuando se reta el habla con las retahílas, los cantos, las rondas, los trabalenguas, las letras dichas y cantadas, esos juegos que encuentran en las palabras y en sus sonidos

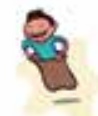


la mejor forma de retar el habla. Desde este análisis, el juego es un lenguaje que relaciona y vincula, estableciendo un diálogo propio, un diálogo lúdico que se encuentra en el disfrute, en el descubrimiento, en el reto, en la incertidumbre, en la seguridad, en la diversión, en la alegría, en la frustración. Pero, así como es un lenguaje en sí mismo, también es vehículo para el lenguaje, para el encuentro con las palabras, las frases, las ideas y las formas diversas del habla.

Pues bien, todas estas maneras de manifestarse el juego en el desarrollo de los niños y las niñas a través de las dimensiones del ser humano, las cuales están en una permanente interconexión en la cual no es posible fijar un límite entre la una y la otra, permiten concluir que el desarrollo infantil, proceso no lineal, único y diferente, se da a partir de los logros que se facilitan en el juego y en el cual el niño y la niña va logrando una serie de adquisiciones propias que no tienen la pretensión de lograrse, pero que se dan, pues el poder del juego se da en su espontaneidad y libertad. Cuando se juega no se va a hacer amigos, pero se hacen. Cuando se juega no se va a aprender de normas y acuerdos, pero se construyen y aprenden. Cuando los niños juegan no pretende desarrollar su pensamiento, pero lo logran. Al jugar, los niños no buscan conocer su cuerpo, pero lo descubren y lo retan. Cuando los niños juegan no piensan en desarrollar lenguaje, pero se comunican de manera inusitada con los otros. Al jugar, los niños no buscan insertarse en la cultura, pero lo hacen. La construyen, deconstruyen y la transforman. Cuando los niños juegan no buscan ser creativos, pero crean, recrean, imaginan y transforman. Pues bien, el juego nos asombra con sus miles de posibilidades y nos invita a reflexionar en que cuando el ser humano juega, se juega la vida misma en la alegría y la seriedad que le exige el jugar.

\section{El juego, las ludotecas y el desarrollo humano}

Si bien el concepto de desarrollo humano se viene abordando desde miradas alternativas a partir de las propuestas desarrolladas por Amartya Sen (1999), Max

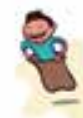


Neef (Max-Neef, Elizalde, \& Hopenhayn, 1986), y Martha Nussbaum (2010), tradicionalmente había sido abordado principalmente por las ciencias económicas desde un enfoque que fundamentaba una teoría que homologaba el desarrollo humano con el desarrollo económico de las personas, los pueblos y los países.

\begin{abstract}
El enfoque economicista se sustenta en un punto de vista fundamentalmente antropocéntrico, donde la naturaleza es vista como un instrumento en beneficio del hombre, para ser explotada y mejorar la calidad material de la vida humana. En este modelo no se consideró un escenario de escasez de recursos y una vez que esta se presentó, tecnología e información cobraron importancia vital. (Bustillo \& Martínez, 2008, p.391)
\end{abstract}

En los años 80 este enfoque se transforma, y es con Amartya Sen (1987), con quien se logra una nueva perspectiva desde la cual el proceso de desarrollo se ve como un proceso de ampliación de las "capacidades" de las personas y no como un aumento de la utilidad y del bienestar y satisfacción económicos, únicamente, sino como la creación de las condiciones necesaria para que las personas logren sus capacidades. Con este nuevo concepto, el desarrollo no tiene como propósito ampliar la producción de los pueblos y países ni su sistema económico, sino lograr que las personas tengan más y mejores opciones para que tengan bienestar, felicidad y una vida más larga. En este orden, se entiende, por ejemplo, que tener una vida más larga implica acceder a condiciones de salud integral, tener bienestar implica tener acceso al conocimiento, tener felicidad implica disponer de opciones de acceso para el disfrute de la vida misma y estar en armonía con un planeta sostenible. Estas opciones para lograr todas las capacidades posibles deben darse en el marco de la libertad, y destacando que las capacidades y las opciones están íntimamente relacionadas y que ambas, a su vez, están estrechamente asociadas a la libertad; entendiendo la libertad de 
aspectos negativos que no aportan al logro de las capacidades, ejemplo: libre para decidir, libre para desplazarse, libre para estudiar, libre de hambre, libre de enfermedad evitable, libre para disfrutar tiempo propio, entre otras libertades.

Este nuevo concepto de desarrollo va en contravía del concepto sobre la riqueza, entendida como la acumulación de bienes materiales; por lo tanto, remplaza el concepto de acumular bienes por el de crear capacidades en los seres humanos, como lo diría Bourdieu (1999).

En este sentido, Nusbaum plantea:

Ante esta situación, la responsabilidad de toda la ciudadanía es asumir el deber de construir una sociedad en la que todos disfruten de unos mínimos de calidad de vida, en la que la justicia social sea una realidad sentida y vivida por la población, en la que el término «libertad» no se identifique con «elegir el producto de consumo» y se asocie a autonomía crítica, responsable y solidaria, en la que la participación sea cualificada y se anime a todos y no solo a un grupo privilegiado a tomar las riendas del devenir político. Habrá que comprometerse sinceramente en dejar ya a un lado democracias simplemente formales, y luchar por que la utopía democrática (fuerza de ideales como la participación activa, la igualdad civil, política y material, la libertad, la solidaridad, la justicia) deje de serlo para transformarse en una realidad más de nuestra vida cotidiana. (Guichot-Reina, 2015, p.12)

En este mismo sentido, la Corporación Juego y Niñez plantea, desde su Metodología Naves (Niños, Aprendiendo, Viviendo, Experimentando y Socializando), que el desarrollo humano se da en la medida en que se suplen unas necesidades que tienen que ver con el desarrollo del ser, el hacer y el estar de

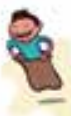


las personas. Implica una mirada en la que es necesario desarrollar unas capacidades y habilidades que le permitan al ser humano construirse como ciudadano y como un agente que construye su propio desarrollo.

Al respecto, Amtya Sen (1999) nos aporta con su planteamiento respecto a que la persona es un ser de necesidades múltiples e interdependientes, que pueden analizarse según unas categorías existenciales y otras axiológicas: unas referidas a las necesidades del Ser, Tener, Hacer y Estar y aquellas referidas a la subsistencia, protección, afecto, entendimiento, participación, ocio, creación, identidad y libertad.

A pesar de esta nueva manera de entender el desarrollo humano, uno de los interrogantes de mayor relevancia hoy tiene que ver con la manera en la cual los estados y las sociedades están dando opciones para que los niños y las niñas logren esas capacidades humanas, lo que les asegura un bienestar integral en el presente y en la configuración de un futuro pensado en lógica de este nuevo desarrollo.

\section{Los niños y adolescentes necesitan un conjunto equilibrado de habilidades cognitivas, sociales y emocionales para tener éxito en la vida moderna. Las habilidades cognitivas se han demostrado necesarias para influir en la probabilidad de éxi- to educativo y en el éxito en el mercado laboral de cara hacia el futuro. A su vez, las habilidades sociales y emocionales, tales como la perseverancia, la sociabilidad y la autoestima se ha demostrado que influyen en numerosas medidas en los resultados sociales. (UNESCO-OCDE, 2016, p.1)}

Podría decirse que las habilidades cognitivas y socioemocionales, al interactuar, generan un conjunto de herramientas propicias para fortalecer la auto- 
nomía en los niños y posibilitan el tener una probabilidad de mayor éxito en las escuelas, en sus barrios, en sus veredas, en las comunidades, en sus ciudades y en su país. El reto que impone esta perspectiva implica un cambio radical en la manera de entender y desarrollar los procesos educativos y de formación, e incluso en la manera de medir y evaluar dichos procesos.

En este sentido, el llamado es a destacar la formación axiológica y existencial, es decir, "esa educación y formación desde las habilidades y capacidades que favorecen los procesos de socialización, aquellos aprendizajes que movilizan directamente el ser, el hacer y el estar en el mundo" (Corporación Día de la Niñez, 2014, p.14). Hoy se estima más a las personas por lo que saben y la suma de sus conocimientos que por su capacidad de valorar y transformar su mundo en condiciones de equilibrio y equidad, condición esencial que se traduce en la capacidad de dar sentido a la existencia humana.

Es aquí donde la Corporación Juego y Niñez propone el programa Ludotecas Naves (niños y niñas aprendiendo, viviendo, experimentando y socializando) como un programa social orientado a favorecer el desarrollo de esas habilidades y capacidades en los niños y las niñas y en todos los participantes, pues se trata de un equipamiento integral entre ludotecario, ambientes de juego, metodología y materiales que, articulados como un sistema pedagógico, mira al niño y la niña como seres integrales capaces de proponer, crear, construir, reconocer en los otros estas mismas capacidades, acordar y comprometerse con los aprendizajes fundamentales que va incorporando.

En este orden es preciso plantearnos que una ludoteca es esencialmente un programa de desarrollo integral desde el juego, que de manera inherente genera aprendizajes centrados en la construcción personal, moral y social que potencia el desarrollo de los niños y las niñas y, por lo tanto, el desarrollo humano.

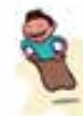




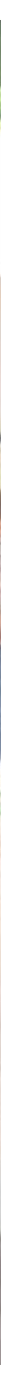


Un ejemplo de esto es lo que sucede en una ludoteca NAVES en Manaure, que funciona hace 18 años en este municipio, y que ha logrado, a partir del reconocimiento de su cultura y del reconocimiento de los niños y las niñas como sujetos activos y transformadores, lugares de participación efectiva, como la radio, en donde ellos y ellas tienen la posibilidad de reflexionar y compartir las reflexiones sobre su realidad y cómo transformarla. Otro ejemplo es lo que sucede en la ludoteca NAVES de Chinchiná, en donde los niños y las niñas comprenden el sentido que tiene establecer acuerdos para el uso de la ludoteca y que se traspone a los acuerdos que se han construido para convivir en sociedad y crecer como ciudadanos, desde el enfoque de convivencia que se le ha dado a la propuesta pedagógica en la cual el juego es un lenguaje que permite las formas positivas de relación, aun en la presencia del conflicto, el cual no se niega ni se evade, sino que se gestiona entre todos. De esto podemos decir que los niños, mediante el juego, acompañados de personas expertas jugadoras e innovadoras, aprenden a resolver cuestiones y situaciones que entrañan una gran complejidad como seres humanos: convivir pacíficamente, concertar y decidir, comunicar y expresar los sentimientos asertivamente, asumir compromisos, respetar los derechos de los demás y a ejercer los propios con responsabilidad, a resolver los conflictos por medio de formas no violentas ni discriminatorias y excluyentes, y a construir con el otro para aportar a la solución de los problemas que colectivamente nos afectan día a día.

Los niños, al jugar, comprenden e incorporan valores para su vida, reflexionan más y desarrollan, con creatividad, respuestas afirmativas frente a situaciones concretas de su vida cotidiana, porque al desarrollar estas habilidades están en la capacidad de relacionar y poner en práctica todo ese saber-hacer desde su ser. Estos aprendizajes favorecen en los niños y jóvenes el saber trabajar en equipo, a cooperar y ayudar especialmente a los más pequeños, a saber cómo pedir ayuda, a saber seguir instrucciones en las rutinas escolares, a manejar sus

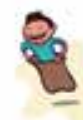


emociones, a entender las perspectivas de los otros y a poder negarse apropiada y asertivamente a las peticiones de otros (Borja, 1994).

Frente a esto, un encuentro de juego en la ludoteca o un día viviendo la propuesta que esta tiene puede constituirse en una experiencia en la cual desde la llegada a la puerta de entrada, como sucede en la ludoteca NAVES de Purificación - Tolima, es un momento en el cual se reconoce a otro legítimo en la convivencia (Maturana, 2001), a un otro que se recibe con afecto, con respecto y con la naturalidad que otorga el encuentro con un amigo; posteriormente, el juego que se favorece allí es un juego que reta a vivir una aventura lúdica que puede ser desde un juego de la tienda, construyendo juntos acuerdos para comprar y vender y agotar las existencias y volver a surtirla, hasta un viaje interespacial, en donde los jugadores astronautas se obligan a pensar en un mundo posible anticipando sucesos y acontecimientos que retarán el más alto grado de imaginación. O como lo que sucede en la ludoteca NAVES de Quibdó, en donde el movimiento y el ritmo se hace presente al jugar a montar coreografías con la música construida con los ritmos y los instrumentos propios de este Pacífico colombiano, desplegando todas las capacidades de expresión del cuerpo con voces, aplausos, pataleos, retahílas que terminan en una única risa colectiva. 0 lo que ocurre en San Andrés, cuando se juega con la arena del mar de los siete colores que se combina con los colores de un juguete girador que obliga a los participantes a mantenerse juntos en una secuencia y movimiento para cuidar que la pelota no se vaya al mar y que, al final, resulta tendido en la arena para todos sentarse sobre él y conversar sobre lo sucedido y disfrutado. Y al salir, después de este espacio de juego, alegría, retos, vértigo, imaginación, creatividad, es posible conversar de manera tranquila para crear acuerdos respecto a lo logrado en el juego y asumir compromisos para un nuevo regreso, lo que se constituye en un pacto que sella la relación de convivencia que se va construyendo. 
Estas historias y miles más se tejen en el contexto de una ludoteca, y el juego que estas proponen a los niños y a las familias constituyen una gran oportunidad de encuentro y de socialización, en donde el aprendizaje, mucho más allá del conocimiento que cada niño o niña puedan adquirir (que ya de por sí es mucho), permite un desarrollo del ser, un aprendizaje existencial, que recobra la pregunta por el sentido: el sentido de la vida, de la política, de la participación, de la solidaridad, de la amistad, de la ética, de la justicia, de la paz.

En este sentido "este espacio para el juego trasciende la función de guardar juguetes hacia una propuesta pedagógica y formativa mucho más profunda" (Corporación Día de la Niñez, 2009, p.53), por esto, la ludoteca "debe ser comprendida como una herramienta, como un pretexto, como un espacio de mediación del juego para formar y educar" (Ibíd., p.65).

Podría decirse que en estas ludotecas se aprende a ser crítico, a ser autónomo, a pensar en libertad, a expresar, a disentir, a distinguir entre lo justo e injusto, entre lo que está bien y lo que está mal. Los niños, las niñas y las familias que participan en las ludotecas aprenden a ser solidarios, a dialogar, a respetar las ideas y pensamientos del otro pese al disenso, a participar y a distinguir que todos somos diferentes, pero compartimos muchas cosas en común que nos enriquecen y nos complementan como seres humanos.

Cuando los niños y las niñas acceden a la posibilidad de esta formación existencial pueden participar de la transformación de sus vidas desde la casa, la escuela, el barrio, la calle y en cualquier escenario o situación en los cuales deban decidir, en donde su voz y voto sean decisivos, en donde sus actos marquen la diferencia y, por ello, en donde las consecuencias de lo que hagan cambien y aporten a la construcción del gran proyecto colectivo, en donde cada uno avanza hacia su desarrollo y aporta al desarrollo de los demás y al desarrollo humano.

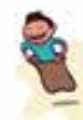


Entender el desarrollo de esta manera es retar a una sociedad a comprender el valor de lo fundamental del juego, de la risa, del abrazo, del encuentro con otros, de la conversación, del acuerdo, del compromiso consigo mismo y con los otros. Implica el desafío de entender que los niños y las niñas crecen, pero que el adulto también lo hace, de entender que el desarrollo es ancho, profundo y con múltiples aristas, de comprender que el respeto a los desarrollos particulares es un indicador de desarrollo social, de entender que el ser humano requiere reencontrarse con el juego desde el juego y de comprender que una ludoteca -más que un lugar para disponer juguetes- es una alternativa posibilitadora para lograr esas comprensiones, constituyéndose en un programa a la medida del ser humano. 

CAPÍTULO 2

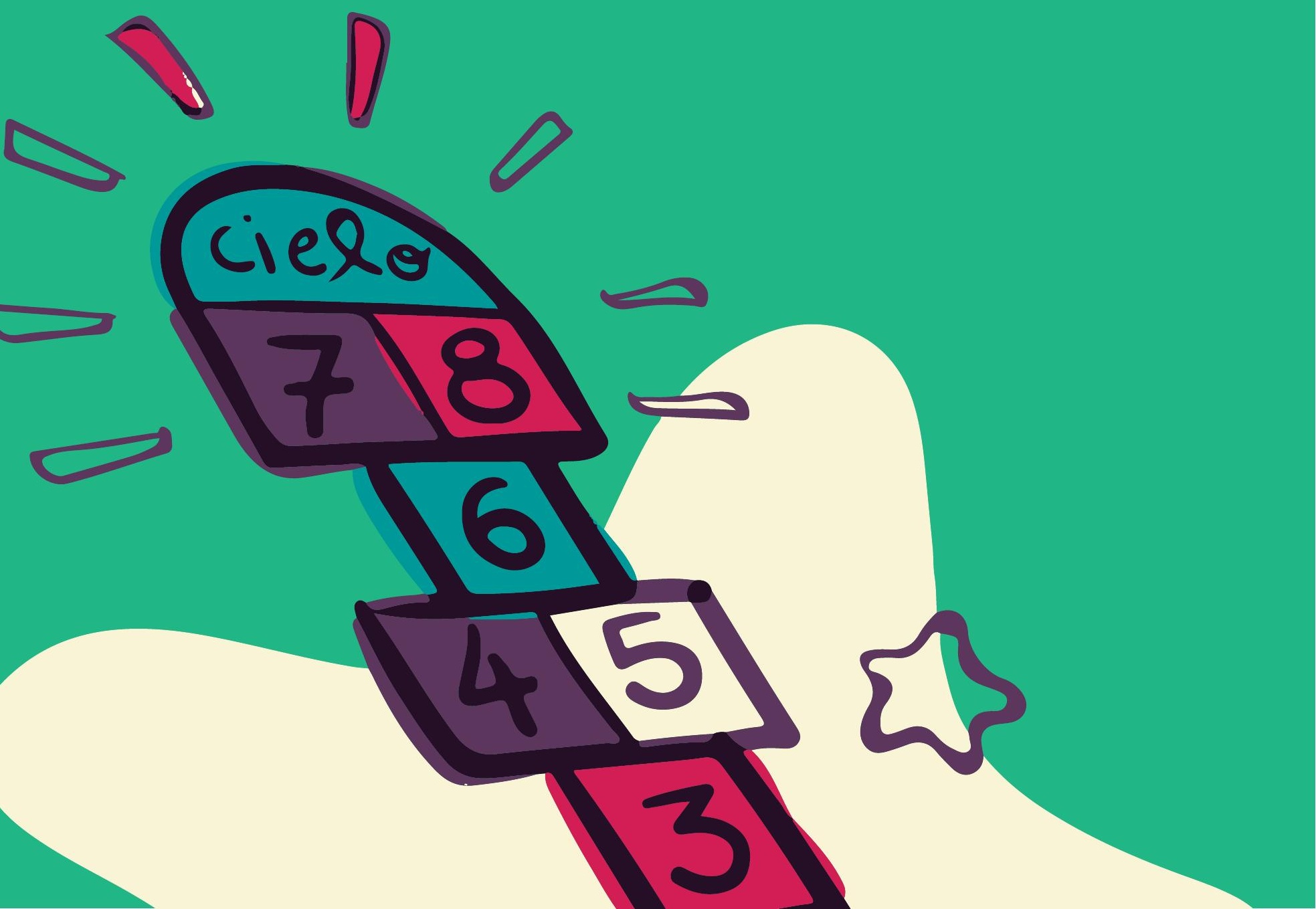




\section{La importancia de evaluar el impacto de las ludotecas en Colombia}

En este capítulo, el lector encontrará el desarrollo del proceso que ha surtido la Corporación Juego y Niñez en la línea de investigación, sistematización y gestión del conocimiento para la mejora continua de sus proyectos $y$, en especial, en torno al modelo

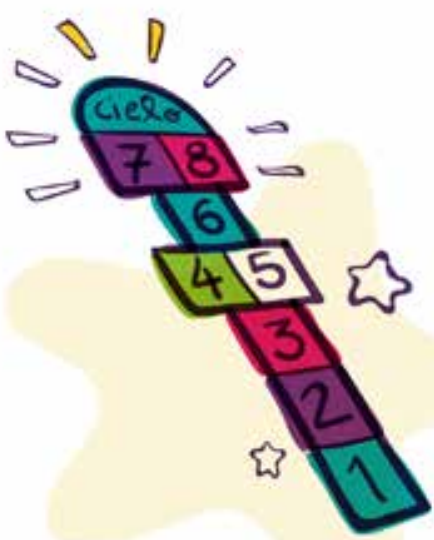
de Ludotecas Naves (Niños y niñas, Aprendiendo, Vivenciando, Experimentando y Socializando), proceso que será la principal razón por la cual la Corporación Juego y Niñez decide, entre los años 2014-2018, contratar con la Universidad Nacional de Colombia la primera investigación longitudinal en Colombia sobre el impacto de las ludotecas Naves en el desarrollo de competencias ciudadanas, emocionales y de creatividad. 
Partiremos de narrar, de manera simultánea, cómo evoluciona el programa de ludotecas Naves en Colombia y cómo, en la Corporación, investigar, sistematizar y transferir conocimiento centrando sus intereses en la reflexión y análisis ha sido fundamental para los impactos que hemos alcanzado 20 años después de su inicio en 1999 en Colombia. Este modelo de implementar ludotecas Naves en más de 100 municipios del país y abrir el camino para que más de 400 ludotecas en Colombia- a veces llamadas de otra manera- se hayan instalado en parques, plazas, polideportivos, casas, recreos, hospitales, cárceles y calles de todo el país, ha sido un reto que muestra resultados, porque se logró que, desde posturas políticas, poniendo la niñez en el centro, dándole un lugar al juego con sentido como fin, los recursos públicos y privados se hayan mantenido como política local en favor de la infancia y adolescencia, asegurando su calidad, por supuesto, con muchas tensiones por su sostenibilidad.

\section{Sistematizar para definir un modelo}

Al poco tiempo de iniciado el desarrollo de las ludotecas Naves por la Corporación Juego y Niñez, resultado de la observación, evaluación y operación, para su estructura administrativa y técnica se definen roles y responsabilidades de los diversos actores interesados en el programa y es así como se propone un modelo desde corresponsabilidades y responsabilidades del desarrollo de la infancia y adolescencia en cada territorio (gráfico 1). Sustenta cómo los recursos privados, desde la experticia de la Corporación, se convierten en el motor inicial para que una ludoteca sea viable, se ponga en marcha y se acompañe técnicamente, por un tiempo, para así dar lugar a que actores locales estatales definan la ludoteca desde una de sus secretarías, para ponerla al servicio del mayor número de participantes, tanto niños como adultos.

Un programa con la niñez en el centro- como ambiente protector-y en donde los gobiernos locales contratan profesionales, que forman y acompañan 


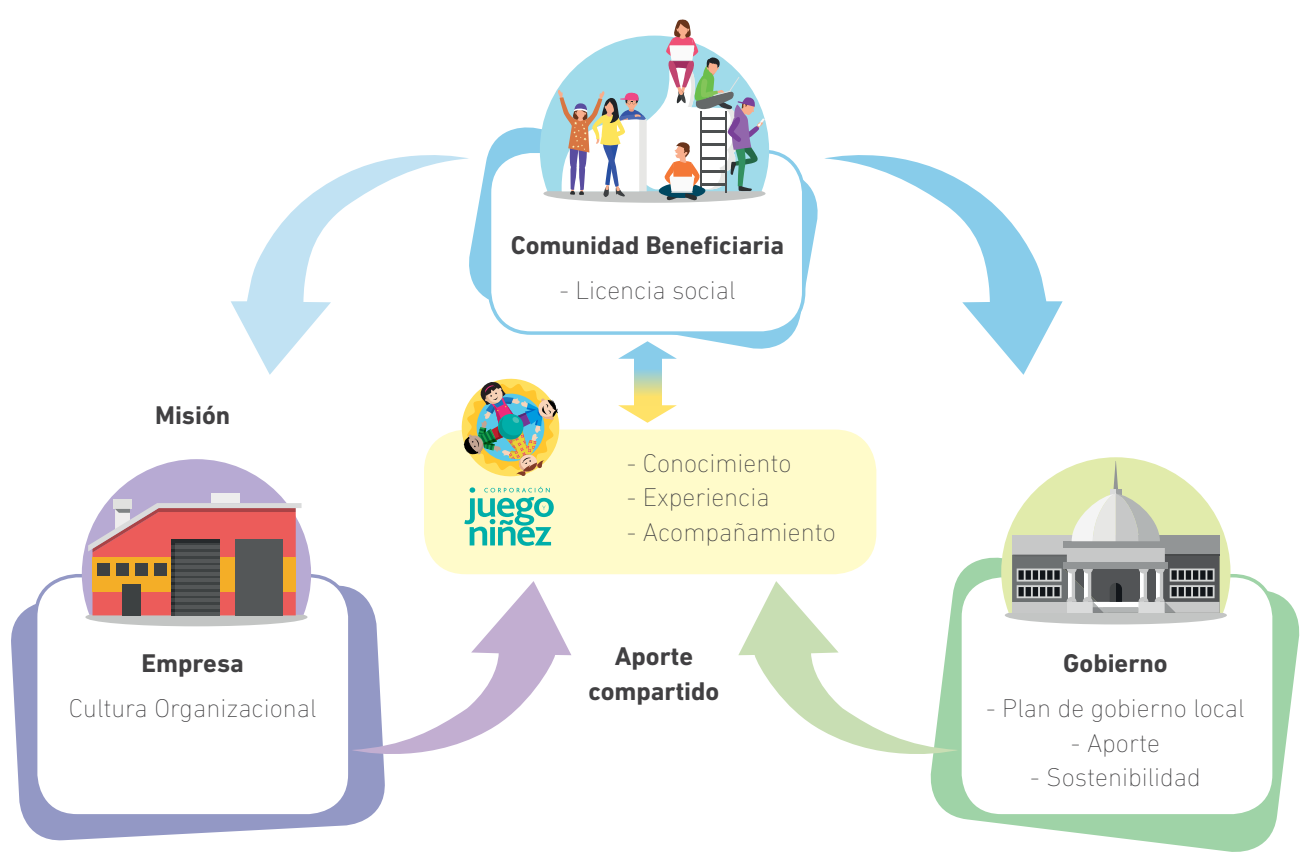

en la Corporación, para que desde el punto de vista metodológico, faciliten, animen, provoquen, propongan, generen reflexión, activen la imaginación y potencien la creatividad, logrando ambientes sociales en donde las expresiones como el juego, es una gran apuesta porque enriquecen la capacidad para potenciar, reconocer y comprender las distintas expresiones de niños, niñas y sus familias. Al llegar a los 20 años de implementar el modelo podemos afirmar que cuando cada actor público o privado asume su rol y responsabilidad, y la sostiene, se 
logra el disfrute pleno de la niñez en ambientes -con perspectiva de derechospara leer, pintar, crear, desarmar, saltar, cantar, conversar, reír y hasta llorarcon un lenguaje cotidiano de respeto, acuerdos, observación, mediación, “subiendo el adulto" al nivel de la mirada de la niñez.

Se han presentado diversas tensiones en su implementación, porque la imposibilidad de sostener recursos tanto de algunos aportantes de empresas privadas como de algunas administraciones municipales, ponen en riesgo asuntos vitales en el cumplimiento de estándares de calidad, tales como la remuneración necesaria del perfil del profesional ludotecario, mantenimiento de la infraestructura, transporte permanente para ludotecas viajeras a periferia y ruralidad, y la continua actualización del personal que los motive a innovar, aumentar cobertura, trascender grupos etarios, entre otros. Tensiones superadas la mayoría de las veces por los ludotecarios, quienes juegan un papel fundamental en la sostenibilidad del programa porque comprenden que su postura política debe ser desde la niñez como sujeto de derechos y sus aprendizajes se internalizan desde la gestión del conocimiento que fortalecen por su experiencia cotidiana en cada entorno diferente y único. Son muchos actores públicos y privados los que están sustentando la calidad de Las Ludotecas Naves como un modelo público- privado- después de 20 años de inicio en diversos departamentos de Colombia. Modelos que se han alimentado por procesos investigativos, de sistematización y de gestión de conocimiento, de los cuales la Corporación Juego y Niñez aprende de manera continua y reconoce que el modelo es posible porque ha contado con la sostenibilidad de recursos provenientes de empresas privadas, convocadas por los despachos de las esposas de los presidentes del país. 


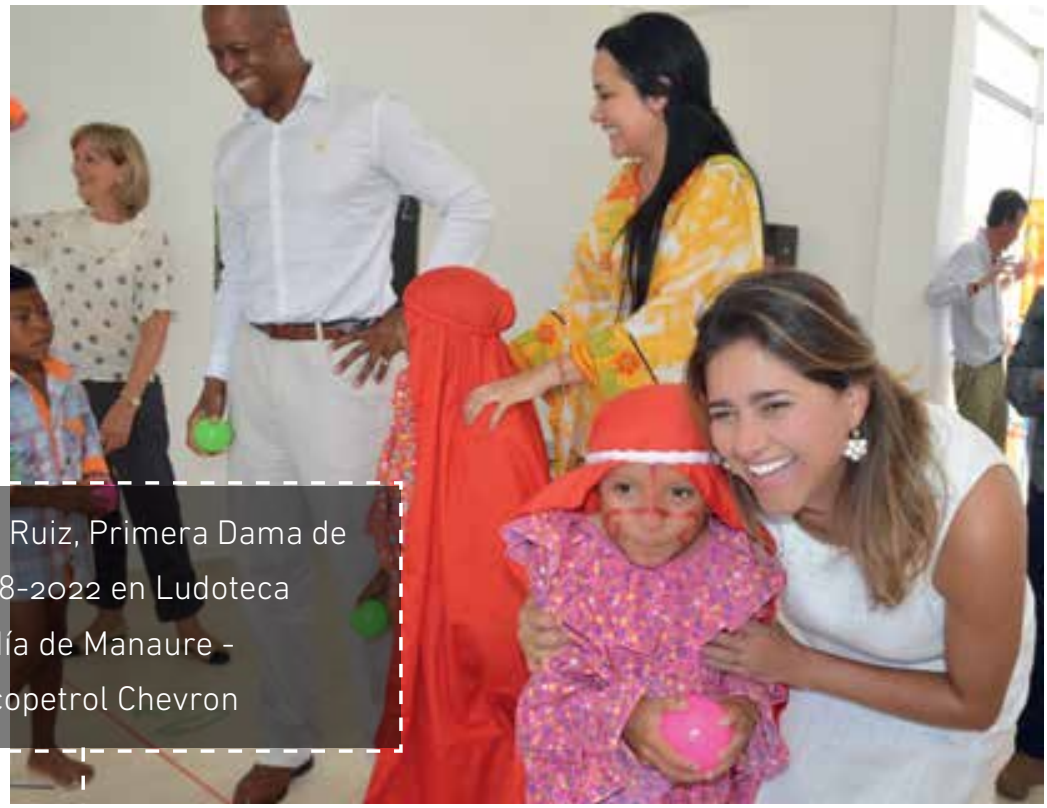

María Juliana Ruiz, Primera Dama de

Colombia 2018-2022 en Ludoteca

NAVES Alcaldía de Manaure -

Asociación Ecopetrol Chevron

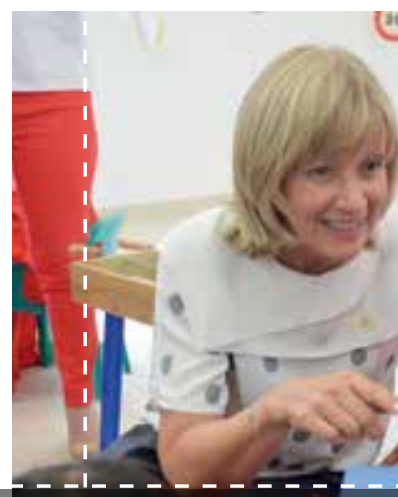

(ن)
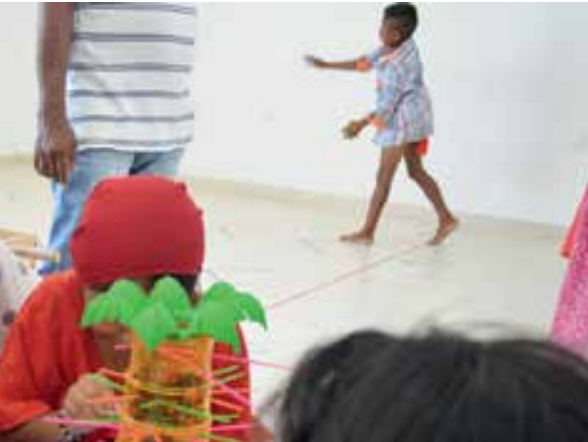

Nohora Puyana de Pastrana, Primera

Dama de Colombia 1998-2002 en

Ludoteca NAVES Alcaldía de Manaure

- Asociación Ecopetrol Chevron

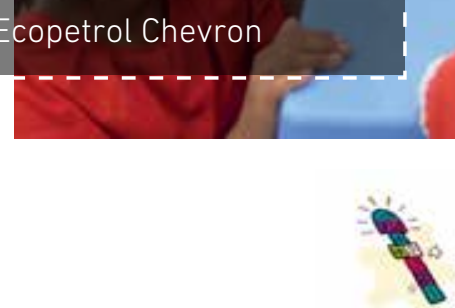

51 


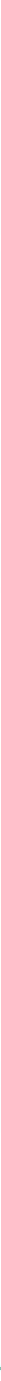


Es así como recursos de organizaciones privadas como Cerrejón, Microsoft, Petrobras, Chevron-Asociación Ecopetrol y Chevron, Colsubsidio, Cafam, Bayer, Pepe Ganga, Politécnico Grancolombiano, Nutresa, Nestlé, Coca Cola, Femsa-Coca Cola, Argos, Procter\&Gamble, Mattel, Arroz Casanare, McDonalds y Fundación Tras La Perla, entre otras, y compromisos y políticas públicas con prioridad en la infancia y adolescencia, han logrado que profesionales ludotecarios y actores locales, como alcaldes, secretarios, gobernadores, y concejales, estén acompañados por la Corporación Juego y Niñez para que, desde su proyecto de vida, porten con gran fuerza y color la camiseta de Ludotecas Naves y, siendo funcionarios públicos, hagan primar el rol de su profesión por encima de una postura partidista, demostrando que cuando la niñez es reconocida como sujeto de derechos, los avances son inmensos, como lo mostrará este libro en los resultados de la investigación longitudinal, y que se desarrollará en los capítulos siguientes.

\section{Investigaciones para la Metodología Naves}

Continuando con la línea de investigación, como constante en la Corporación Juego y Niñez, entre los años 2006 y 2008 se realizan dos procesos seguidos de investigación; el primero de tipo dramático con la Universidad Santo Tomás, y otro con un grupo de investigadores externos basados en la investigación de acción participativa. Desde ambos procesos, se recorrieron más de 20 ludotecas Naves que, para ese momento, se habían puesto en marcha y se logró darle volumen a las voces y sentires de quienes cada mañana llegaban a las ludotecas a generar lazos y huellas imborrables y vitales para el desarrollo de niños y niñas. Estas sistematizaciones desarrollaron una propuesta de metodología propia para que la Corporación Juego y Niñez, desde la experiencia de la cotidianidad de los territorios, contara con un norte para abordar la atención y mantener la calidad en una ludoteca Naves acompañada técnicamente u operada directamente por la Corporación. 
Como se explica en el gráfico 2, la Metodología Naves se convierte en ese derrotero cotidiano para que cada programa, proyecto, acción o intervención que desarrolla en el país la Corporación, cuente con ese sello de calidad al lograr realizarlo aplicando sus posturas, componentes y acciones. Desde ludotecas Naves, Celebración Día de la Niñez o cada nuevo programa que propone con otros sectores -salud, medio ambiente, educación y vivienda, entre otros-, aporta a cada colaborador o actor participante, como modificar las formas de ser y estar de los participantes en la relación consigo mismo, con el otro y con el entorno.

Esta Metodología propia, que cuenta con su debido registro de derechos de autor de la Corporación Juego y Niñez, explica a quienes quieren asumirla que es necesario adoptar al menos tres posturas, movilizar componentes estratégicos y propiciar su operación con buenas prácticas, de manera que se logre comprender el rol y calidad de quien se debe poner al frente del juego con la infancia y la adolescencia: a) Postura Política: respecto a reconocer el niño y la niña como sujetos de derechos para ejercer su participación, autonomía y ciudadanía; b) Postura Teórica: que aporta todos los argumentos sobre porqué el juego es una experiencia creativa, una necesidad vital, una acción libre particular y colectiva, y el desarrollo infantil, un proceso no lineal; c) Postura Estratégica: prueba que la articulación de actores es esa constante para activar y movilizar a las comunidades desde sus necesidades, así como incidir en los espacios políticos sobre la garantía de los derechos de la infancia.

\section{Sistematizar, investigar, gestión de conocimiento: una constante}

Cada programa y proyecto que la organización desarrolla en el país -ya sea de corto aliento o de más de tres años- mantiene la constante de revisarse permanentemente desde la sistematización e investigación. Mantener alianzas con la academia es un indicador que da cuenta del mejoramiento constante de sus inter- 


\section{GRÁFICO 2. METODOLOGÍA NAVES}
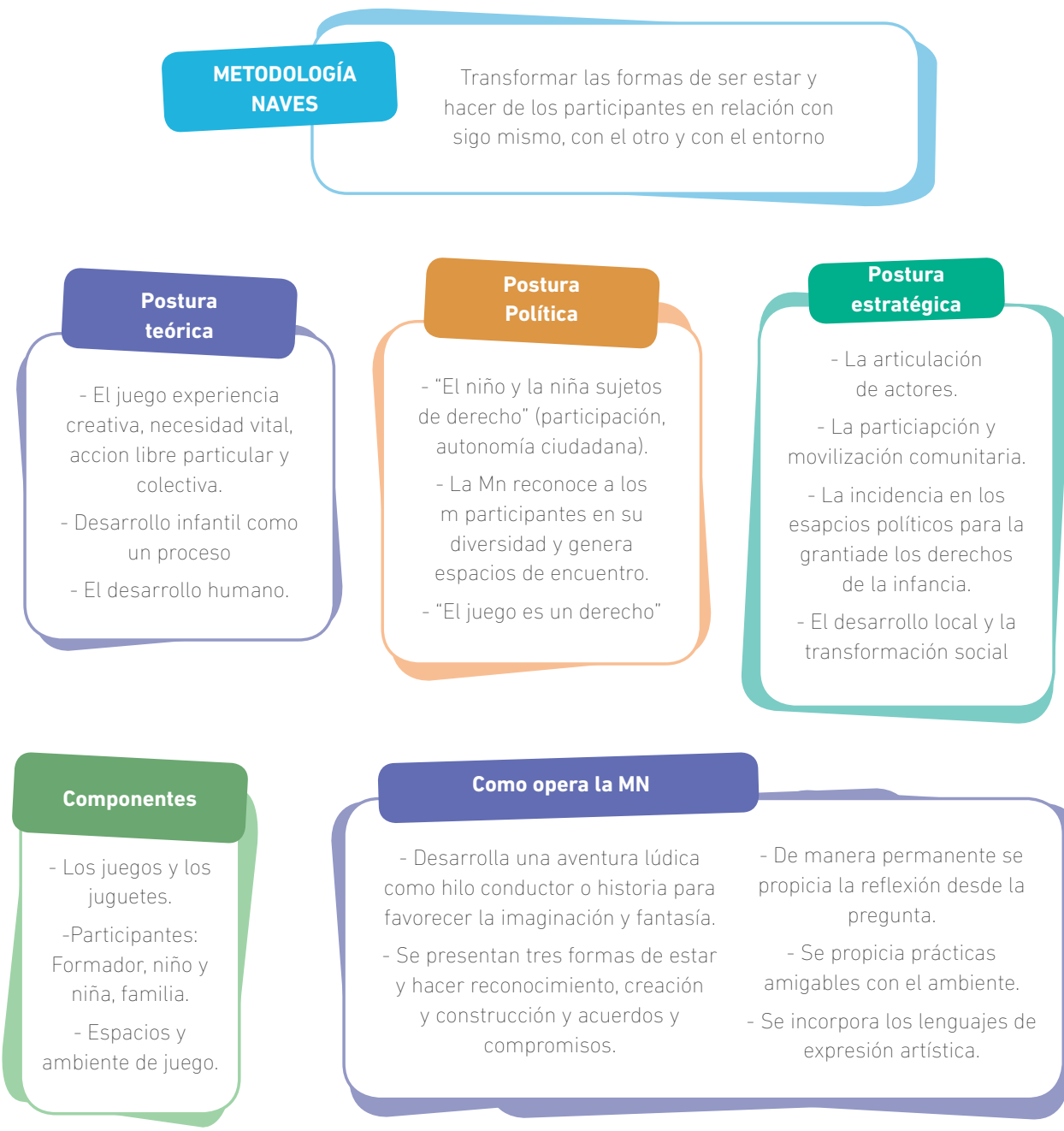

\section{Como opera la MN}

- Desarrolla una aventura lúdica como hilo conductor o historia para favorecer la imaginación y fantasía.

- Se presentan tres formas de estar y hacer reconocimiento, creación

y construcción y acuerdos y compromisos.
- De manera permanente se propicia la reflexión desde la

$$
\text { pregunta. }
$$

- Se propicia prácticas amigables con el ambiente.

- Se incorpora los lenguajes de expresión artística.

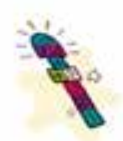


venciones en los territorios. Cada sistematización y evaluación que la Corporación ha realizado le ha permitido aprender y trascender, por cuanto cada experiencia implementada se ha convertido, a su vez, en el punto de llegada de cada nuevo proyecto. Es así como, por ejemplo, se impacta con la Bayer Ludoteca Naves durante más de tres años, entre 2005 y 2009, a partir de los hallazgos de las diversas sistematizaciones documentadas en cada lugar donde operaba el programa.

Entre los años 2009 a 2013, con el fin de identificar aprendizajes y mejorar rutinas organizacionales en la operación de un proyecto de ludotecas viajeras para llegar a la primera infancia en el marco de la atención integral, como parte de la oferta del Ministerio de Educación (MEN), y el Instituto Colombiano de Bienestar Familiar (ICBF), para 45 mil familias rurales y urbanas. Un equipo interno y externo de investigadores acompañan la sistematización desde miles de diarios de campo, innovadores aprendizajes de campo y diversas lecciones aprendidas. También se da cuenta de cómo se estaba trascendiendo de espacios fijos de ludotecas a ambientes que, desde la vida cotidiana y el entorno, se transformaban en novedosas aventuras de juego propiciadas por cerca de 2.000 profesionales cargados de pasión y entrega por su comunidad, entre nutricionistas, pedagogos y sicosociales.

La sistematización permitió documentar un libro sobre cómo se generaban vínculos afectivos sin importar si había que subirse a un caballo, burro, yegua, lancha, bus o a pie para acceder a los parques, polideportivos, escuelas rurales, canchas, casas de familia y hasta debajo de los árboles, para propiciar encuentros de aprendizaje con las familias y su primera infancia. Sistematización que corroboró que el 50 \% de las familias pasaron de o (cero) horas a un promedio de hora y media diaria de juego en familia en su casa, favoreciendo la educación inicial en el país. Impacto que trascendió a la formación de más de 800 hogares comunitarios con los que se sistematizó un modelo de atención. 
Entre 2012 y 2016, estos aprendizajes se consolidan y hacen posible que cada buena práctica documentada, al adentrarse en las teorías y disciplinas de gestión de conocimiento, permita que cada colaborador avance hacia la escritura para dejar expreso el conocimiento acumulado a partir de cada experiencia culminada. Es así como es posible aportar de manera eficiente en proyectos en el país, como Cultivarte, liderado por Banco Davivienda; diplomados sobre educación inicial, de la mano del Politécnico Grancolombiano; encuentros internacionales para transferir aprendizajes en alianza con Colsubsidio y la Gobernación de Cundinamarca; Ludociencia en poblaciones rurales, por el empeño del Grupo de Energía de Bogotá; Apúntate a Moverte, con la empresa Coca Cola y con participación en la medición de la Universidad de los Andes, para llegar a miles de escolares y docentes del país para aprender sobre hábitos saludables; Ludonutrición para hacer un seguimiento nutricional con escolares de tres ciudades, en donde su patrocinador, Fundación Femsa Mexico, le apostó a las ludotecas saludables.

Con el mismo interés por encontrar oportunidades de mejora en su quehacer, en 2016, de la mano de ICBF, OEl y el Ministerio de Vivienda, entre otros, se aportó a nuevas comunidades el conocimiento y la Metodología Naves para fortalecer la educación inicial, los entornos protectores y el tejido social. Igualmente, este conocimiento permitió convocar cerca de nueve instituciones públicas y privadas para conformar una mesa nacional que, al cabo de tres años, culminará con una propuesta de lineamientos técnicos para ludotecas en Colombia.

Cada proyecto ejecutado por la Corporación ha estado mediado por un proceso investigativo, sea con personal interno o con alianzas con la academia, como en los casos de las investigaciones de educación inicial de la Universidad San Buenaventura y la implementación de un modelo de atención para jóvenes con la Universidad Gran Colombia, y en el municipio de Icononzo, con el aporte de 


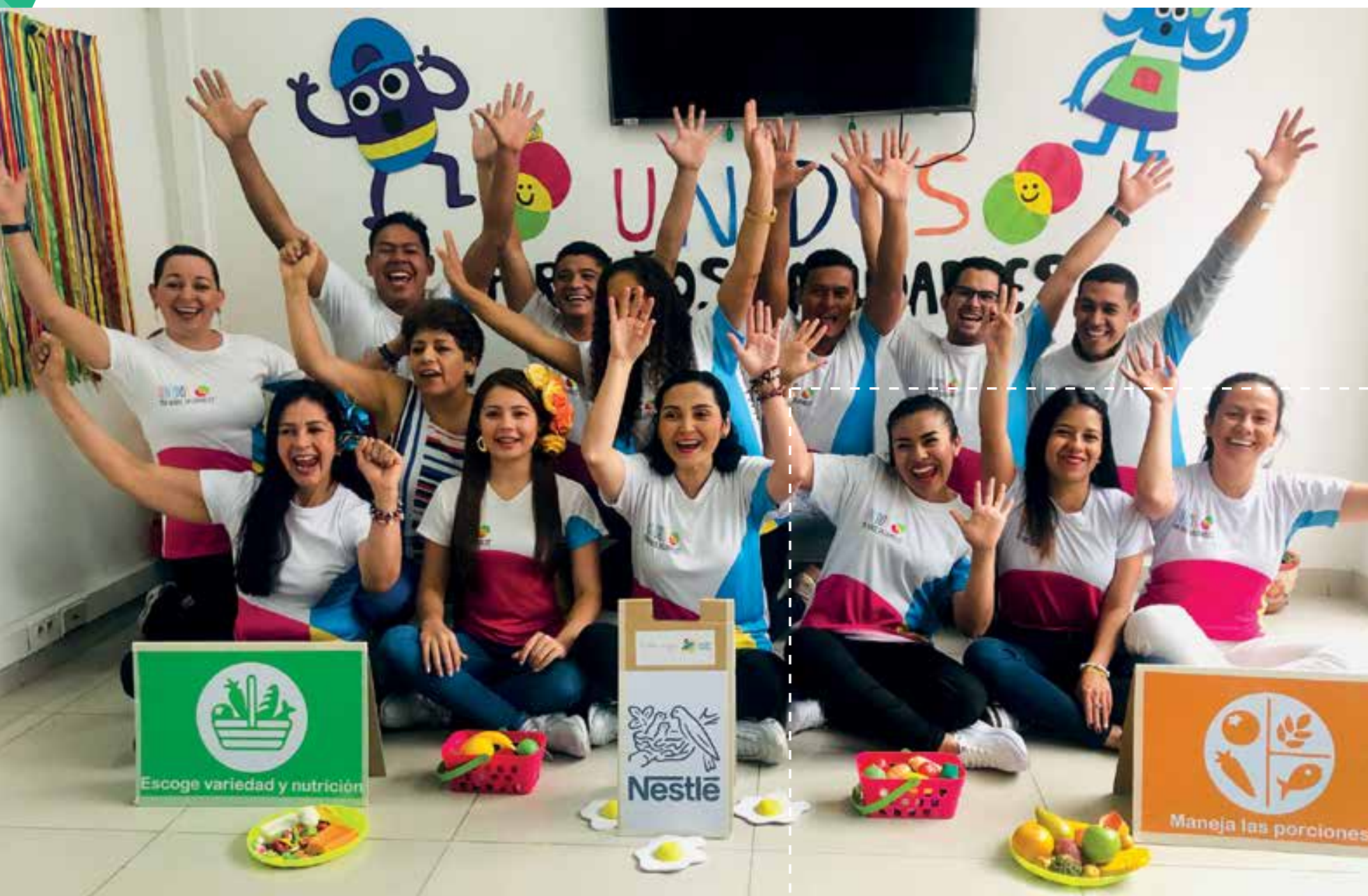

Profesionales de Nestlé Niños Saludables 
Petrobras. Muy importante también que en proyectos como Unidos por Niños Saludables, de la empresa Nestlé, operado por la Corporación desde su metodología, su impacto se haya medido por instancias académicas como la Universidad La Sabana y sus resultados nos permitan mejorar su implementación. La investigación y la gestión de conocimiento siguen siendo las mejores oportunidades que tiene la Corporación Juego y Niñez para aprender y desaprender y así con más certezas fortalecer la Metodología Naves al servicio de la asistencia técnica en modelos como este de Ludotecas Naves, que está al servicio de entes públicos y privados, en Colombia y en el mundo. Ludotecas como programas sostenibles y parte de políticas públicas de niñez y adolescencia deben ser soñadas desde la perspectiva de derechos y la investigación será la gran aliada.

\section{¿Por qué una investigación longitudinal?}

Continuando el proceso anterior, como pilar fundamental de la mejora continua de la Corporación Juego y Niñez, y como parte de su Sistema Integrado de Gestión, los órganos directivos de la Corporación Juego y Niñez comprenden la necesidad de poner nuevamente en manos de la academia especializada del país su quehacer cotidiano, y es así como en 2015 se da inicio al contrato con el Grupo de Investigación Cognición y Lenguaje en la Infancia, de la Facultad de Medicina de la Universidad Nacional de Colombia, bajo la dirección de Rita Flórez Romero, profesora e investigadora de esta universidad, con Jaime Castro Martínez, miembro del grupo de investigación, y con María Cristina Torrado y Marta Torrado, investigadoras del Observatorio de Infancia de la misma Universidad. Se inicia la primera y única investigación longitudinal sobre Ludotecas en Colombia, de manera que no solo tuviera la constatación de la eficacia de su metodología en las Ludotecas Naves, sino que hallara oportunidades de mejora continua con progresión en los proyectos en los que participa y, por ello, a partir de los resultados que estamos publicando en este texto, los años venideros serán un reto constante en su quehacer para que la calidad de la atención a los participantes

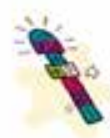


en todo el país en las Ludotecas Naves, y en cada proyecto que opera o asiste técnicamente, por parte de la Corporación Juego y Niñez, se desarrolle con los mejores estándares de calidad.

Evaluar el impacto de las ludotecas Naves en el desarrollo de competencias ciudadanas, emocionales y de creatividad le aportan al país una conversación permanente desde la reflexión, para que las acciones cotidianas que favorecen a niños y niñas en estas ludotecas de los diferentes municipios se enriquezcan y encuentren un verdadero sentido a su razón de ser. Resultados que trascenderán como aporte importante al inicio de proyectos que buscan objetivos similares para beneficiar la infancia y adolescencia en Colombia. Pesquisa que da soporte científico a un programa de educación no formal que, con estos hallazgos, se abre un camino en las políticas públicas departamentales y nacionales, y que estará a la orden de cada ambiente o territorio en donde se disponen posibilidades para que los niños y las niñas se diviertan cuando se encuentran con otros niños y niñas de su edad y su familia. Este estudio deja abierta preguntas y provocaciones para que la ciencia se formule nuevos cuestionamientos para la siguiente inspección científica sobre ludotecas y por supuesto que para La Corporación Juego y Niñez en la mejor herramienta para innovar en cada oferta de juego que propone y especialmente para que el juego en la casa, el barrio, el colegio, la biblioteca, el parque, etc, sea un asunto serio con el sentido de lo que es "Jugar para ser feliz" y no sólo para entretenerse o aprender cosas. 
......- CAPÍtULO 3

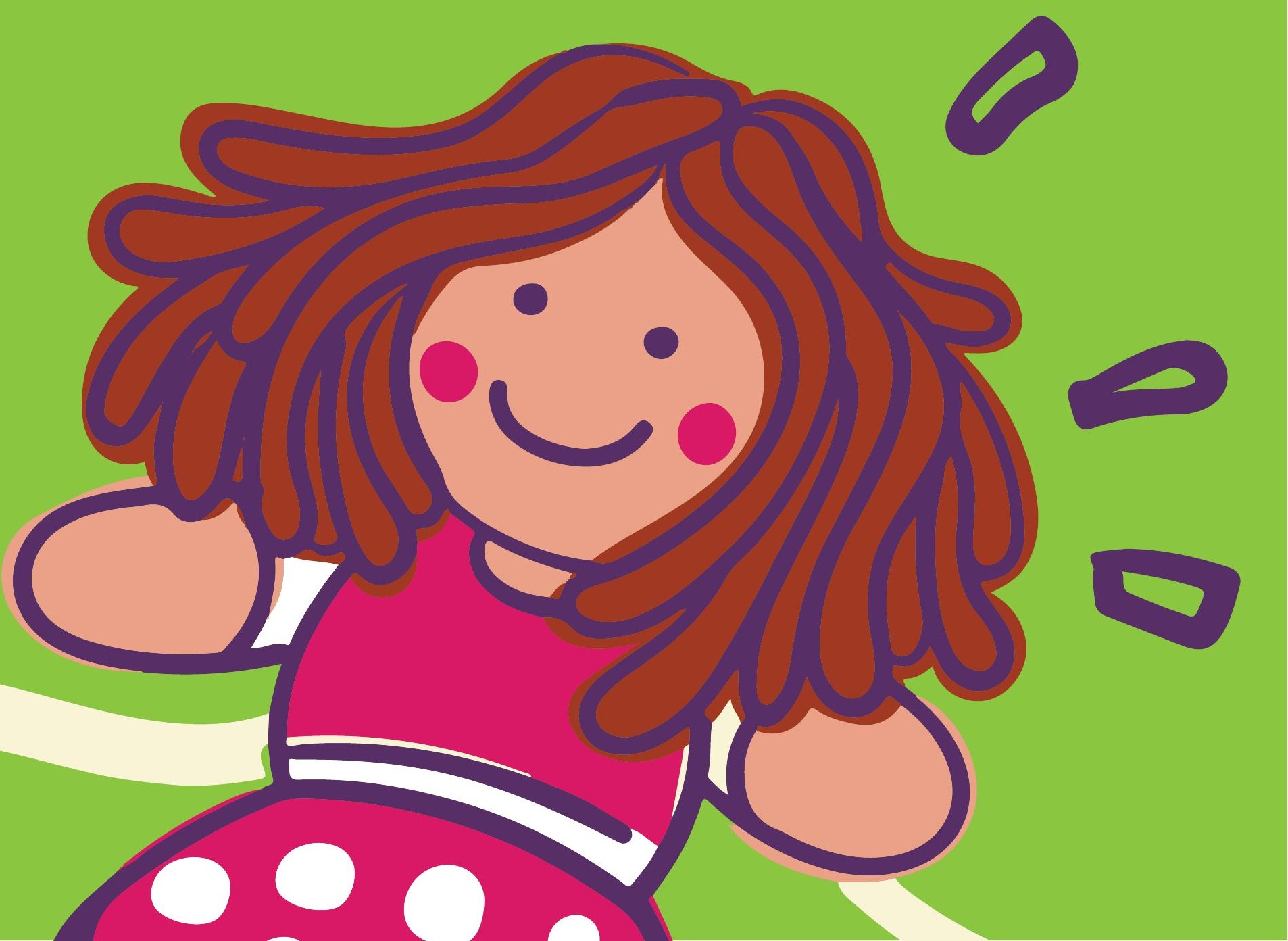




\section{Juego y ludotecas en el desarrollo de competencias ciudadanas, emocionales y de creatividad en niños: estableciendo}

\section{una línea base}

Iniciamos este capítulo con los resultados del primer momento del estudio longitudinal que se realizó durante cuatro años en distintas regiones de Colombia, cuyo propósito fue evaluar el impacto de las ludotecas en el desarrollo de competencias en niños. Este estuvo centrado en la comprensión del comportamiento de distintos tipos de competencias en la infancia: emocionales, ciudadanas y de creatividad, en un escenario concreto como el de las ludotecas, y en poder identificar el impacto que pueden producir estas en el desarrollo infantil.

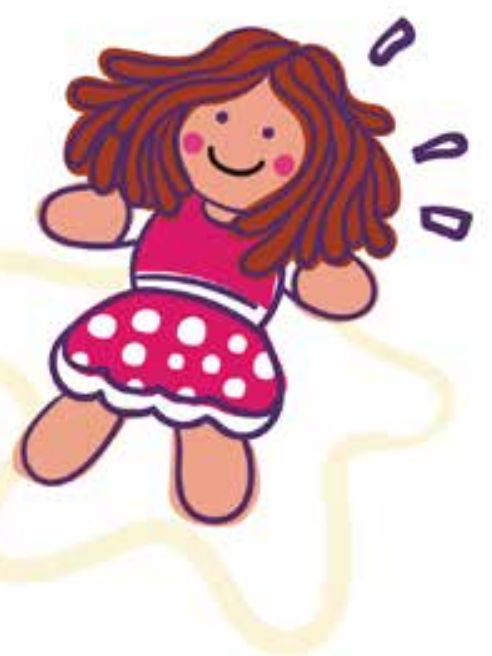




\section{Las competencias en la infancia}

Es importante iniciar comprendiendo el concepto de competencias. La competencia en la infancia hace referencia a un constructo amplio, el cual se vincula a una serie de conceptos que se relacionan con las capacidades, conocimientos, habilidades, destrezas y actitudes de los niños y niñas para actuar, de manera adaptativa, ante el medio, especialmente social, y bajo contextos ecológicos e históricos particulares, guardando relación estos con un desempeño adecuado durante el ciclo vital (Masten, 2006; Masten et al., 1995). Por ello, se considera un conjunto multidimensional que suele estar relacionado con el concepto de competencia social, en donde se incluye un repertorio amplio de capacidades y destrezas motoras, emocionales, del lenguaje, ciudadanas, entre otras. Estas guardan una relación importante con el desarrollo infantil en general, y juegan un papel clave en aspectos como la motivación o la toma de decisiones participativas (Fredricks \& Eccles, 2002), o con el desempeño posterior durante la adolescencia o la adultez temprana (Ireland, Sayers, Deere, Emond, \& Tobias, 2016; Kapeleris \& Paivio, 2011; Masten, Desjardins, McCormick, Kuo, \& Long, 2010; Shiner \& Masten, 2012). Dichas competencias parecen variar con el tiempo, y pueden tener ejecuciones distintas en razón al género (Fredricks \& Eccles, 2002; van der Wilt, van Kruistum, van der Veen, \& van Oers, 2015).

En Colombia, el concepto de competencias en la infancia se encuentra manifiesto en el "Documento 10", del Ministerio de Educación Nacional - MEN (2009). En este, las competencias se refieren a "capacidades generales que posibilitan los haceres, saberes y el poder hacer, que los niños manifiestan a lo largo de su desarrollo" (p.16). Guardan relación con los conocimientos de los niños para interactuar con los otros, con el entorno y con ellos mismos. Así, las competencias agencian y propician cambios hacia nuevos niveles de conocimiento. Para propósitos de este capítulo, nos interesa comprender lo que significan las competencias ciudadanas, emocionales y de creatividad en niños y niñas.Se 
entiende por competencias ciudadanas, "el conjunto de capacidades y habilidades cognitivas, emocionales y comunicativas -integradas- relacionadas con conocimientos básicos (contenidos, procedimientos, mecanismos), que orientan moral y políticamente nuestra acción ciudadana" (Ruiz \& Chaux, 2005, p.32). Dichas competencias hacen posible que el ciudadano actúe de manera constructiva en la sociedad democrática (Chaux, 2004). En la infancia, el desarrollo de esta competencia se vincula con la evolución de la comprensión de los derechos por parte del niño, con el alfabetismo político (political literacy) y con la participación infantil (Invernizzi \& Williams, 2008). Relacionado con esta competencia, para este estudio fue particularmente importante los conceptos asociados a la participación, la convivencia, la interacción en el juego, el manejo de conflictos y el manejo de reglas; estos son definidos de la siguiente manera:

Participación y Autonomía: de acuerdo con Moreno (2000), la participación de niños y niñas es definida como un proceso formativo, el cual les permite actuar autónomamente y esto fomenta y motiva el desarrollo de sus capacidades principalmente, con el fin de que los niños logren tener una participación activa tanto en su desarrollo como en la construcción de su entorno social, promoviendo una conciencia ciudadana.

Convivencia: siguiendo el planteamiento de Ortega (2006), este concepto hace referencia al reconocimiento de compartir diferentes escenarios y actividades siguiendo un conjunto de normas, con el fin de comprender los distintos puntos de vista de los demás y promover así un ambiente de solidaridad, autoestima, tolerancia, comprensión y respeto hacia sí mismo y hacia los otros.

Interacción en el juego: en el juego infantil, acorde con lo que Duek (2016) menciona, se construyen vínculos en diferentes ámbitos. Es por ello por lo que, por medio del juego, los niños configuran experiencias que les posibilitan desa- 
rrollar espacios de interacción y convivencia, conservando la característica del juego al ser una actividad lúdica, creativa y dinámica. Es una actividad específica en la que cada niño organiza su relación con el mismo, con otros niños y con su entorno social.

Manejo de conflictos: de acuerdo con Ochman y Escalante (2013), existen tres maneras diferentes de abordar el componente de manejo de conflictos: uno, es a partir de la aceptación del conflicto; otro, es analizando y considerando los elementos, causas y consecuencias del conflicto y, por último, por medio de la habilidad de negociación, diálogo y solución de conflictos.

Manejo de reglas: para Garoz-Puerta (2005), el juego cumple su función como una de las principales actividades de la etapa infantil. Entre otras razones, con el fin de brindar conocimiento y conciencia social. Este conocimiento y conciencia social los da el contexto, el cual a su vez está determinado por la cultura, y dicha cultura es la que establece una serie de reglas, cada una con un significado particular. Con esto, los niños por medio del juego aprenden a jugar, aprenden la importancia del cumplimiento y manejo de las reglas, también aprenden por qué son importantes las reglas para convivir en sociedad y, finalmente, aprenden y toman conciencia que su participación influye y tiene un impacto para la vida y para la interacción social.

Por su parte, se comprende por competencia emocional el conjunto de conocimientos, capacidades, habilidades y actitudes necesarias para conocer, expresar y regular de forma apropiada los fenómenos emocionales, en formas socialmente adecuadas, y la decodificación de estos procesos en sí mismos y en los otros (Bisquerra \& Pérez-Escoda, 2007; Pérez-Escoda, Velar, \& Ruiz-Bueno, 2014; Saarni, 1999). Esta permite comprender, interactuar y transformar el entorno; de ahí la importancia que adquiere en la interacción entre la persona y 

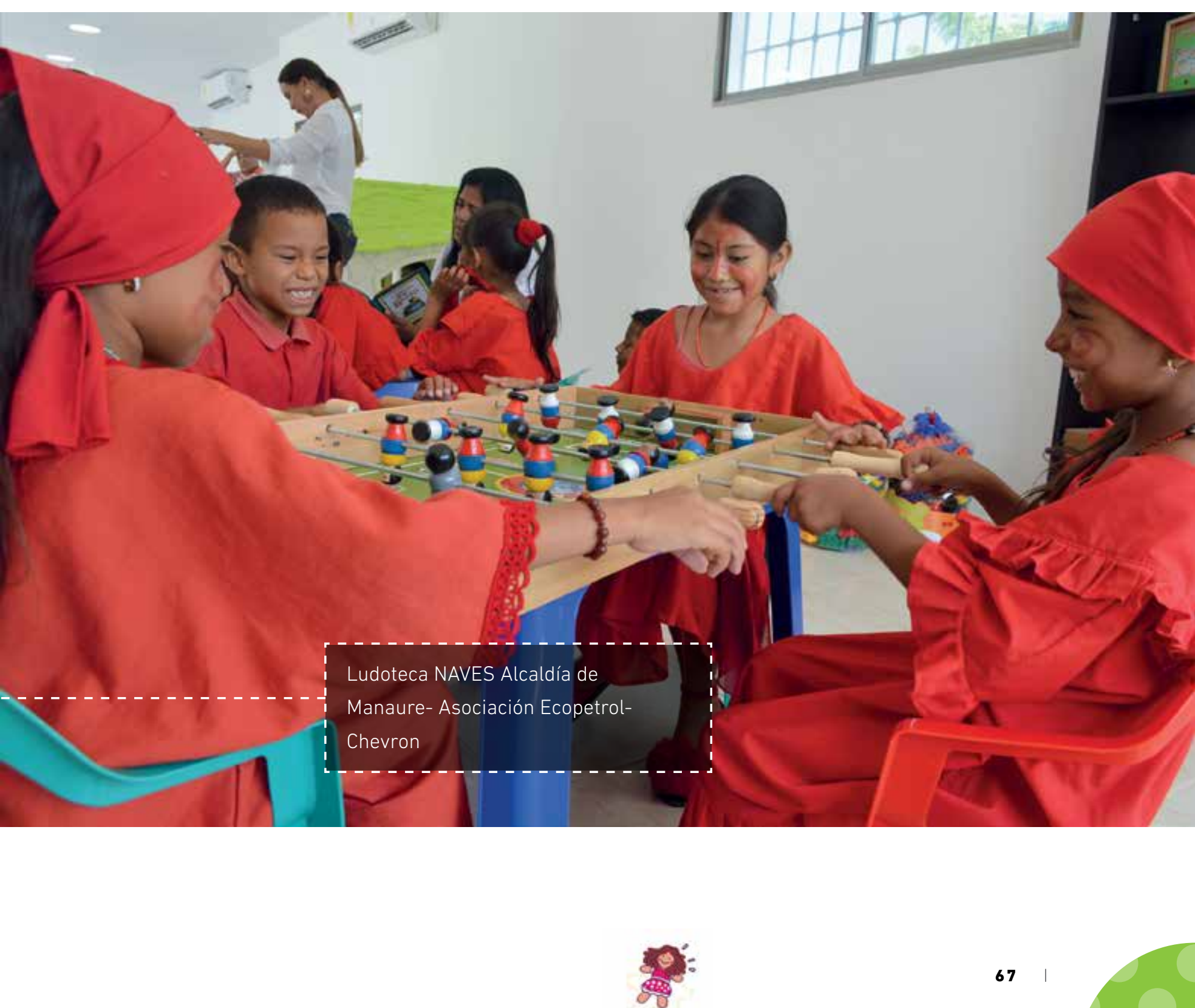
ambiente, y su papel en el aprendizaje (Gaeta \& López, 2013; Salazar \& Chiang, 2007). Diversos estudios han mostrado cómo componentes de esta competencia -como la regulación emocional- se convierten en vías para el desarrollo de la competencia social (Penela, Walker, Degnan, Fox, \& Henderson, 2015), o cómo esta guarda relación con el desarrollo del lenguaje en la infancia (Beck, Kumschick, Eid, \& Klann-Delius, 2012). En este estudio se tuvo en cuenta los conceptos de expresión de emociones, empatía y autorregulación emocional.

Expresión de emociones: la expresión de emociones se desarrolla gracias a la interpretación de la información proveniente de la observación de los rostros de las demás personas. Dicha información es integrada con los datos existentes en la memoria, así como las experiencias pasadas relacionadas con el conocimiento de las emociones (Salazar \& Chiang, 2007). Adicionalmente, según Fragoso-Luzuriaga (2015), esta capacidad es desarrollada gracias a las relaciones sociales desde una edad temprana. Estas interacciones facilitan la aparición de patrones afectivos que se hacen regulares y proporcionan la identificación de algunas emociones. Matsumoto, Hwang, López y Pérez-Nieto (2013), señalan que dicha capacidad se sigue ampliando en los años siguientes y en distintos contextos sociales, por ejemplo, con pares y amigos.

Según Riquelme, Munita, Jara y Montero (2013), en la etapa preescolar los niños tienen la capacidad de inferir emociones básicas a partir de la expresión facial y, de esta manera, interpretan las consecuencias de dichas emociones, permitiéndoles diferenciar las emociones propias de las de los demás. Sánchez-Aragón y Díaz-Loving (2009), señalan que los niños inicialmente tienden a reconocer mejor la alegría en comparación con expresiones de emociones negativas, por ejemplo, la tristeza y la rabia. Gradualmente, logran diferenciar las emociones negativas y son capaces de interpretar y entender el lenguaje emocional. Este proceso se puede asociar a la denominada alfabetización 
emocional (Matsumoto et al., 2013). Finalmente, Sánchez-Aragón y Díaz-Loving (2009), describen la expresión de emociones como la capacidad de manifestar emociones relacionadas con estados o situaciones personales; de este modo se busca influir en los estados de ánimo de las demás personas. La expresión de emociones se entiende como la habilidad para comunicar y compartir con los demás los pensamientos y sentimientos sobre diferentes eventos de la vida.

Empatía: López, Arán-Filippetti y Richaud (2014), mencionan que la empatía es uno de los componentes fundamentales para el desarrollo de vínculos sociales y de conductas prosociales; de esta forma, la empatía comienza a desarrollarse tempranamente. Los niños que están en la etapa preescolar serán capaces de desplegar mensajes emocionales no verbales, como son los abrazos o el gesto de fruncir el ceño, entre otros. Un componente fundamental en el desarrollo de la empatía es la congruencia emocional. Root y Denham (2010), señalan que este componente es el eje que provee el balance entre los pensamientos, las acciones y las emociones que se expresan y son sentidas. Alrededor de los 4 años los niños adquieren este componente, el cual les ayuda a comprender las emociones de otros, y a expresar y regular una gama más amplia de emociones. Por su parte, Denham (2007) define la empatía como la capacidad de comprender los sentimientos y emociones de los demás. Esta es considerada una habilidad indispensable para los seres humanos, teniendo en cuenta que toda nuestra vida transcurre en contextos sociales complejos. López et al. (2014), recalcan que, gracias a la naturaleza social de la humanidad, es esencial el reconocimiento y la comprensión de los estados emocionales de los demás.

Autorregulación: Rodríguez, Russián y Moreno (2009), definen la autorregulación como la habilidad de controlar las emociones en forma eficaz, generando homeostasis emocional y evitando respuestas impulsivas en situaciones de ira, provocación o miedo. En otras palabras, es percibir el propio estado afectivo 
sin dejarse afectar por él, de manera que no obstaculice el razonamiento y permita tomar decisiones acordes con los valores, normas sociales y culturales. Para Fayne, García, Montero y Valencia (2013)2007, las estrategias que los niños pequeños utilizan para regular sus emociones están en función de si se incrementa o si se disminuye el malestar emocional. Las estrategias que ellos utilizan están basadas en el cambio de atención, como distraerse, autocalmarse y buscar consuelo. Si el niño logra dirigir la atención lejos de la fuente del estrés, esto se asociará con un menor malestar emocional. Por otra parte, Rendón (2007) menciona que las conductas que intensifican la emoción, tales como la agresión y el llanto, mantienen la atención centrada en la fuente de malestar y dificultan las habilidades del niño para manejar el estrés y lidiar con las emociones.

La creatividad, por otro lado, es comprendida como la capacidad de utilizar la información y los conocimientos de forma nueva, de encontrar soluciones divergentes a los problemas, de inventar novedades eficientes y de generar ideas nuevas, apropiadas y de alta calidad (Donolo \& Elisondo, 2007). Se caracteriza por desempeños tanto de pensamiento racional, como por altos niveles de desarrollo emocional o de sentimientos, altos niveles de desarrollo físico y mental, y por altos niveles de conciencia (Saracho, 2002). En este estudio nos interesó conocer sobre pensamiento divergente, flexibilidad y elaboración, competencias definidas de la siguiente forma:

Pensamiento divergente: es la capacidad para producir un contenido que no solo es novedoso, original e inesperado sino, además, apropiado, útil y adaptado a la tarea en cuestión (UNESCO-OCDE, 2016). De acuerdo con Miguel Ángel Herrera (2004), es la posibilidad de dar diferentes soluciones a un mismo problema, es decir, de proponer diversas formas de llevar a cabo una actividad. 
Flexibilidad: esta competencia tiene que ver con la adaptación para cada momento (Lado, Ismach, \& Rossi, 2002). Implica provocar situaciones que permitan dichas adaptaciones a través de mediaciones (Ramírez, 2009). Se considera la flexibilidad como un elemento importante para el juego, junto con la espontaneidad y la versatilidad (Marín, 2009). Dicha flexibilidad permite estimular una actitud positiva en temas como la tolerancia, la cooperación, la coeducación, la solidaridad, entre otras (Santos \& Salgado, 2006).

Elaboración: relacionada con el pensamiento divergente y convergente, la elaboración hace referencia a la capacidad de planear de forma ordenada el desarrollo de una actividad, de manera creativa (Donolo \& Elisondo, 2007).

Diversas estrategias se han propuesto para el desarrollo de las competencias en la infancia, buena parte de estas en el escenario educativo, debido a que su evolución parece guardar relación con el éxito académico (Han, 2014) professional development (PD. Este último autor destaca, como motores del desarrollo de las competencias en el ambiente educativo, la retroalimentación de los procesos de aprendizaje, la reflexión constante o el reconocimiento de las necesidades contextuales de los niños.

\section{El lugar de las ludotecas en el desarrollo de competencias en la infancia}

Como escenario alternativo (o complementario) al escolar, aparecen las ludotecas. Diversos investigadores concuerdan en afirmar que estas son lugares ideales para potencializar competencias necesarias para el desarrollo integral y para facilitar la interacción entre pares (Kalinowski, 2010; Ochsner \& Gross, 2005; Ringoot et al., 2013). Así, las ludotecas pueden ser consideradas espacios únicos en donde se logran cambios individuales, familiares y sociales importantes (Nicholson, 2013). Según Managers (2005), las ludotecas promueven que el adulto 

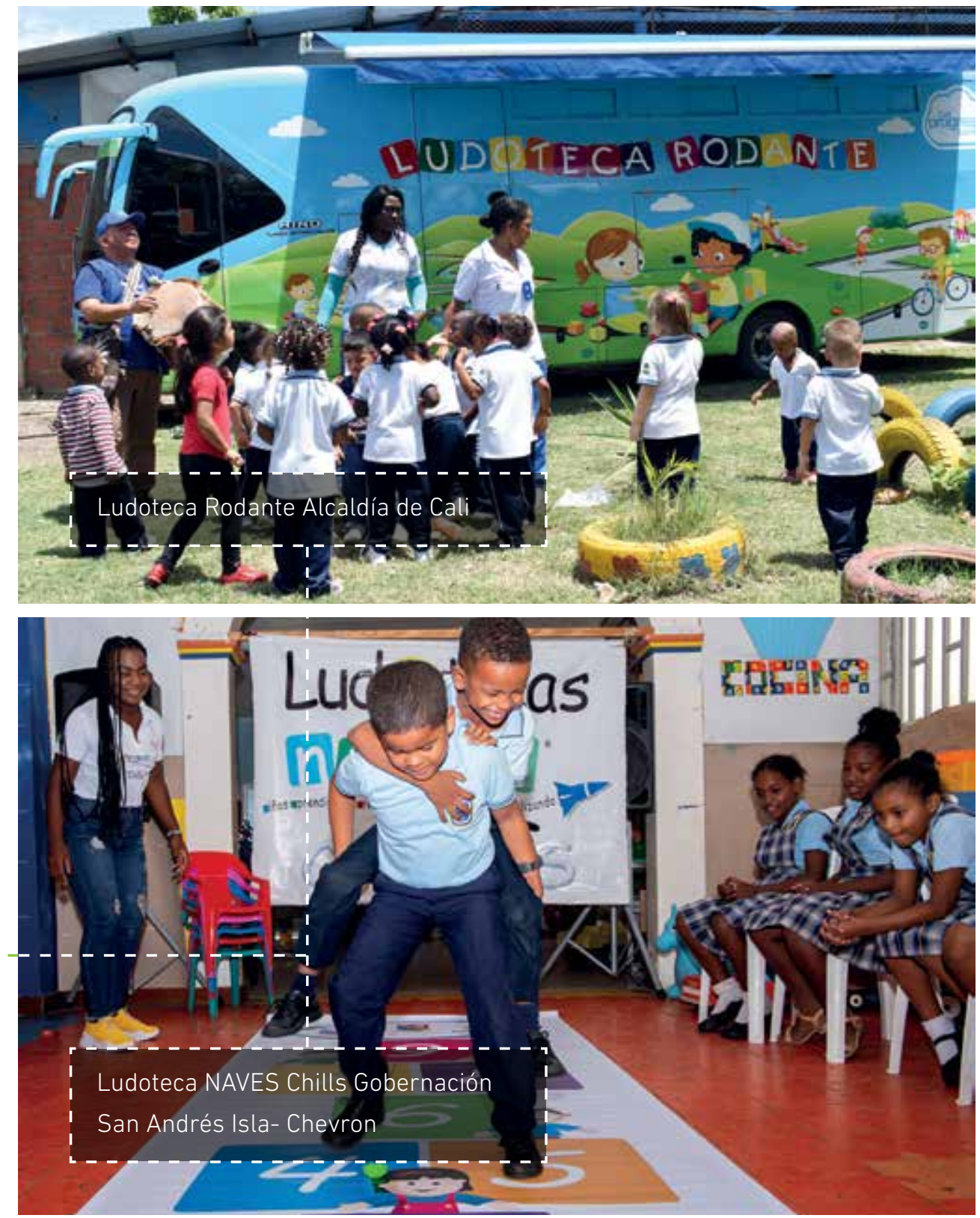

72

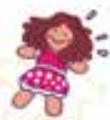


se comprometa en el juego con el niño, y realice un proceso de acompañamiento, fomentando así el desarrollo -en el infante- de la imaginación, la creatividad y la autonomía. Para este mismo autor, en ellas no solo se administran y prestan juguetes, sino que se interactúa con historias, cuentos y relatos, puesto que estas no son solo un lugar físico, sino también un espacio simbólico; es decir, son sitios de construcción de experiencias que facilitan el aprendizaje de los niños.

De acuerdo con Rosas et al. (2015), las ludotecas crean un espacio específico en el que el niño puede disfrutar del juego y de la interacción con sus pares, beneficiando así su desarrollo cognitivo, psicomotor y socioafectivo. En esta misma línea, según Reyes (2012), las ludotecas son aprovechadas como un recurso compensatorio que permite la participación de un amplio número de niños que se benefician de actividades de desarrollo global y de una intervención de carácter psicológico y social. De igual forma, Fleisher (2015), sostiene que en ellas se aprovecha el juego como un factor innato de aprendizaje, con el objetivo de desplegar una gama más amplia de habilidades, entre ellas, las emocionales. Es por ello por lo que las ludotecas posibilitan la interacción entre niños y adultos y, en general, entre el niño y la sociedad. Esta dinámica permite una perspectiva de mayor conciencia del mundo que rodea al niño (Corporación Día de la Niñez, 2009). Sin embargo, según Santos y Salgado (2006), el juego en las ludotecas, por sí solo, no es suficiente. Se requiere que la dinámica lúdica en estos escenarios se ciña a determinados objetivos, acompañados de una metodología bien estructurada, con el fin de contar con una orientación más apropiada. Esto marca una diferencia entre la ludoteca y otros espacios para el juego.

En Colombia, la incorporación de programas de ludotecas con carácter social ha tenido una historia reciente. Solo hasta 1998, por medio de la gestión de entidades públicas y privadas, y con el liderazgo de la Presidencia de la República de Colombia, se crea el programa de ludotecas NAVES (Niños y Niñas 
Aprendiendo, Viviendo, Experimentando y Socializando) que, como pocos en el país, ha conseguido sostenerse a lo largo del tiempo. Este programa está orientado a mejorar la calidad de vida de la población infantil más vulnerable a través de los escenarios lúdicos propuestos para los niños y sus familias (Corporación Día de la Niñez, 2009). Actualmente, funciona en las modalidades de ludotecas fijas e itinerantes en 149 municipios de Colombia, y atienden alrededor de 68.428 niños en todo el país (Corporación Juego y Niñez, 2017).

Si bien hasta acá se ha mencionado la importancia de las ludotecas en el desarrollo infantil, especialmente en el desarrollo motor, cognitivo, comunicativo, afectivo, moral y social, y en la facilitación de procesos de aprendizaje, aún son pocos los estudios que detallan estos efectos en estas dimensiones del desarrollo, y son menos los que hacen referencia a variables como la edad o el género. De encontrarse efectos positivos de estos escenarios en la infancia media o tardía en Colombia, es posible sugerir la incorporación de prácticas basadas en el juego o en las ludotecas en escenarios de educación primaria y secundaria, o la modificación de las políticas públicas locales para favorecer dichos escenarios y prácticas.

\section{Sobre este estudio}

Este estudio contó con la participación de 529 niños de seis municipios de Colombia; de estos, 247 eran niños (46.7\% de la muestra) y 282 niñas (53.3\%), con edades comprendidas entre el año y los 13 años ( $M=7.5$ años; $D E=1.89)$. Esta muestra se dividió en dos grupos: Uno de ellos estuvo conformado por 354 niños (167 niños y 187 niñas), que asistían a ludotecas; el otro, por 175 niños (80 niños y 95 niñas), que asistían regularmente a jardines infantiles o colegios de estas mismas ciudades. El criterio de selección de las ludotecas fue el tiempo de funcionamiento de esta (mayor a 2 años). Se actuó con las autoridades locales y ludotecarios de las distintas ciudades para ubicar la muestra de niños

\section{| $\mathbf{7 4}$}


del grupo comparación. La edad promedio de los niños que asistían a las ludotecas fue de 7.5 años ( $D E=2.07$ ) y la de los niños que no asistían fue de 7.4 años $(D E=1.45)$. No se encontraron diferencias significativas entre los grupos por edad $(t=1.01 ; p=.312)$ o género $\left(x^{2}=.10 ; p=.751\right)$. Dado que se trataba de menores de edad, para todos los casos se solicitó consentimiento informado de los padres, antes de las observaciones. Estas solicitudes se hicieron por medio de los directivos y maestros de los centros educativos y de los ludotecarios.

Luego de identificadas las ludotecas, jardines y colegios en los que se harían las observaciones, y luego de obtenidos los consentimientos de los padres, los observadores de campo (dos en cada ciudad), asistieron durante mes y medio a cada escenario de observación. Se realizaron observaciones de 15 niños durante una semana, ya fuese en la ludoteca, en colegios o jardines, dependiendo de la disponibilidad de los niños en las instituciones. Estas observaciones fueron repetidas durante la semana. Las observaciones se hicieron en parejas, como estrategia de triangulación de la información recabada. En promedio, se realizaron tres visitas por semana a cada institución, para tener consistencia en las valoraciones. Para esta investigación se diseñó un instrumento de observación dividido en las 3 dimensiones señaladas en la introducción: competencias ciudadanas, competencias emocionales y creatividad. Cada dimensión, a su vez, evaluaba distintos componentes: en la dimensión de competencia ciudadana se valoraba participación y autonomía (PA), convivencia (CV), interacción en el juego (IJ), manejo de conflictos (MC) y manejo de reglas (MR); en la dimensión de competencia emocional se valoraba la expresión de emociones (EE), empatía (EM) y autorregulación (AR); y en la dimensión de creatividad se valoraba pensamiento divergente (PD), flexibilidad (FX) y elaboración (EB) (ver Tabla 1 para distribución de componentes por dimensiones). Cada componente podía ser caracterizado en uno de cuatro niveles, que iban de un nivel bajo de expresión del componente (Valor 1), hasta un nivel alto (Valor 4). 


\section{DISTRIBUCIÓN DE COMPONENTES POR DIMENSIÓN}

\begin{tabular}{|c|c|c|c|}
\hline DIMENSIÓN & & VIATURA & COMPONENTE \\
\hline \multirow{5}{*}{ Competencia Ciudadana (CC) } & 1 & $P A$ & Participación y autonomía \\
\hline & 2 & CV & Convivencia \\
\hline & 3 & IJ & Interacción en el juego \\
\hline & 4 & $M C$ & Manejo de conflictos \\
\hline & 5 & $M R$ & Manejo de reglas \\
\hline \multirow{3}{*}{ Competencia Emocional (CE) } & 1 & $E E$ & Expresión de emociones \\
\hline & 2 & $E P$ & Empatía \\
\hline & 3 & $A R$ & Autorregulación \\
\hline \multirow{3}{*}{ Creatividad (CR) } & 1 & $P D$ & Pensamiento divergente \\
\hline & 2 & $F X$ & Flexibilidad \\
\hline & 3 & $E B$ & Elaboración \\
\hline
\end{tabular}

Además, el instrumento se diseñó para recoger información en dos situaciones distintas de observación: una, en un escenario de juego natural (espacio de descanso de los niños en ludoteca, jardín o colegio); y otra, en un escenario de juego en situación artificial (juego dirigido o propuesto por el observador). Si bien estos instrumentos tuvieron validación de contenido mediante jueces expertos, se realizó una evaluación de consistencia interna a través del estadístico de alfa de Cronbach tanto a la prueba general $(\alpha=.934)$ como al instrumento en cada situación: natural ( $\alpha=.890$ ) y artificial ( $\alpha=.877)$. De igual forma, se calculó la fiabilidad para cada dimensión (CC $\alpha=.873$; CE $\alpha=.809 ;$ CR $\alpha=.856$ ). A su vez, se quiso probar la consistencia de la prueba por medio de la evaluación del coeficiente de forma paralela entre las pruebas en situación natural y en situación 
artificial. El coeficiente de equivalencia, calculado mediante el coeficiente de correlación de Pearson, fue de $r_{\mathrm{g}}=.806$, y para cada dimensión fue de $r_{\mathrm{cc}}=.716$; $r_{c e}=.685 ;$ y $r_{c r}=.707$. Para todos los casos $p<.001$. Lo anterior señala la validez del instrumento utilizado.

La información fue recolectada y subida a una plataforma online diseñada para tal fin, desde la cual se conformó la base de datos para el análisis. Se utilizaron distintas estrategias estadísticas para las comparaciones, principalmente correlaciones con $r$ de Pearson, pruebas $t$ de diferencias de medias y ANOVA. Los análisis se realizaron utilizando el paquete de análisis estadístico para las ciencias sociales SPSS versión 23.

\section{Sobre los resultados del estudio en la línea base}

Si bien no era el propósito central de este estudio, se realizó una correlación entre los valores totales de las observaciones en cada competencia. Los análisis muestran que todas ellas encuentran relación entre sí: CC-CE $r=.685$; CC-CR $r=.814$; CE-CR $r=.650$. Para todos los casos $p<.001$.

Los análisis muestran diferencias entre los valores promedio de los grupos que asisten y que no asisten a ludotecas en cada una de las dimensiones evaluadas en la línea base: competencias ciudadanas (CC), emocionales (CE) y creatividad (CR). Para todos los casos, estos valores llegan a ser mayores en el grupo de niños que asiste a las ludotecas (ver Tabla 2). Una prueba t para muestras independientes señala diferencias significativas para competencias ciudadanas $\left(\Delta_{C C}=1.72 ; t=2.83 ; p=.005\right)$, y creatividad $\left(\Delta_{C R}=1.81 ; t=4.35\right.$; $p=.000)$. No se encontraron diferencias significativas, generales, para competencias emocionales $\left(\Delta_{\mathrm{CE}}=0.426 ; t=1.22 ; p=.221\right)$. 


\section{DESCRIPTIVOS GENERALES DEL DESEMPEÑO DE CADA GRUPO POR COMPETENCIA EN LA LÍNEA BASE}

\begin{tabular}{lcccccc}
\cline { 2 - 6 } & \multicolumn{5}{c}{ GRUPO } \\
\cline { 2 - 6 } & Media & $\begin{array}{c}\text { Desviación } \\
\text { estándar }\end{array}$ & $\begin{array}{c}\text { Media de error } \\
\text { estándar }\end{array}$ & Media & $\begin{array}{c}\text { Desviación } \\
\text { estándar }\end{array}$ & $\begin{array}{c}\text { Media de error } \\
\text { estándar }\end{array}$ \\
\cline { 2 - 6 } & 29.29 & 6.39 & 0.34 & 27.56 & 5.80 & 0.47 \\
\hline $\begin{array}{l}\text { Competencia } \\
\text { Ciudadana (CC) }\end{array}$ & 17.38 & 3.57 & 0.19 & 16.95 & 3.46 & 0.28 \\
\hline $\begin{array}{l}\text { Competencia } \\
\text { Emocional (CE) }\end{array}$ & 15.94 & 3.99 & 0.21 & 14.12 & 4.35 & 0.36 \\
\hline Creatividad (CR) & & & & & & \\
\hline
\end{tabular}

En la Tabla 3 se muestran las diferencias en cada una de las competencias ciudadanas entre el grupo de niños que asiste a las ludotecas y el grupo de niños que no asiste en la línea base. Las diferencias fueron significativas para los componentes de participación y autonomía $\left(\Delta_{\mathrm{PA}}=0.36 ; p=.02\right)$, convivencia $\left(\Delta_{\mathrm{CV}}=\right.$ 0.73; $p=.000)$, interacción en el juego $\left(\Delta_{\mathrm{IJ}}=0.23 ; p=.049\right)$, y manejo de reglas $\left(\Delta_{\mathrm{MR}}=0.37 ; p=.021\right)$. No se encontraron diferencias significativas para manejo de conflictos $\left(\triangle_{\mathrm{MC}}=0.03 ; p=.825\right)$. 


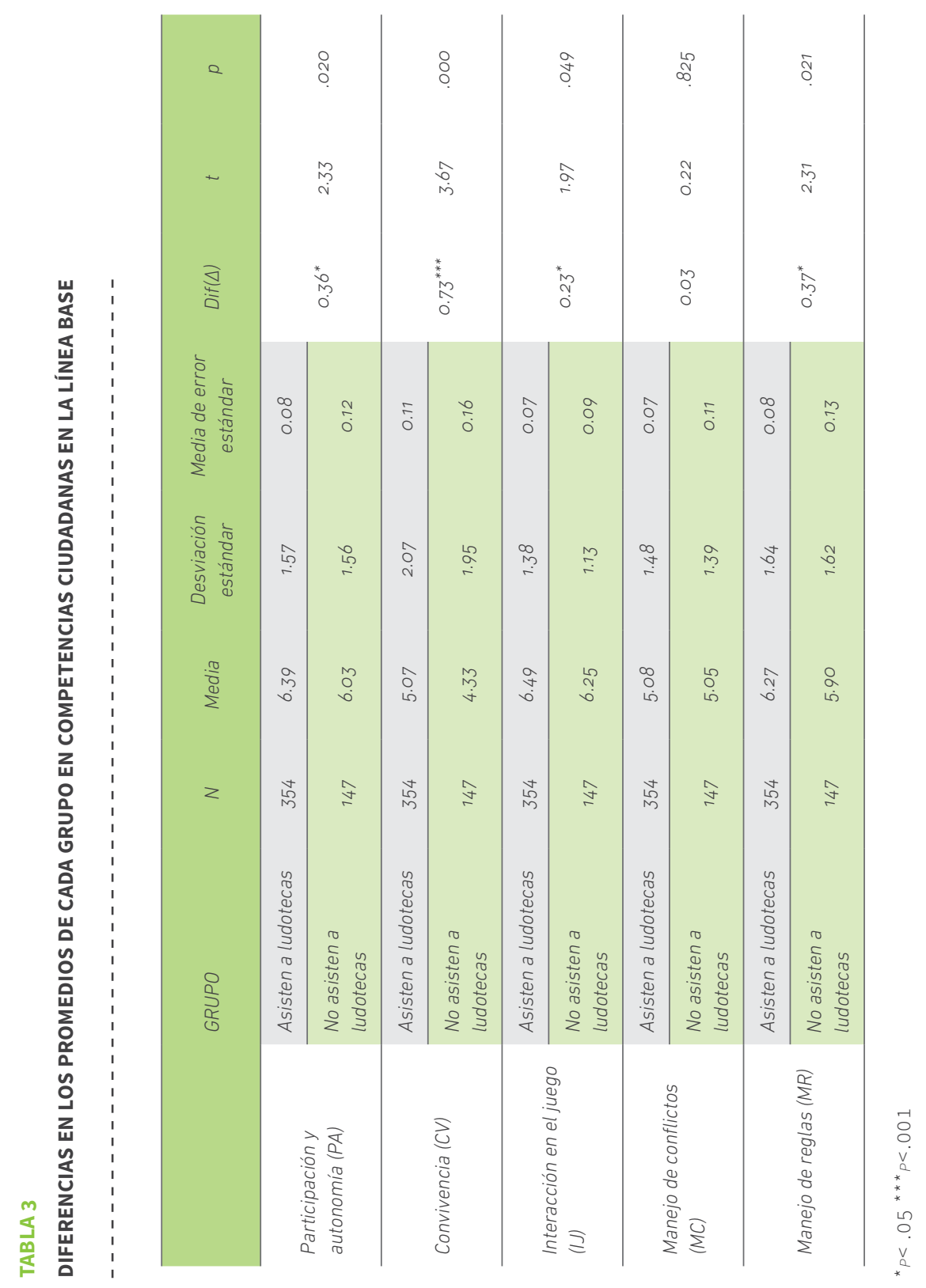


En la Tabla 4 se muestran las diferencias en cada una de las competencias emocionales entre el grupo de niños que asiste a las ludotecas y el grupo de niños que no asiste en la línea base. Las diferencias fueron significativas para los componentes de expresión de emociones $\left(\Delta_{\mathrm{EE}}=0.24 ; p=.05\right)$, y empatía $\left(\triangle_{\mathrm{EP}}=\right.$ 0.33; $p=.025)$. No se encontraron diferencias significativas para autorregulación $\left(\triangle_{\mathrm{AR}}=-0.15 ; p=.29\right)$.

TABLA 4

\section{DIFERENCIAS EN LOS PROMEDIOS DE CADA GRUPO EN COMPETENCIAS EMOCIONALES EN LA LÍNEA BASE}

\begin{tabular}{|c|c|c|c|c|c|c|c|c|}
\hline & GRUPO & $N$ & Media & $\begin{array}{c}\text { Desviación } \\
\text { estándar }\end{array}$ & $\begin{array}{c}\text { Media de error } \\
\text { estándar }\end{array}$ & $\operatorname{Dif}(\Delta)$ & $t$ & $p$ \\
\hline \multirow{2}{*}{$\begin{array}{l}\text { Expresión de } \\
\text { emociones (EE) }\end{array}$} & $\begin{array}{l}\text { Asisten a } \\
\text { ludotecas }\end{array}$ & 354 & 5.96 & 1.15 & 0.06 & \multirow{2}{*}{$0.24^{*}$} & \multirow{2}{*}{1.93} & \multirow{2}{*}{.050} \\
\hline & $\begin{array}{l}\text { No asisten a } \\
\text { ludotecas }\end{array}$ & 147 & 5.72 & 1.32 & 0.10 & & & \\
\hline \multirow{2}{*}{ Empatía (EP) } & $\begin{array}{l}\text { Asisten a } \\
\text { ludotecas }\end{array}$ & 354 & 5.53 & 1.51 & 0.08 & \multirow{2}{*}{$0.33^{*}$} & \multirow{2}{*}{2.25} & \multirow{2}{*}{.025} \\
\hline & $\begin{array}{l}\text { No asisten a } \\
\text { ludotecas }\end{array}$ & 147 & 5.20 & 1.54 & 0.12 & & & \\
\hline \multirow{2}{*}{$\begin{array}{l}\text { Autorregulación } \\
(A R)\end{array}$} & $\begin{array}{l}\text { Asisten a } \\
\text { ludotecas }\end{array}$ & 354 & 5.88 & 1.73 & 0.09 & \multirow{2}{*}{-0.15} & \multirow{2}{*}{-1.03} & \multirow{2}{*}{.29} \\
\hline & $\begin{array}{l}\text { No asisten a } \\
\text { ludotecas }\end{array}$ & 147 & 6.03 & 1.38 & 0.11 & & & \\
\hline
\end{tabular}

$*_{p<.05}$

En la Tabla 5 se muestran las diferencias en cada una de las competencias de creatividad entre el grupo de niños que asiste a las ludotecas y el grupo de niños que no asiste en la línea base. Las diferencias fueron significativas para los 
componentes de pensamiento divergente $\left(\triangle_{\mathrm{PD}}=0.85 ; p=.000\right)$, flexibilidad $\left(\triangle_{\mathrm{FX}}=\right.$ o.53; $p=.000)$ y elaboración $\left(\Delta_{\mathrm{EB}}=0.43 ; p=.003\right)$.

TABLA 5

\section{DIFERENCIAS EN LOS PROMEDIOS DE CADA GRUPO EN CREATIVIDAD EN LA LÍNEA BASE}

\begin{tabular}{|c|c|c|c|c|c|c|c|c|}
\hline & GRUPO & N & Media & $\begin{array}{c}\text { Desviación } \\
\text { estándar }\end{array}$ & $\begin{array}{c}\text { Media de error } \\
\text { estándar }\end{array}$ & $\operatorname{Dif}(\Delta)$ & $t$ & $p$ \\
\hline \multirow{2}{*}{$\begin{array}{l}\text { Pensamiento } \\
\text { divergente (PD) }\end{array}$} & $\begin{array}{l}\text { Asisten a } \\
\text { ludotecas }\end{array}$ & 354 & 5.42 & 1.83 & 0.09 & \multirow{2}{*}{$0.85^{* * *}$} & \multirow{2}{*}{4.61} & \multirow{2}{*}{.000} \\
\hline & $\begin{array}{l}\text { No asisten a } \\
\text { ludotecas }\end{array}$ & 147 & 4.56 & 1.99 & 0.16 & & & \\
\hline \multirow{2}{*}{ Flexibilidad (FX) } & $\begin{array}{l}\text { Asisten a } \\
\text { ludotecas }\end{array}$ & 354 & 5.83 & 1.40 & 0.07 & \multirow{2}{*}{$0.53^{* * *}$} & \multirow{2}{*}{3.60} & \multirow{2}{*}{.000} \\
\hline & $\begin{array}{l}\text { No asisten a } \\
\text { ludotecas }\end{array}$ & 147 & 5.30 & 1.53 & 0.12 & & & \\
\hline \multirow{2}{*}{ Elaboración } & $\begin{array}{l}\text { Asisten a } \\
\text { ludotecas }\end{array}$ & 354 & 4.69 & 1.48 & 0.07 & \multirow{2}{*}{$0.43^{* *}$} & \multirow{2}{*}{2.97} & \multirow{2}{*}{.003} \\
\hline & $\begin{array}{l}\text { No asisten a } \\
\text { ludotecas }\end{array}$ & 147 & 4.26 & 1.53 & 0.12 & & & \\
\hline
\end{tabular}

${ }^{* *} p<.01{ }^{* * *} p<.001$

La figura 1 resume los perfiles de las competencias en los grupos que asisten y que no asisten a ludotecas. Se pueden observar picos altos para participación y autonomía, interacción en el juego y manejo de reglas, puntajes cercanos entres los grupos en manejo de conflictos y un puntaje superior del grupo comparación en autorregulación: 


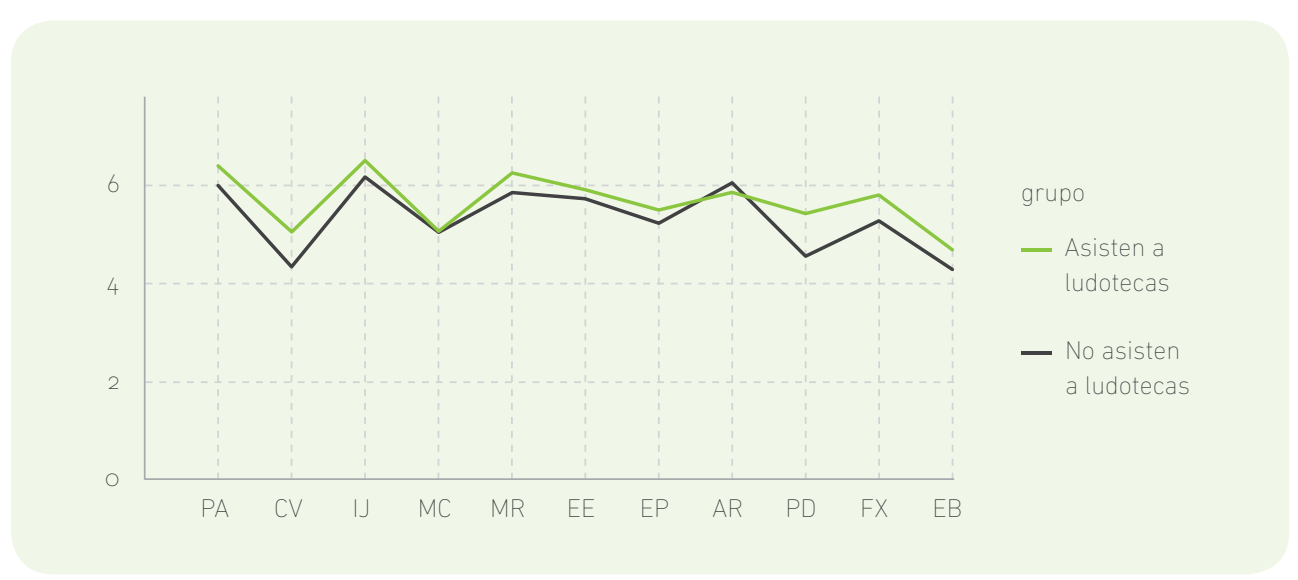

FIGURA 1. PERFILES DE LAS COMPETENCIAS EN GRUPOS DE NIÑOS QUE ASISTEN Y QUE NO ASISTEN A LUDOTECAS EN LA LÍNEA BASE

NOtA: PA=PARTICIPACIÓN Y AUTONOMÍA; CV=CONVIVENCIA; IJ=INTERACCIÓN EN EL JUEGO; MC=MANEJO DE CONFLICTOS; MR=MANEJo DE REGLAS; EE=EXPRESIÓN DE EMOCIONES; EP=EMPATía; AR=Autorregulación; PD=PenSAMIENTO DIVERgENTE; FX=FLEXIBILIDAD; EB=ELABORACIÓN.

En la Tabla 6 se puede observar que los niños que asisten a las ludotecas tienen, comparativamente con los niños que no asisten, en la línea base, mayores puntajes en convivencia $(\triangle C V=0.95 ; p=.002)$, manejo de reglas $(\triangle M R=0.58$; $p=.015)$, empatía $(\triangle \mathrm{EP}=0.53 ; p=.019)$, pensamiento divergente $(\triangle \mathrm{PD}=0.98$; $p=.000)$, flexibilidad $(\Delta \mathrm{FX}=0.74 ; p=.001)$ y elaboración $(\Delta \mathrm{EB}=0.6 ; p=.005)$. 


\section{DIFERENCIAS EN LOS PROMEDIOS DE PUNTAJES DE NIÑOS EN CADA COMPONENTE EN LA LÍNEA BASE}

\begin{tabular}{|c|c|c|c|c|c|c|c|c|}
\hline \multicolumn{2}{|c|}{ GRUPO } & $N$ & Media & $\begin{array}{c}\text { Desviación } \\
\text { estándar }\end{array}$ & $\begin{array}{c}\text { Media de error } \\
\text { estándar }\end{array}$ & $\operatorname{Dif}(\triangle)$ & $t$ & $p$ \\
\hline \multirow{2}{*}{$\begin{array}{l}\text { Participación y } \\
\text { autonomía (PA) }\end{array}$} & $\begin{array}{l}\text { Asisten a } \\
\text { ludotecas }\end{array}$ & 167 & 6.44 & 1.54 & 0.11 & \multirow{2}{*}{0.299} & \multirow{2}{*}{1.31} & \multirow{2}{*}{.190} \\
\hline & $\begin{array}{l}\text { No asisten a } \\
\text { ludotecas }\end{array}$ & 65 & 6.14 & 1.58 & 0.19 & & & \\
\hline \multirow{2}{*}{ Convivencia (CV) } & $\begin{array}{l}\text { Asisten a } \\
\text { ludotecas }\end{array}$ & 167 & 5.03 & 2.08 & 0.16 & \multirow{2}{*}{$0.953^{* *}$} & \multirow{2}{*}{3.16} & \multirow[b]{2}{*}{.002} \\
\hline & $\begin{array}{l}\text { No asisten a } \\
\text { ludotecas }\end{array}$ & 65 & 4.08 & 1.98 & 0.24 & & & \\
\hline \multirow{2}{*}{$\begin{array}{l}\text { Interacción en el } \\
\text { juego (IJ) }\end{array}$} & $\begin{array}{l}\text { Asisten a } \\
\text { ludotecas }\end{array}$ & 167 & 6.46 & 1.40 & 0.10 & \multirow{2}{*}{0.055} & \multirow{2}{*}{0.33} & \multirow{2}{*}{.740} \\
\hline & $\begin{array}{l}\text { No asisten a } \\
\text { ludotecas }\end{array}$ & 65 & 6.40 & 1.01 & 0.12 & & & \\
\hline \multirow{2}{*}{$\begin{array}{l}\text { Manejo de conflictos } \\
\text { (MC) }\end{array}$} & $\begin{array}{l}\text { Asisten a } \\
\text { ludotecas }\end{array}$ & 167 & 5.02 & 1.44 & 0.11 & \multirow{2}{*}{0.178} & \multirow{2}{*}{0.85} & \multirow{2}{*}{.394} \\
\hline & $\begin{array}{l}\text { No asisten a } \\
\text { ludotecas }\end{array}$ & 65 & 4.85 & 1.36 & 0.16 & & & \\
\hline \multirow{2}{*}{$\begin{array}{l}\text { Manejo de reglas } \\
\text { (MR) }\end{array}$} & $\begin{array}{l}\text { Asisten a } \\
\text { ludotecas }\end{array}$ & 167 & 6.46 & 1.60 & 0.12 & \multirow{2}{*}{$0.584^{*}$} & \multirow{2}{*}{2.45} & \multirow{2}{*}{.015} \\
\hline & $\begin{array}{l}\text { No asisten a } \\
\text { ludotecas }\end{array}$ & 65 & 5.88 & 1.67 & 0.20 & & & \\
\hline \multirow{2}{*}{$\begin{array}{l}\text { Expresión de } \\
\text { emociones (EE) }\end{array}$} & $\begin{array}{l}\text { Asisten a } \\
\text { ludotecas }\end{array}$ & 167 & 5.88 & 1.26 & 0.09 & \multirow{2}{*}{0.311} & \multirow{2}{*}{1.67} & \multirow{2}{*}{.095} \\
\hline & $\begin{array}{l}\text { No asisten a } \\
\text { ludotecas }\end{array}$ & 65 & 5.57 & 1.28 & 0.16 & & & \\
\hline
\end{tabular}


EL JUEGO: UN ASUNTO SERIO EN LA FORMACIÓN DE LOS NIÑOS Y LAS NIÑAS

\begin{tabular}{|c|c|c|c|c|c|c|c|c|}
\hline \multicolumn{2}{|c|}{ GRUPO } & $N$ & Media & Desviación & Media de error & $\operatorname{Dif}(\Delta)$ & $t$ & $p$ \\
\hline \multirow{2}{*}{ Empatía (EP) } & $\begin{array}{l}\text { Asisten a } \\
\text { ludotecas }\end{array}$ & 167 & 5.51 & 1.52 & 0.11 & \multirow{2}{*}{$0.530^{*}$} & \multirow{2}{*}{2.36} & \multirow{2}{*}{.019} \\
\hline & $\begin{array}{l}\text { No asisten a } \\
\text { ludotecas }\end{array}$ & 65 & 4.98 & 1.55 & 0.19 & & & \\
\hline \multirow{2}{*}{$\begin{array}{l}\text { Autorregulación } \\
(A R)\end{array}$} & $\begin{array}{l}\text { Asisten a } \\
\text { ludotecas }\end{array}$ & 167 & 5.82 & 1.85 & 0.14 & \multirow{2}{*}{-0.087} & \multirow{2}{*}{-0.39} & \multirow{2}{*}{.692} \\
\hline & $\begin{array}{l}\text { No asisten a } \\
\text { ludotecas }\end{array}$ & 65 & 5.91 & 1.34 & 0.16 & & & \\
\hline \multirow{2}{*}{$\begin{array}{l}\text { Pensamiento } \\
\text { divergente (PD) }\end{array}$} & $\begin{array}{l}\text { Asisten a } \\
\text { ludotecas }\end{array}$ & 167 & $5 \cdot 31$ & 1.84 & 0.14 & \multirow{2}{*}{$0.988^{* * *}$} & \multirow{2}{*}{3.57} & \multirow{2}{*}{.000} \\
\hline & $\begin{array}{l}\text { No asisten a } \\
\text { ludotecas }\end{array}$ & 65 & 4.32 & 2.00 & 0.24 & & & \\
\hline \multirow{2}{*}{ Flexibilidad (FX) } & $\begin{array}{l}\text { Asisten a } \\
\text { ludotecas }\end{array}$ & 167 & 5.88 & 1.35 & 0.10 & \multirow{2}{*}{$0.742^{* * *}$} & \multirow{2}{*}{3.30} & \multirow{2}{*}{.001} \\
\hline & $\begin{array}{l}\text { No asisten a } \\
\text { ludotecas }\end{array}$ & 65 & 5.14 & 1.60 & 0.19 & & & \\
\hline \multirow{2}{*}{ Elaboración (EB) } & $\begin{array}{l}\text { Asisten a } \\
\text { ludotecas }\end{array}$ & 167 & 4.62 & 1.46 & 0.11 & \multirow{2}{*}{$0.601^{* *}$} & \multirow{2}{*}{2.81} & \multirow{2}{*}{.005} \\
\hline & $\begin{array}{l}\text { No asisten a } \\
\text { ludotecas }\end{array}$ & 65 & 4.02 & 1.46 & 0.18 & & & \\
\hline
\end{tabular}

${ }^{\star} P<.05^{* \star} p<.01^{* * *} p<.001$

En la Tabla 7 se observa que las niñas que asisten a las ludotecas tienen, comparativamente con las niñas que no asisten, en la línea base, mayores puntajes en participación y autonomía $(\triangle P A=0.4 ; p=.05)$, convivencia $(\triangle C V=0.56$; $p=.036)$, interacción en el juego $(\Delta \mathrm{J}=0.37 ; p=.024)$ y pensamiento divergente $(\triangle \mathrm{PD}=0.75 ; p=.003)$. 


\section{DIFERENCIAS EN LOS PROMEDIOS DE PUNTAJES DE NIÑAS EN CADA COMPONENTE EN LA LÍNEA BASE}

\begin{tabular}{|c|c|c|c|c|c|c|c|c|}
\hline \multicolumn{2}{|c|}{ GRUPO } & $N$ & Media & $\begin{array}{c}\text { Desviación } \\
\text { estándar }\end{array}$ & $\begin{array}{c}\text { Media de error } \\
\text { estándar }\end{array}$ & $\operatorname{Dif}(\Delta)$ & $t$ & $p$ \\
\hline \multirow{2}{*}{$\begin{array}{l}\text { Participación y } \\
\text { autonomía (PA) }\end{array}$} & $\begin{array}{l}\text { Asisten a } \\
\text { ludotecas }\end{array}$ & 187 & 6.35 & 1.59 & 0.11 & \multirow{2}{*}{$0.402^{*}$} & \multirow{2}{*}{1.91} & \multirow{2}{*}{.05} \\
\hline & $\begin{array}{l}\text { No asisten a } \\
\text { ludotecas }\end{array}$ & 82 & 5.95 & 1.54 & 0.17 & & & \\
\hline \multirow{2}{*}{ Convivencia (CV) } & $\begin{array}{l}\text { Asisten a } \\
\text { ludotecas }\end{array}$ & 187 & 5.10 & 2.06 & 0.15 & \multirow{2}{*}{$0.565^{*}$} & \multirow{2}{*}{2.11} & \multirow{2}{*}{.036} \\
\hline & $\begin{array}{l}\text { No asisten a } \\
\text { ludotecas }\end{array}$ & 82 & 4.54 & 1.91 & 0.21 & & & \\
\hline \multirow{2}{*}{$\begin{array}{l}\text { Interacción en el } \\
\text { juego (IJ) }\end{array}$} & $\begin{array}{l}\text { Asisten a } \\
\text { ludotecas }\end{array}$ & 187 & 6.51 & 1.36 & 0.10 & \multirow{2}{*}{$0.379^{*}$} & \multirow{2}{*}{2.27} & \multirow{2}{*}{.024} \\
\hline & $\begin{array}{l}\text { No asisten a } \\
\text { ludotecas }\end{array}$ & 82 & 6.13 & 1.20 & 0.13 & & & \\
\hline \multirow{2}{*}{$\begin{array}{l}\text { Manejo de } \\
\text { conflictos (MC) }\end{array}$} & $\begin{array}{l}\text { Asisten a } \\
\text { ludotecas }\end{array}$ & 187 & 5.13 & 1.50 & 0.11 & \multirow{2}{*}{-0.079} & \multirow{2}{*}{-0.40} & \multirow{2}{*}{.686} \\
\hline & $\begin{array}{l}\text { No asisten a } \\
\text { ludotecas }\end{array}$ & 82 & 5.21 & 1.40 & 0.15 & & & \\
\hline \multirow{2}{*}{$\begin{array}{l}\text { Manejo de reglas } \\
\text { (MR) }\end{array}$} & $\begin{array}{l}\text { Asisten a } \\
\text { ludotecas }\end{array}$ & 187 & 6.10 & 1.65 & 0.12 & \multirow{2}{*}{0.182} & \multirow{2}{*}{0.84} & \multirow{2}{*}{.401} \\
\hline & $\begin{array}{l}\text { No asisten a } \\
\text { ludotecas }\end{array}$ & 82 & 5.91 & 1.58 & 0.17 & & & \\
\hline \multirow{2}{*}{$\begin{array}{l}\text { Expresión de } \\
\text { emociones (EE) }\end{array}$} & $\begin{array}{l}\text { Asisten a } \\
\text { ludotecas }\end{array}$ & 187 & 6.04 & 1.04 & 0.07 & \multirow{2}{*}{0.196} & \multirow{2}{*}{1.17} & \multirow{2}{*}{.244} \\
\hline & $\begin{array}{l}\text { No asisten a } \\
\text { ludotecas }\end{array}$ & 82 & 5.84 & 1.34 & 0.14 & & & \\
\hline
\end{tabular}




\begin{tabular}{|c|c|c|c|c|c|c|c|c|}
\hline \multicolumn{2}{|c|}{ GRUPO } & \multirow{2}{*}{$\begin{array}{c}N \\
187\end{array}$} & \multirow{2}{*}{$\begin{array}{l}\text { Media } \\
5.55\end{array}$} & \multirow{2}{*}{$\begin{array}{c}\text { Desviación } \\
\text { estándar } \\
1.50\end{array}$} & \multirow{2}{*}{$\begin{array}{c}\text { Media de error } \\
\text { estándar } \\
0.11\end{array}$} & \multirow{3}{*}{$\begin{array}{l}\text { Dif( } \triangle) \\
0.185\end{array}$} & \multirow{3}{*}{$\begin{array}{c}t \\
0.92\end{array}$} & \multirow{3}{*}{$\begin{array}{c}p \\
.356\end{array}$} \\
\hline \multirow{2}{*}{ Empatía (EP) } & $\begin{array}{l}\text { Asisten a } \\
\text { ludotecas }\end{array}$ & & & & & & & \\
\hline & $\begin{array}{l}\text { No asisten a } \\
\text { ludotecas }\end{array}$ & 82 & $5 \cdot 37$ & 1.52 & 0.16 & & & \\
\hline \multirow{2}{*}{$\begin{array}{l}\text { Autorregulación } \\
(A R)\end{array}$} & $\begin{array}{l}\text { Asisten a } \\
\text { ludotecas }\end{array}$ & 187 & 5.94 & 1.61 & 0.11 & \multirow{2}{*}{-0.198} & \multirow{2}{*}{-1.00} & \multirow{2}{*}{.314} \\
\hline & $\begin{array}{l}\text { No asisten a } \\
\text { ludotecas }\end{array}$ & 82 & 6.13 & 1.42 & 0.15 & & & \\
\hline \multirow{2}{*}{$\begin{array}{l}\text { Pensamiento } \\
\text { divergente (PD) }\end{array}$} & $\begin{array}{l}\text { Asisten a } \\
\text { ludotecas }\end{array}$ & 187 & $5 \cdot 51$ & 1.83 & 0.13 & \multirow{2}{*}{$0.757^{* *}$} & \multirow{2}{*}{3.04} & \multirow{2}{*}{.003} \\
\hline & $\begin{array}{l}\text { No asisten a } \\
\text { ludotecas }\end{array}$ & 82 & 4.76 & 1.97 & 0.21 & & & \\
\hline \multirow{2}{*}{ Flexibilidad (FX) } & $\begin{array}{l}\text { Asisten a } \\
\text { ludotecas }\end{array}$ & 187 & 5.78 & 1.44 & 0.10 & \multirow{2}{*}{0.354} & \multirow{2}{*}{1.83} & \multirow{2}{*}{.068} \\
\hline & $\begin{array}{l}\text { No asisten a } \\
\text { ludotecas }\end{array}$ & 82 & 5.43 & 1.47 & 0.16 & & & \\
\hline \multirow{2}{*}{ Elaboración (EB) } & $\begin{array}{l}\text { Asisten a } \\
\text { ludotecas }\end{array}$ & 187 & 4.76 & 1.49 & 0.10 & \multirow{2}{*}{0.313} & \multirow{2}{*}{1.56} & \multirow{2}{*}{.120} \\
\hline & $\begin{array}{l}\text { No asisten a } \\
\text { ludotecas }\end{array}$ & 82 & $4 \cdot 45$ & 1.56 & 0.17 & & & \\
\hline
\end{tabular}

${ }^{*} P<.05{ }^{* \star} P<.01$

Para identificar la existencia de posibles diferencias por competencias entre rangos de edad (menores de 6 años, de 6 a 9 años y mayores de 9 años), se realizó un ANOVA de un factor. Este, en sentido general, muestra diferencias por edad en competencias ciudadanas y creatividad (Tabla 8): 


\begin{tabular}{lccc}
\hline COMPETENCIA & $G L$ & $F$ & $P$ \\
\hline Ciudadana (CC) & $(2,351)$ & 5.690 & .004 \\
\hline Emocional (CE) & $(2,351)$ & 2.072 & .128 \\
\hline Creatividad (CR) & $(2,351)$ & 5.746 & .004 \\
\hline
\end{tabular}

Dado que los valores de $F$ fueron significativos para competencia ciudadanas y creatividad $(p<.01)$, se realizó una prueba post hoc de Bonferroni, encontrándose diferencias significativas en CC entre el grupo de niños menores de 6 años $(M=27.32)$ y el grupo de niños de 6 a 9 años $(M=29.69 ; p=.012)$, y entre los menores de 6 años y los mayores de $9(M=30.77 ; p=.009)$. No se encontraron diferencias significativas entre el grupo de niños de entre 6 y 9 años y los de más de 9 años $(p=.872)$. Para CR las diferencias se establecieron entre el grupo de niños menores de 6 años $(M=15.04)$ y los mayores de 9 años $(M=17.49 ; p=.002)$, y entre el grupo de niños de 6 a 9 años $(M=15.94)$, y los mayores de 9 años $(p=.045)$. No se encontraron diferencias significativas en los puntajes entre los niños menores de 6 años y el grupo de niños de 6 a 9 años $(p=.232)$. A continuación, se presenta gráficamente los desempeños por cada competencia para el grupo de niños que asiste a ludotecas.

En el grupo de niños no intervenidos, el ANOVA solo muestra diferencias por grupo de edad en creatividad, tendiendo a disminuir todas las competencias después de los 6 años (ver tabla 12). La prueba post hoc de Bonferroni en CR solo muestra diferencias entre los niños menores de 6 años $(M=16.86)$, y el grupo de niños de 6 a 9 años $(M=13.83 ; p=.041)$. A continuación, se presenta gráficamente los desempeños por cada competencia para el grupo de niños que no asiste a ludotecas. 


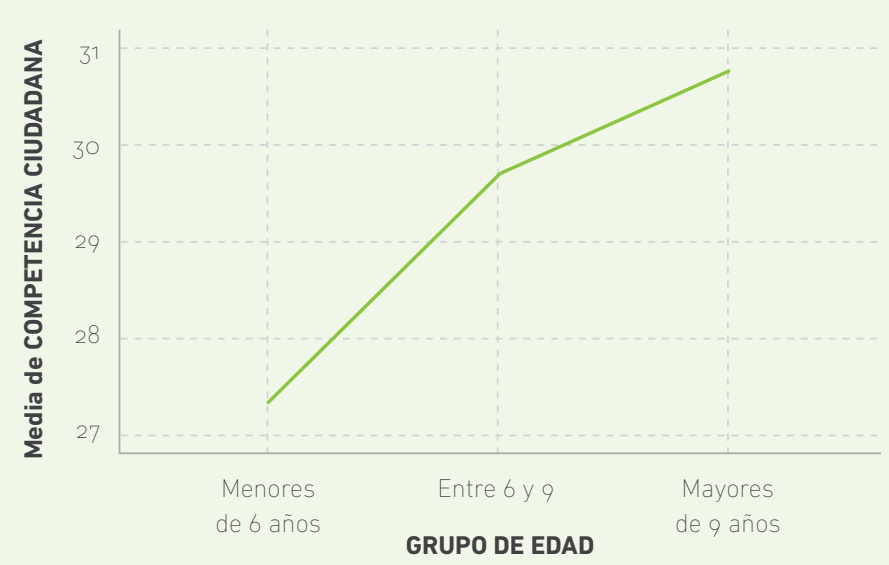

FIGURA 2. DIFERENCIAS EN EL DESEMPEÑO EN COMPETENCIAS CIUDADANAS POR

RANGOS DE EDAD EN NIÑOS QUE ASISTEN A LUDOTECAS EN LA LÍNEA BASE.

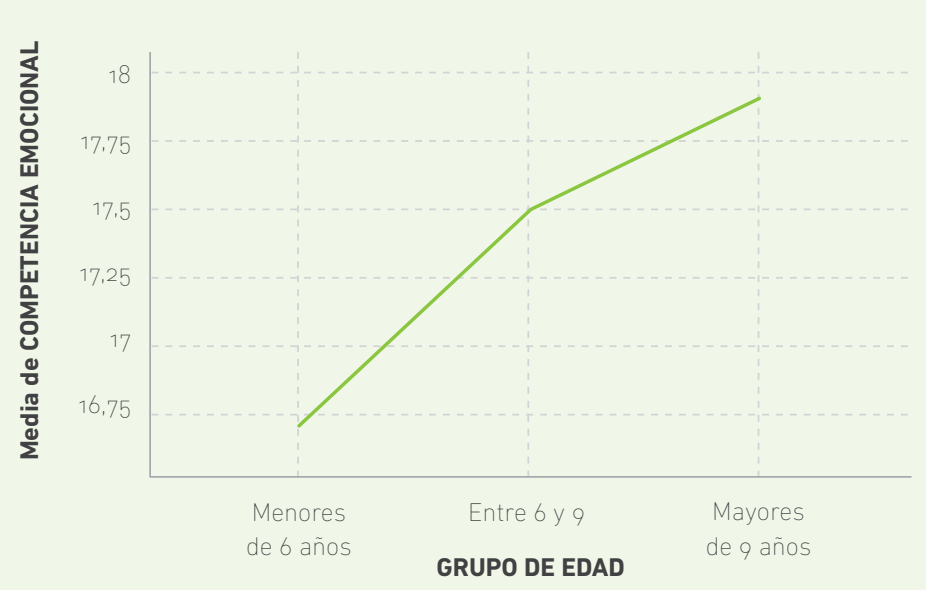

FIGURA 3. DIFERENCIAS EN EL DESEMPEÑO EN COMPETENCIAS EMOCIONALES POR RANGOS DE EDAD EN NIÑOS QUE ASISTEN A LUDOTECAS EN LA LÍNEA BASE. 


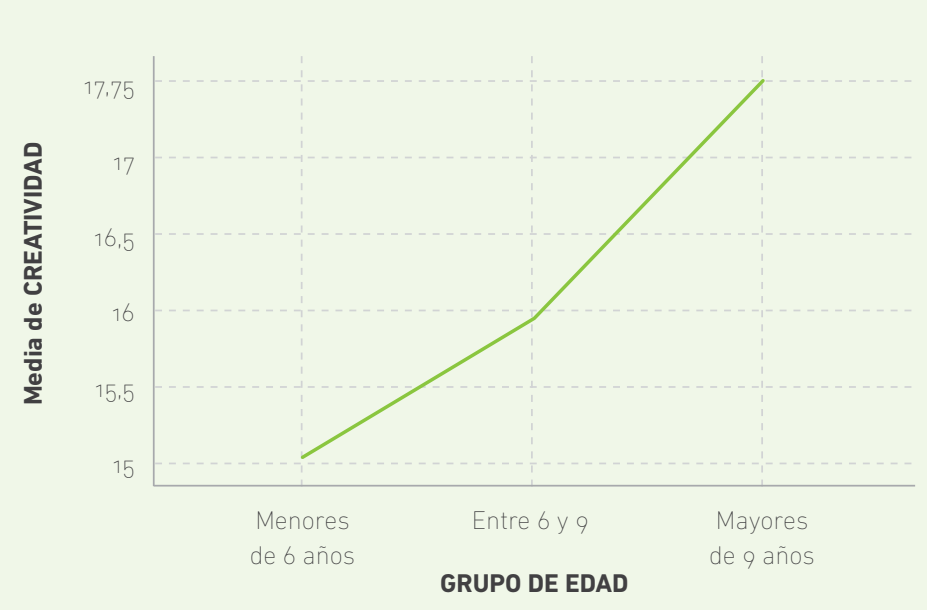

FIGURA 4. DIFERENCIAS EN EL DESEMPEÑO EN CREATIVIDAD POR RANGOS

DE EDAD EN NIÑOS QUE ASISTEN A LUDOTECAS EN LA LÍNEA BASE.

TABLA 12

ANOVA POR COMPETENCIA EN EL GRUPO DE NIÑOS QUE NO

ASISTEN A LAS LUDOTECAS EN LA LÍNEA BASE

\begin{tabular}{lccc}
\hline COMPETENCIA & $g l$ & $F$ & $p$ \\
\hline COMPETENCIA CIUDADANA & $(2,144)$ & 2.064 & .131 \\
\hline COMPETENCIA EMOCIONAL & $(2,144)$ & 1.576 & .210 \\
\hline CREATIVIDAD & $(2,144)$ & 3.136 & .046 \\
\hline
\end{tabular}




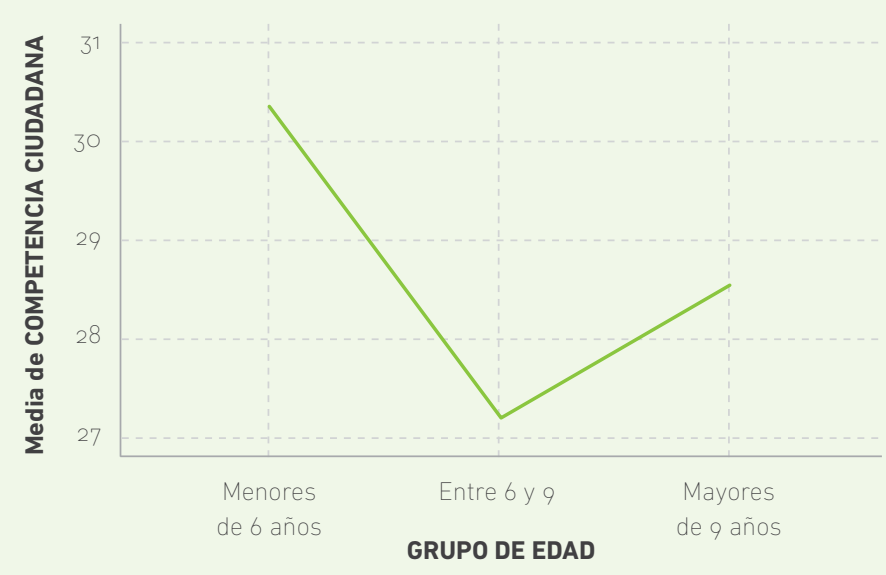

FIGURA 5. DIFERENCIAS EN EL DESEMPEÑO EN COMPETENCIAS CIUDADANAS POR

RANGOS DE EDAD EN NIÑOS QUE NO ASISTEN A LUDOTECAS EN LA LÍNEA BASE.

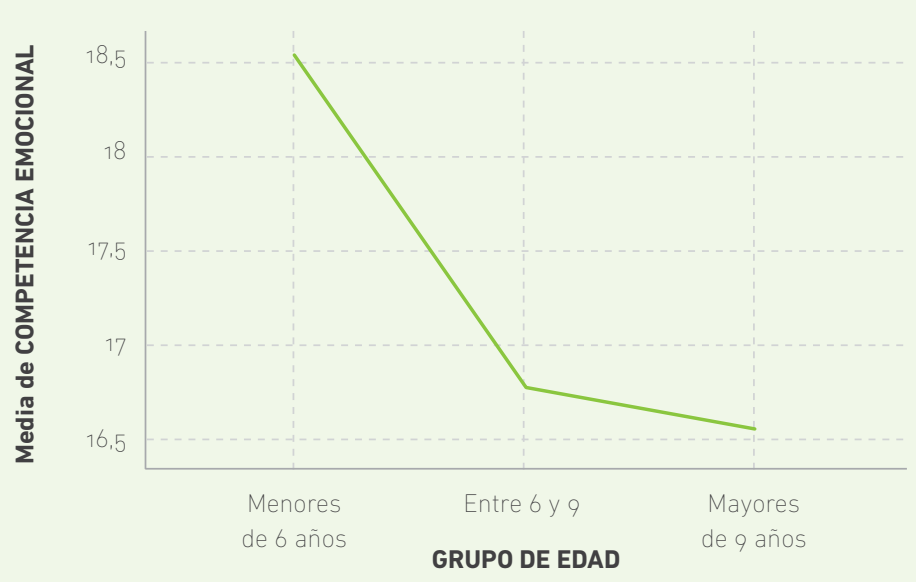

FIGURA 6. DIFERENCIAS EN EL DESEMPEÑO EN COMPETENCIAS EMOCIONALES POR RANGOS DE EDAD EN NIÑOS QUE NO ASISTEN A LUDOTECAS EN LA LÍNEA BASE. 


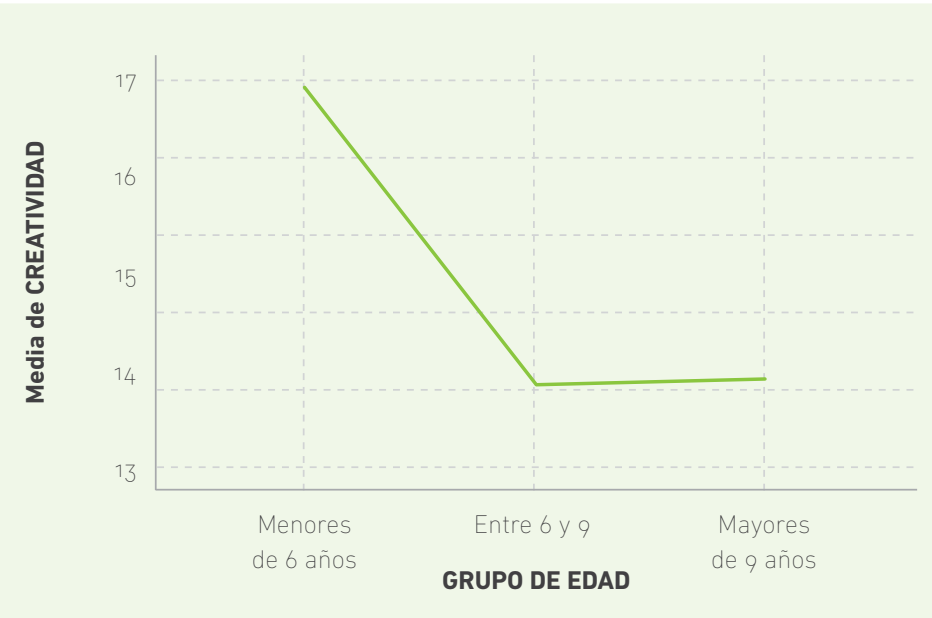

FIGURA 7. DIFERENCIAS EN EL DESEMPEÑO EN CREATIVIDAD POR RANGOS DE EDAD EN NIÑOS QUE NO ASISTEN A LUDOTECAS EN LA LÍNEA BASE.

\section{Conclusiones de la línea de base}

Los puntajes generales encontrados en este primer momento del estudio señalan impactos importantes del juego y las ludotecas, principalmente en las competencias ciudadanas y la creatividad y, parcialmente, en las competencias emocionales. Para el caso de las competencias ciudadanas, las diferencias con el grupo contraste resultaron significativas para participación y autonomía, convivencia, interacción en el juego y manejo de reglas. Las competencias emocionales que se vieron afectadas fueron expresión de emociones y empatía, y las de creatividad fueron pensamiento divergente, flexibilidad y elaboración. Lo anterior indica que estas competencias son las que posiblemente se ven más afectadas por la exposición a mayores situaciones de juego de niños y niñas en escenarios lúdicos. De igual forma, se encontraron diferencias significativas en las competencias entre grupos de edad, tendiendo a aumentar con el tiempo 
en los niños que asisten a estos escenarios, en comparación con quienes solo van a la escuela. Las competencias de estos últimos tienden a disminuir con la edad. En general, estos hallazgos muestran el posible impacto que tienen las ludotecas en el desarrollo ciudadano, emocional y creativo de niños y niñas a lo largo del ciclo vital.

Los resultados sobre la interacción en el juego eran apenas esperados. Diversos autores, como Marín (2009), Fleisher (2015) y Ringoot et al. (2013), ya habían señalado el efecto que tiene el juego sobre las capacidades de los niños de interactuar con los objetos y con los otros. Por otra parte, siguiendo a Benedet y Zanella (2011), y a Riquelme et al. (2013), suponemos que el manejo de reglas se ve afectado porque el juego implica tanto la comprensión de la existencia de reglas sociales como el reconocimiento de la importancia de cumplirlas. Al respecto de la convivencia, se confirma lo señalado por Mejía y Londoño (2011), en el sentido de que la exposición a escenarios de juego se convierte en pieza clave para la convivencia en sociedad. Por su parte, el efecto sobre la autonomía confirma lo señalado por Managers (2005) y Power (2011), en términos de que el juego podría permitirle al niño autoadministrar los recursos que se le ofrecen para la actividad lúdica, aumentando esta capacidad.

A pesar de estos hallazgos, aún no es muy claro el porqué de la poca diferencia en el manejo de conflictos entre niños que asisten a las ludotecas y el grupo comparación en este momento del estudio. Al respecto, se suscitan un par de hipótesis: por una parte, es posible suponer, debido a los puntajes (ninguno superior a 6 puntos), que para los niños partícipes de la muestra existe dificultad en dicha resolución. La otra hipótesis (la más probable para los investigadores), es que lo encontrado pudo deberse a una dificultad en la evaluación de la resolución de conflictos solo por medio de la observación de situaciones. La observación de esta competencia puede tornarse difícil en escenarios cons- 
tantemente mediados por reglas, como son los de las ludotecas. Al respecto, se requieren nuevos estudios que sean más sensibles al componente del conflicto y su resolución. Los estudios tradicionales sobre solución de conflictos en niños apelan a una observación más prolongada en escenarios familiares (Abuhatoum \& Howe, 2013); mientras que otros, por el contrario, se basan en el uso de cuestionarios a los padres (Weaver, Shaw, Crossan, Dishion, \& Wilson, 2015), o en otras técnicas basadas en el reporte de pares y en narrativas personales, como el Revised Class Play Method (Davidson, Walton, \& Cohen, 2013; Masten, Morison, \& Pellegrini, 1985).

Suponemos que la no diferencia significativa, general, en la competencia emocional, la cual es calculada como la suma de tres componentes, se atribuye a un efecto estadístico de arrastre del puntaje general por el componente de autorregulación, el cual no mostró diferencias significativas en este primer momento. Sin embargo, los análisis específicos señalan diferencias en la expresión de emociones y en la empatía. Estos resultados confirman lo señalado por Niec y Russ (2002) y Power (2011), en términos de los efectos positivos del juego sobre la empatía, especialmente a partir de juegos sociodramáticos. Por otro lado, sobre la expresión de emociones, es poco lo que los estudios mencionan en su relación con el juego. Siguiendo a Reed y Brown (2000), suponemos que esta llega a ser importante también en los juegos sociodramáticos. Los resultados sobre la regulación emocional, en este momento, aún son inciertos. Algunas teorías de la emociones y el juego sugieren que esta se ve influenciada significativamente durante el juego activo (LaFreniere, 2013). Sin embargo, y de acuerdo con la literatura, esta competencia es dependiente del desarrollo a largo del tiempo. El estudio longitudinal podría dar luces sobre cómo se ve afectada esta competencia por la exposición prolongada a escenarios lúdicos. 
El grupo de componentes en donde se encontraron mayores efectos fue en el de creatividad. Las relaciones entre juego y creatividad han sido ampliamente reportadas por la literatura (Holmes, Romeo, Ciraola, \& Grushko, 2015; Saracho, 2002). Por ello, se sabe que las actividades lúdicas ayudan al niño a adquirir competencias de conocimiento específico, a mantener la curiosidad y el asombro, lo que conduce a un mayor pensamiento creativo e imaginativo (Johnson, 2007).

Los resultados por género sobre las competencias ciudadanas muestran un mayor efecto de las ludotecas, especialmente en manejo de reglas en los niños, y en la participación e interacción en el juego de las niñas. Señalando, con ello, efectos interesantes sobre capacidades regulatorias o morales, y aumentando las capacidades sociales de las niñas. Los escenarios lúdicos también parecen tener un efecto importante sobre las competencias emocionales de los niños, más que de las niñas. Este impacto en los varones parece estar dirigido particularmente al desarrollo de la empatía. Los niños, más que las niñas, se ven afectados por los escenarios lúdicos en su creatividad, especialmente en la flexibilidad y en la elaboración.

Al comparar los desempeños en las competencias por grupos etarios, los investigadores nos encontramos con un hecho interesante del cual no teníamos referentes. Lo aquí encontrado muestra que, al parecer, la exposición prolongada a escenarios lúdicos, a lo largo del tiempo, parece tener un efecto significativo en los niños, especialmente sobre las competencias ciudadanas y la creatividad, lo cual sugiere que el juego puede tener un lugar importante en el proceso educativo infantil, particularmente superando los 6 años de edad, lo que daría pistas sobre el alcance de modificar las prácticas educativas para incorporar estos escenarios y estrategias lúdicas a la educación primaria y secundaria.

\section{$1 \quad 94$}




\section{CAPÍTULO 4}

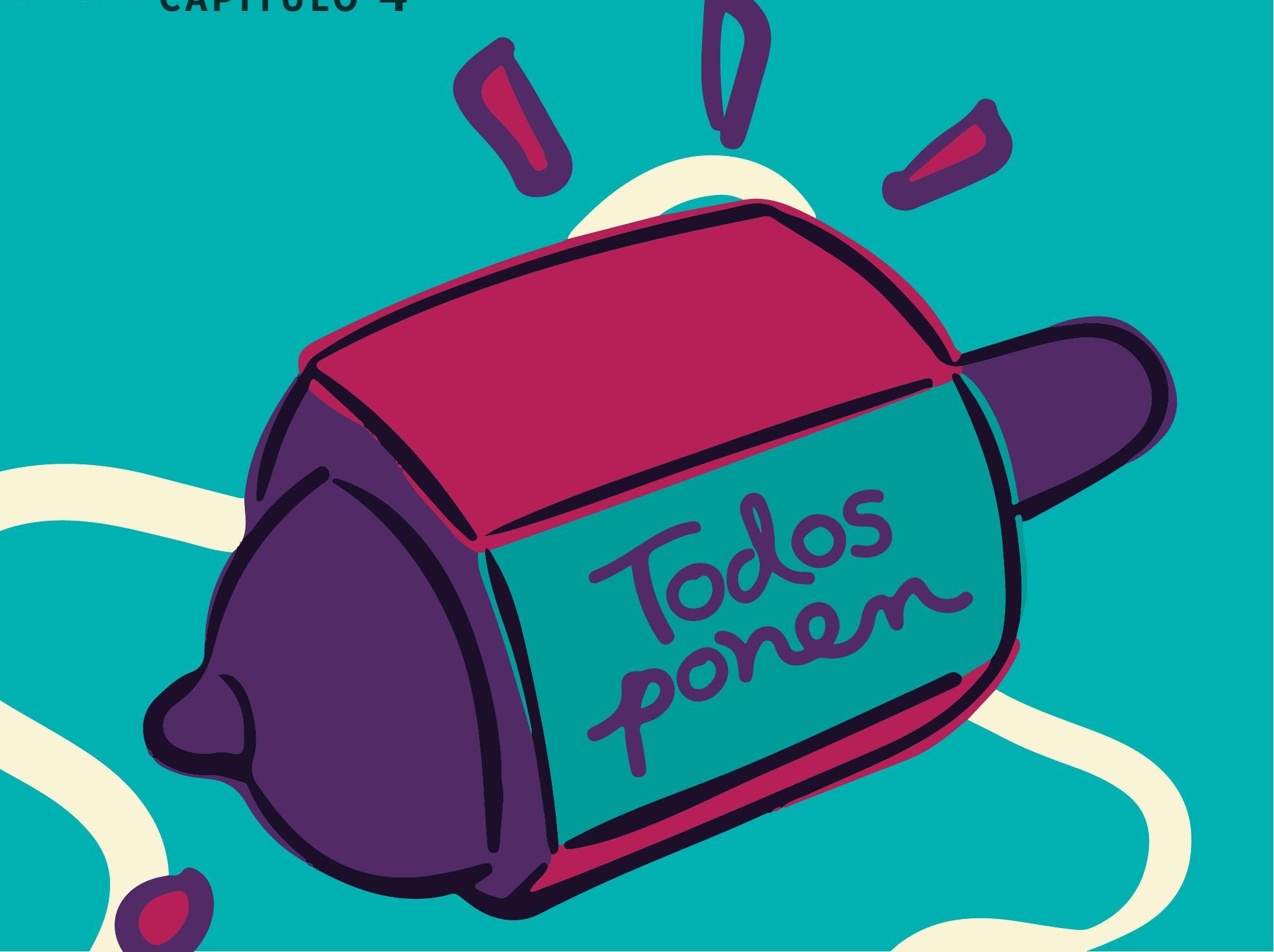




\section{El impacto de las ludotecas en el desarrollo de competencias ciudadanas, emocionales y de creatividad: hallazgos finales}

En este capítulo, el lector encontrará los resultados del estudio longitudinal mencionado en el capítulo anterior, centrado en la comprensión del comportamiento de distintos tipos de competencias en la infancia: emocionales, ciudadanas y de

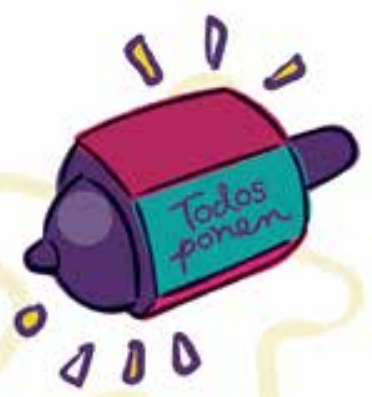
creatividad, en un escenario concreto como el de las ludotecas. Este capítulo muestra los impactos, a lo largo del tiempo, que producen las ludotecas en el desarrollo de niños y niñas. Se presentan, a su vez, los relatos de los impactos de las ludotecas en la vida de las personas que asisten a ella, por medio de entrevistas a niños, sus familias y cuidadores. Por último, se presentan los análisis de los instrumentos de caracterización de las ludotecas, desde donde se señalan aspectos importantes para su mejoramiento. Estos resultados le serán útiles al lector interesado en soportes científicos que justifiquen el uso de las ludotecas en prácticas promotoras del desarrollo infantil. 


\section{Comparaciones generales por competencia}

Los análisis realizados con la información recolectada durante los distintos años, señalan mayores puntajes en competencias ciudadanas, emocionales y creatividad para el grupo de niños que asisten a las ludotecas. En todos los casos, esta diferencia entre los puntajes en competencias, de niños que asisten a la ludoteca y niños que no, es significativa (ver Tabla 1).

TABLA 1

\section{COMPARACIONES ENTRE NIÑOS QUE ASISTEN A LA LUDOTECA Y NIÑOS QUE NO, POR COMPETENCIAS}

\begin{tabular}{|c|c|c|c|c|c|c|c|}
\hline Ludoteca & & $N$ & Media & $\begin{array}{c}\text { Desviación } \\
\text { estándar }\end{array}$ & $\begin{array}{c}\text { Media de error } \\
\text { estándar }\end{array}$ & $t$ & $p$ \\
\hline \multirow{2}{*}{$\begin{array}{l}\text { COMPETENCIA } \\
\text { CIUDADANA }\end{array}$} & Pertenece & 348 & 6.39 & 1.08 & 0.05 & \multirow{2}{*}{5.05} & \multirow{2}{*}{.000} \\
\hline & No pertenece & 183 & 5.84 & 1.25 & 0.09 & & \\
\hline \multirow{2}{*}{$\begin{array}{l}\text { COMPETENCIA } \\
\text { EMOCIONAL }\end{array}$} & Pertenece & 348 & 6.31 & 0.91 & 0.04 & \multirow{2}{*}{6.86} & \multirow{2}{*}{.000} \\
\hline & No pertenece & 183 & 5.66 & 1.09 & 0.08 & & \\
\hline \multirow{2}{*}{ CREATIVIDAD } & Pertenece & 348 & 5.92 & 1.32 & 0.07 & \multirow{2}{*}{5.42} & \multirow{2}{*}{.000} \\
\hline & No pertenece & 183 & 5.24 & 1.41 & 0.10 & & \\
\hline
\end{tabular}

Esto señala una diferencia con lo encontrado en fases anteriores, particularmente con los hallazgos de los años 2016 y 2017. El puntaje promedio en competencias ciudadanas de los niños que asisten a la ludoteca es de 6.4, en comparación con los 5.8 del puntaje promedio de los niños que no asisten. Esta diferencia es significativa $(p<.001)$. Lo anterior señala que los niños que asisten a la ludoteca desarrollan más competencias ciudadanas que los que no lo hacen. 
En competencias emocionales, el puntaje promedio de los niños que asisten a la ludoteca es de 6.3, en comparación con los 5.7 del puntaje promedio de los niños que no asisten. Esta diferencia es significativa $(p<.001)$. Lo anterior evidencia que los niños que asisten a la ludoteca desarrollan más competencias emocionales que los que no lo hacen.

Por último, en las competencias asociadas a la creatividad, el puntaje promedio de los niños que asisten a la ludoteca es de 5.9, en comparación con los 5.2 del puntaje promedio de los niños que no asisten. Esta diferencia es significativa $(p<.001)$. Lo anterior muestra que los niños que asisten a la ludoteca desarrollan más creatividad que los que no lo hacen.

\section{Comparaciones generales por competencia - participantes antiguos}

Al igual que con los resultados anteriores, un análisis realizado solo con los participantes de años anteriores, muestra mayores puntajes en competencias ciudadanas, emocionales y creatividad para el grupo de niños que asisten a las ludotecas. En todos los casos, esta diferencia es significativa con el grupo de niños que no asiste (ver Tabla 2).

\section{Comparaciones específicas por competencias ciudadana}

Los análisis realizados señalan diferencias significativas en cada uno de los puntajes de las competencias ciudadanas, entre los niños que asisten a la ludoteca y los que no asisten. Esto señala el efecto a favor del desarrollo de los niños que asisten a las ludotecas, en comparación con los que no asisten (ver Tabla 3). 
TABLA 2

COMPARACIONES ENTRE NIÑOS ANTIGUOS QUE ASISTEN A LA

\section{LUDOTECA Y NIÑOS QUE NO, POR COMPETENCIAS}

\begin{tabular}{|c|c|c|c|c|c|c|c|}
\hline Ludoteca & & $N$ & Media & $\begin{array}{c}\text { Desviación } \\
\text { estándar }\end{array}$ & $\begin{array}{c}\text { Media de error } \\
\text { estándar }\end{array}$ & $t$ & $p$ \\
\hline \multirow{2}{*}{$\begin{array}{l}\text { COMPETENCIA } \\
\text { CIUDADANA }\end{array}$} & Pertenece & 303 & 6.45 & 1.07 & 0.06 & \multirow{2}{*}{2.84} & \multirow{2}{*}{.005} \\
\hline & No pertenece & 132 & 6.10 & 1.22 & 0.10 & & \\
\hline \multirow{2}{*}{$\begin{array}{l}\text { COMPETENCIA } \\
\text { EMOCIONAL }\end{array}$} & Pertenece & 303 & 6.32 & 0.91 & 0.05 & \multirow{2}{*}{4.80} & \multirow{2}{*}{.000} \\
\hline & No pertenece & 132 & 5.84 & 1.07 & 0.09 & & \\
\hline \multirow{2}{*}{ CREATIVIDAD } & Pertenece & 303 & 5.95 & 1.31 & 0.07 & \multirow{2}{*}{3.97} & \multirow{2}{*}{.000} \\
\hline & No pertenece & 132 & $5 \cdot 36$ & 1.47 & 0.12 & & \\
\hline
\end{tabular}

TABLA 3

COMPARACIONES ENTRE NIÑOS QUE ASISTEN A LA LUDOTECA Y

NIÑOS QUE NO, POR COMPETENCIAS CIUDADANAS

\begin{tabular}{|c|c|c|c|c|c|c|c|}
\hline Ludoteca & & $N$ & Media & $\begin{array}{c}\text { Desviación } \\
\text { estándar }\end{array}$ & $\begin{array}{c}\text { Media de error } \\
\text { estándar }\end{array}$ & $t$ & $p$ \\
\hline \multirow{2}{*}{ PARTICIPACIÓN } & Pertenece & 338 & 6.86 & 1.16 & 0.06 & \multirow{2}{*}{3.29} & \multirow{2}{*}{.001} \\
\hline & No pertenece & 182 & 6.46 & 1.41 & 0.10 & & \\
\hline \multirow{2}{*}{ CONVIVENCIA } & Pertenece & 338 & 5.63 & 1.90 & 0.10 & \multirow{2}{*}{2.65} & \multirow{2}{*}{.008} \\
\hline & No pertenece & 182 & 5.17 & 1.85 & 0.13 & & \\
\hline \multirow{2}{*}{$\begin{array}{l}\text { INTERACCIÓN EN } \\
\text { EL JUEGO }\end{array}$} & Pertenece & 338 & 6.84 & 0.97 & 0.05 & \multirow{2}{*}{3.25} & \multirow{2}{*}{.001} \\
\hline & No pertenece & 182 & 6.49 & 1.27 & 0.09 & & \\
\hline \multirow{2}{*}{$\begin{array}{l}\text { MANEJODE } \\
\text { CONFLICTOS }\end{array}$} & Pertenece & 338 & 5.69 & 1.55 & 0.08 & \multirow{2}{*}{5.22} & \multirow{2}{*}{.000} \\
\hline & No pertenece & 182 & 4.89 & 1.71 & 0.12 & & \\
\hline \multirow{2}{*}{$\begin{array}{l}\text { MANEJO DE } \\
\text { REGLAS }\end{array}$} & Pertenece & 338 & 6.84 & 1.10 & 0.06 & \multirow{2}{*}{4.82} & \multirow{2}{*}{.000} \\
\hline & No pertenece & 182 & 6.21 & 1.56 & 0.11 & & \\
\hline
\end{tabular}

100 


\section{Comparaciones específicas por competencias emocionales}

A su vez, los análisis señalan diferencias significativas en cada uno de los puntajes de las competencias emocionales, entre los niños que asisten a la ludoteca y los que no asisten. Esto señala el efecto a favor del desarrollo de los niños que asisten a las ludotecas, en comparación con los que no asisten (ver Tabla 4).

TABLA 4

COMPARACIONES ENTRE NIÑOS QUE ASISTEN A LA LUDOTECA Y NIÑOS QUE NO, POR COMPETENCIAS EMOCIONALES

\begin{tabular}{|c|c|c|c|c|c|c|c|}
\hline Ludoteca & & $N$ & Media & $\begin{array}{l}\text { Desviación } \\
\text { estándar }\end{array}$ & $\begin{array}{c}\text { Media de error } \\
\text { estándar }\end{array}$ & $t$ & $p$ \\
\hline \multirow{2}{*}{$\begin{array}{l}\text { EXPRESIÓN DE } \\
\text { EMOCIONES }\end{array}$} & Pertenece & 338 & 6.32 & 0.87 & 0.04 & \multirow{2}{*}{5.52} & \multirow{2}{*}{.000} \\
\hline & No pertenece & 182 & 5.82 & 1.13 & 0.08 & & \\
\hline \multirow{2}{*}{ EMPATIAA } & Pertenece & 338 & 5.91 & 1.23 & 0.06 & \multirow{2}{*}{4.39} & \multirow{2}{*}{.000} \\
\hline & No pertenece & 182 & 5.41 & 1.26 & 0.09 & & \\
\hline \multirow{2}{*}{ AUTORREGULACIÓN } & Pertenece & 338 & 6.67 & 1.12 & 0.06 & \multirow{2}{*}{7.09} & \multirow{2}{*}{.000} \\
\hline & No pertenece & 182 & 5.76 & 1.52 & 0.11 & & \\
\hline
\end{tabular}

\section{Comparaciones específicas por competencias relacionadas con la creatividad}

Por último, los análisis señalan diferencias significativas en cada uno de los puntajes de las competencias relacionadas con la creatividad, entre los niños que asisten a la ludoteca y los que no asisten. Esto señala el efecto a favor del desarrollo de los niños que asisten a las ludotecas, en comparación con los que no asisten (ver Tabla 5). 
TABLA 5

COMPARACIONES ENTRE NIÑOS QUE ASISTEN A LA LUDOTECA Y NIÑOS QUE NO, POR COMPETENCIAS RELACIONADAS CON LA CREATIVIDAD

\begin{tabular}{|c|c|c|c|c|c|c|c|}
\hline Ludoteca & & $N$ & Media & $\begin{array}{l}\text { Desviación } \\
\text { estándar }\end{array}$ & $\begin{array}{c}\text { Media de error } \\
\text { estándar }\end{array}$ & $t$ & $p$ \\
\hline \multirow{2}{*}{$\begin{array}{l}\text { PENSAMIENTO } \\
\text { DIVERGENTE }\end{array}$} & Pertenece & 338 & 5.81 & 1.68 & 0.09 & \multirow{2}{*}{3.91} & \multirow{2}{*}{.000} \\
\hline & No pertenece & 182 & 5.18 & 1.80 & 0.13 & & \\
\hline \multirow{2}{*}{ FLEXIBILIDAD } & Pertenece & 338 & 6.68 & 0.97 & 0.05 & \multirow{2}{*}{7.22} & \multirow{2}{*}{.000} \\
\hline & No pertenece & 182 & 5.93 & 1.36 & 0.10 & & \\
\hline \multirow{2}{*}{ ELABORACIÓN } & Pertenece & 338 & 5.22 & 1.80 & 0.09 & \multirow{2}{*}{3.78} & \multirow{2}{*}{.000} \\
\hline & No pertenece & 182 & 4.60 & 1.68 & 0.12 & & \\
\hline
\end{tabular}

\section{Resumen de las comparaciones de los desempeños en competen-} cias entre niños que asisten a las ludotecas y los que no lo hacen

Los análisis anteriores pueden ser resumidos en el siguiente gráfico, el cual muestra los desempeños de los niños que asisten a las ludotecas en cada una de las competencias antes mencionadas, en comparación con los niños que no asisten a las ludotecas. Para todos los casos, las diferencias entre los dos grupos fueron estadísticamente significativas.

\section{Comparaciones por género}

Debido a las diferencias encontradas entre los desempeños del grupo de niños que asiste a las ludotecas, se quiso conocer las posibles diferencias que existían entre niños y niñas en cada una de las competencias seleccionadas. Los resultados muestran diferencias en convivencia ( $\mathrm{Dif}=0.48 ; p=.017)$, pensamiento divergente ( $\mathrm{Dif}=0.48 ; p=.006$ ) y elaboración ( $\mathrm{Dif}=0.57 ; p=.002$ ). Para todos los casos, los puntajes fueron mayores en los niños que en las niñas. 


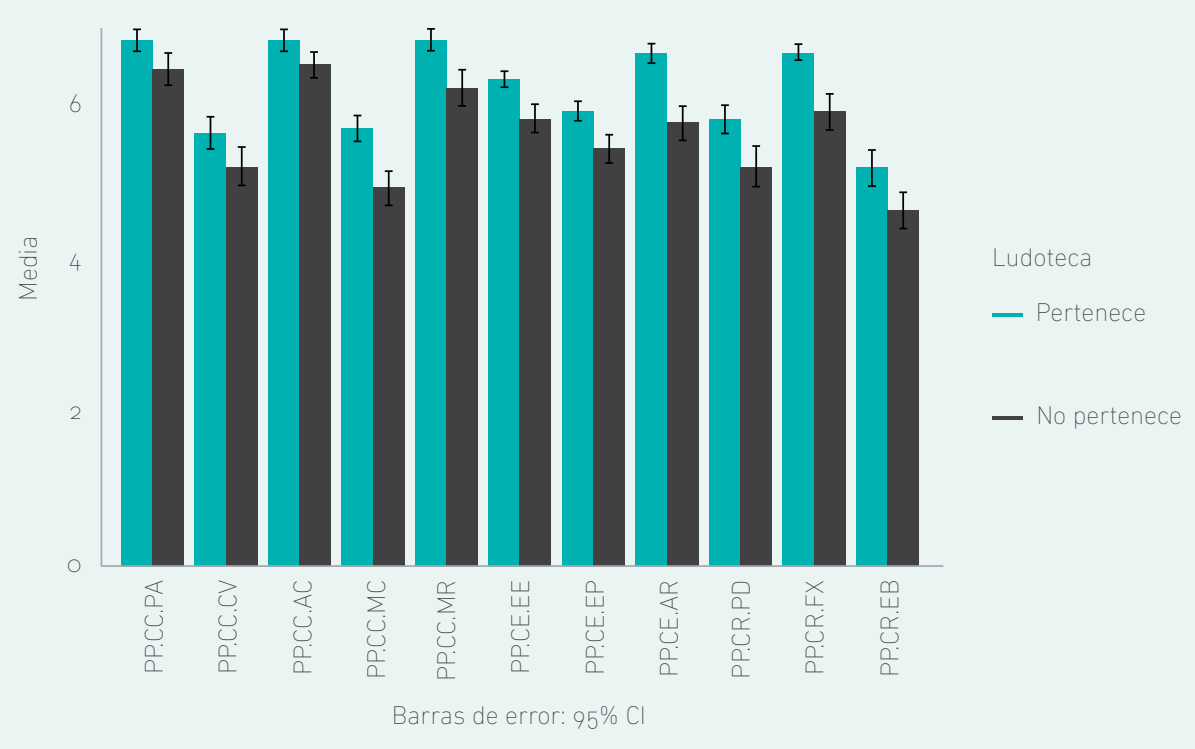

\section{Resultado longitudinal}

A continuación se presentan los resultados del análisis longitudinal realizado a partir de la información de los puntajes calculados para cada una de las competencias generales y específicas durante cada uno de los años. Este análisis permite identificar el valor del impacto de asistir a una ludoteca, en la competencia infantil seleccionada.

Para identificar este valor de impacto (Imp), se inicia estableciendo los valores esperados, inicial y final, de acuerdo con la regresión lineal en cada grupo de niños (entre quienes asisten y los que no - líneas puntuadas en la gráfica). Luego, se procede a estimar la diferencia de estos valores por periodo, inicial y final, para determinar el rango respectivo. Por último, se procede a estimar la diferencia entre los rangos final e inicial. Este valor resultante será el puntaje de impacto de la ludoteca en la competencia respectiva. 


\section{Resultados en la competencia ciudadana}

A partir de la información recolectada durante cada año, se estima los puntajes iniciales y finales de la siguiente forma:

\begin{tabular}{cccc}
\hline G1.CCf & G2.CCf & G1.CCi & G2CCi \\
\hline 31.7 & 29.35 & 28.9 & 27.85 \\
\hline
\end{tabular}

$\Delta$ (Diferencia)

$$
\begin{aligned}
& \Delta f=G_{1} . C C f-G_{2} . C C f=31.7-29.35=2.35 \\
& \triangleq i=G_{1} . C C i-G_{2} . C C i=28.9-27.85=1.05
\end{aligned}
$$$$
\operatorname{ImpCC}=2.35-1.05=1.3
$$

Este puntaje (1.3), indica que cada niño que asiste a la ludoteca tiene una probabilidad de tener 1.3 puntos por encima de su par que no asiste en competencia ciudadana.

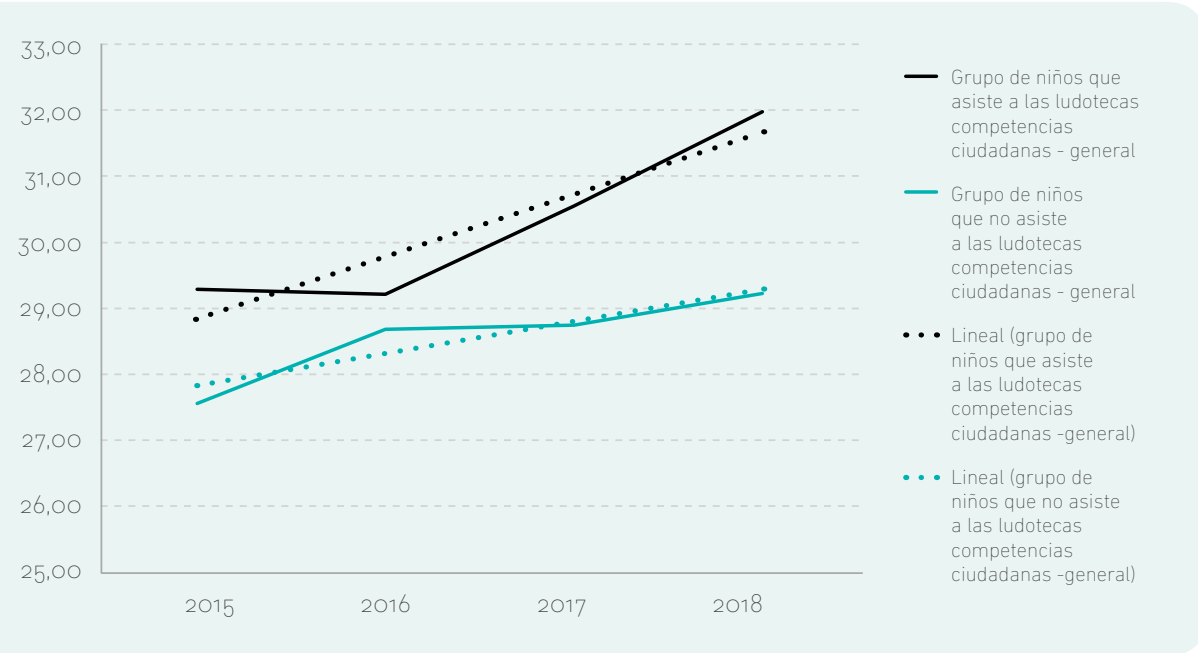

En cuanto a las competencias ciudadanas, en específico, se encuentra lo siguiente: En participación y autonomía se encuentran cambios a lo largo del 
tiempo, con puntajes relativamente similares en 2015 y 2017, y puntajes más elevados en 2016 y 2018. En general, la tendencia es positiva.

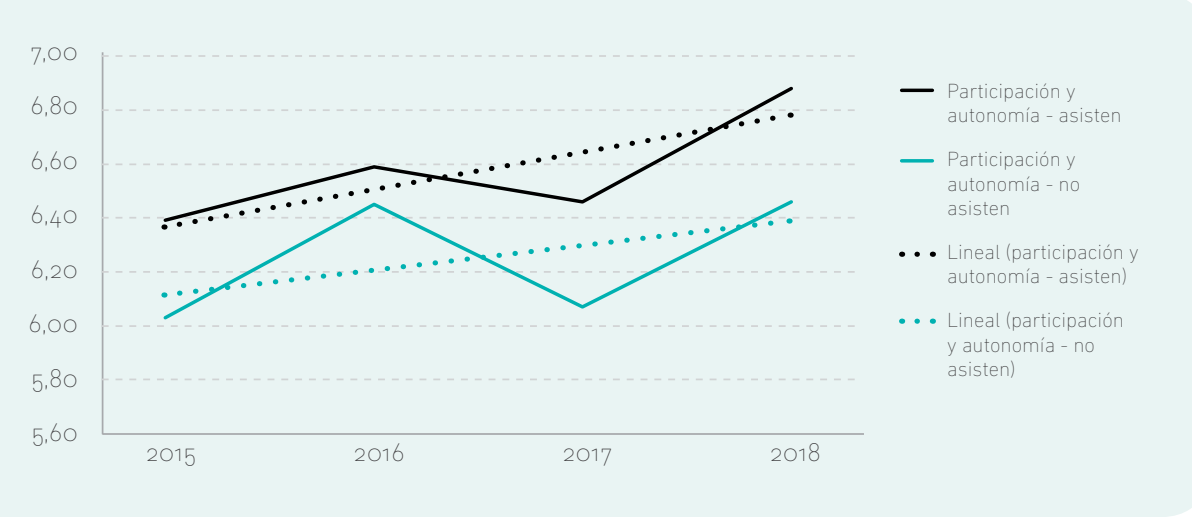

Convivencia tiene un comportamiento un tanto distinto. Inicia con puntajes relativamente altos en 2015, que luego descienden en 2016 para luego subir en 2017 y estabilizarse en 2018.

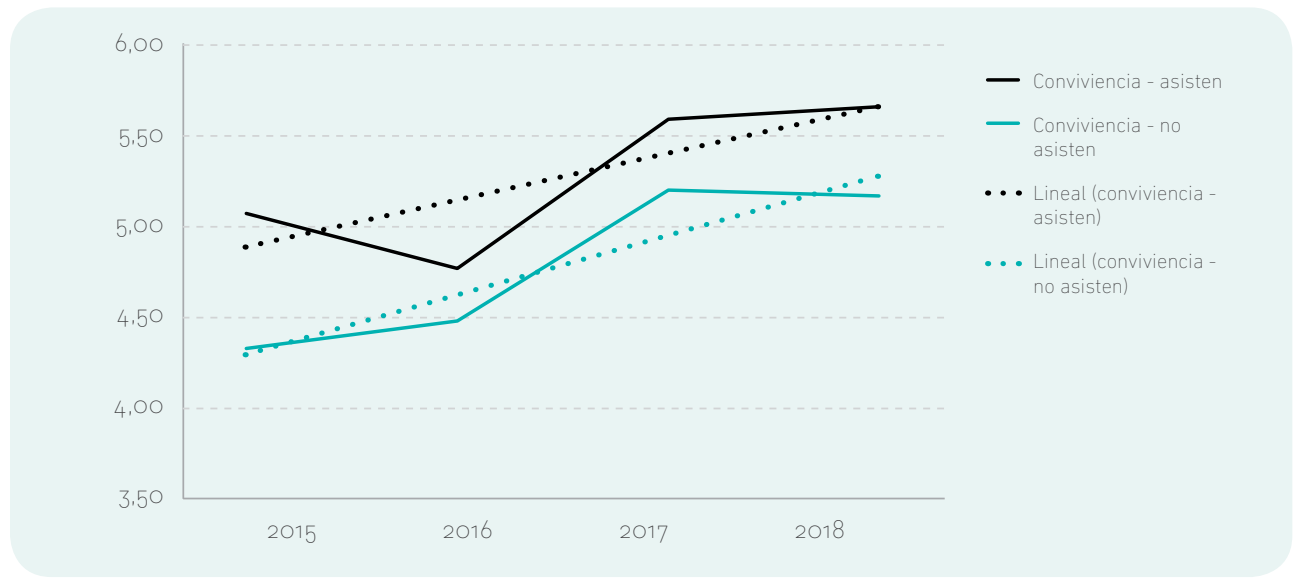

Interacción en el juego tiene un comportamiento variable entre 2015 y 2016. La brecha entre los grupos se acrecienta entre 2017 y 2018. En general tiene una tendencia positiva. 


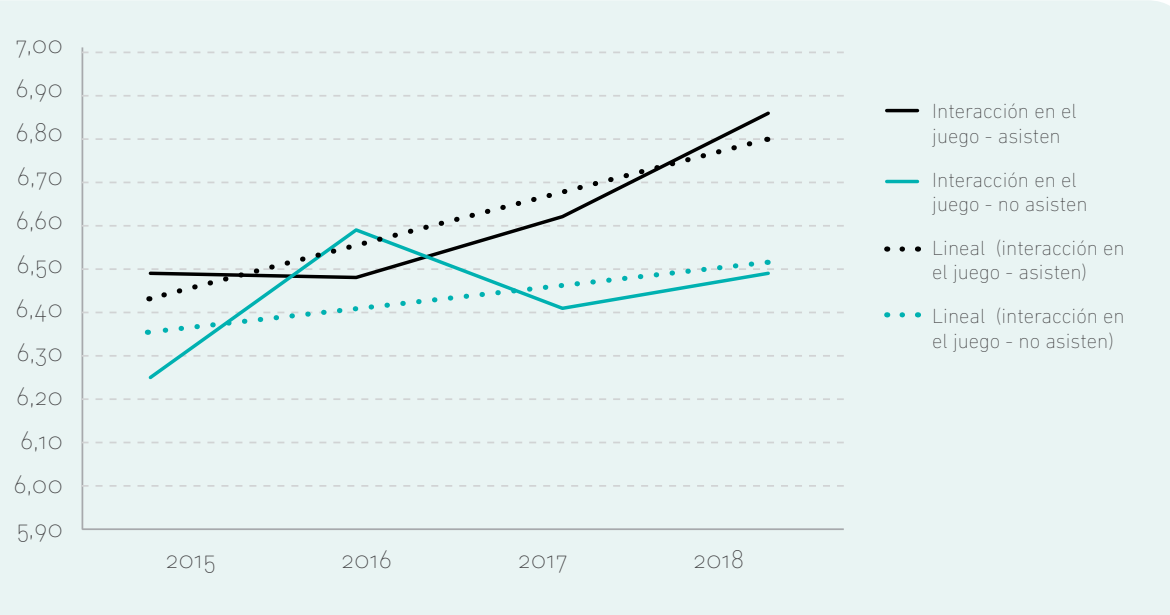

Manejo de conflictos inicial con un puntaje casi idéntico entre los dos grupos en el año 2015; luego presenta un descenso en 2016 y un ascenso en 2017 y 2018. La diferencia final entre las tendencias es significativa.

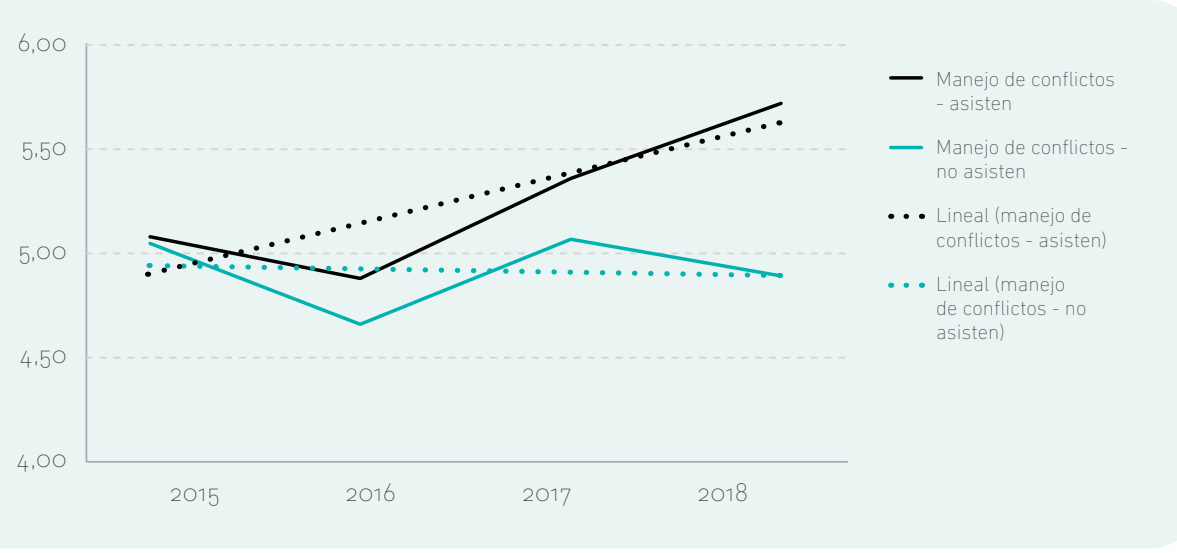

Manejo de reglas tiene un punto de comunión entre los grupos en el año 2016. Luego las brechas se van incrementando entre 2017 y 2018. 


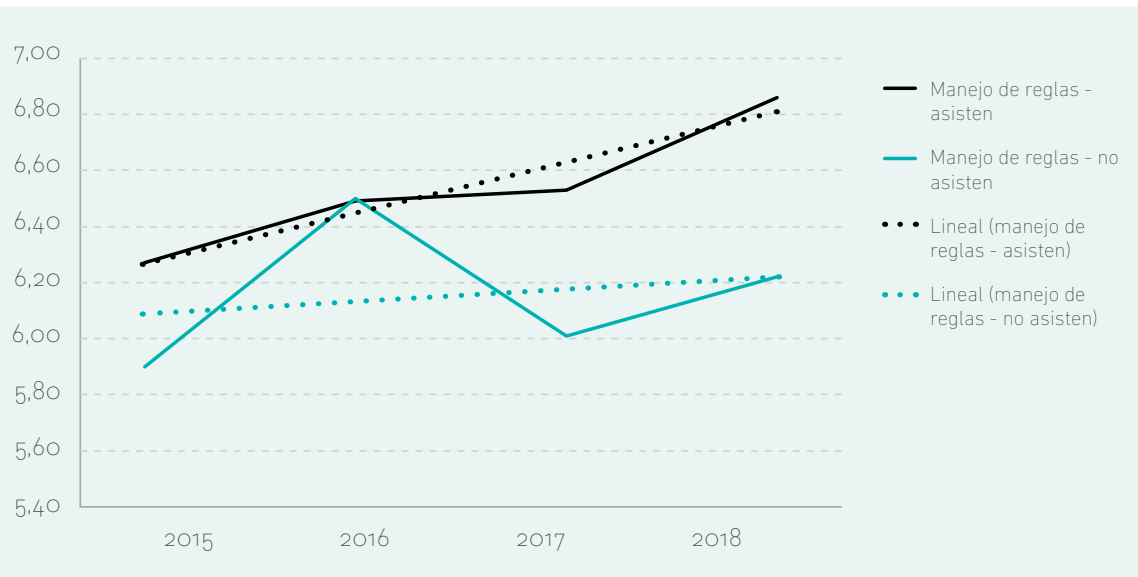

Como se puede apreciar, los mayores impactos a lo largo del tiempo se identifican en el manejo de conflictos, el manejo de reglas y la interacción en el juego. Desde esta perspectiva, no se observan cambios que señalen impactos en participación y autonomía, y en convivencia.

\section{Resultados en la competencia emocional}

Para la competencia emocional, los valores estimados son los siguientes:

\begin{tabular}{cccc}
\hline G1.CEf & G2.CEf & G1.CEi & G2CEi \\
\hline 18.7 & 16.8 & 17.1 & 16.8 \\
\hline
\end{tabular}

$$
\begin{aligned}
& \Delta \text { (Diferencia) } \\
& \Delta f=G_{1} . C E f-G 2 . C E f=18.7-16.8=1.9 \\
& \Delta i=G 1 . C E i-G 2 . C E i=17.1-16.8=0.3 \\
& \text { ImpCE }=1.9-0.3=1.6
\end{aligned}
$$

Este puntaje (1.6), indica que cada niño que asiste a la ludoteca tiene una probabilidad de tener 1.6 puntos, en competencia emocional, por encima de su par que no asiste. Este valor es muy superior al encontrado para la competencia 
ciudadana, toda vez que los valores máximos posibles son diferentes en cada competencia, dado que los puntajes generales de la competencia se calculan como la sumatoria de los puntajes en cada una de las subcompetencias (competencias específicas). El puntaje de la competencia ciudadana se calcula como la suma de cinco subcompetencias (participación y autonomía, convivencia, interacción en el juego, manejo de conflictos y manejo de reglas), mientras que para la competencia emocional se calcula como la suma de solo tres de estas (expresión de emociones, empatía y autorregulación). Lo anterior señala que el asistir a una ludoteca tiene un impacto muy significativo en la competencia emocional general del niño o niña.

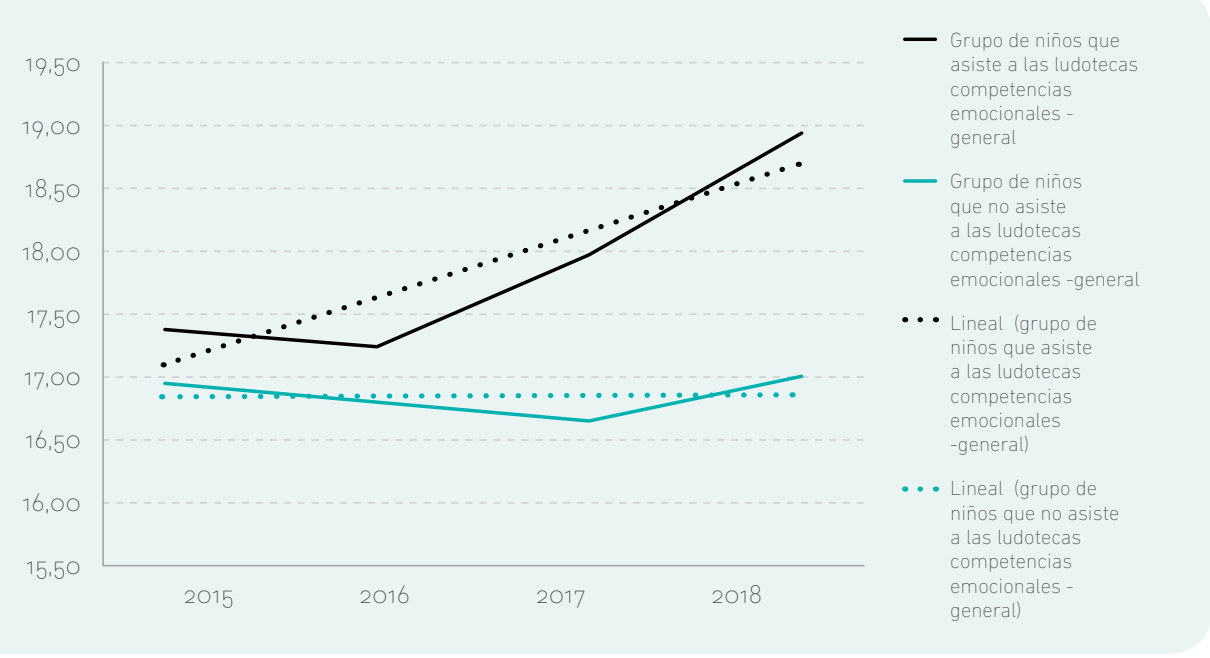

Sobre cada competencia emocional en específico, se observa lo siguiente: En expresión de emociones se observa una disminución de la brecha entre grupos en el año 2016, y un aumento significativo de la misma entre 2017 y 2018. 


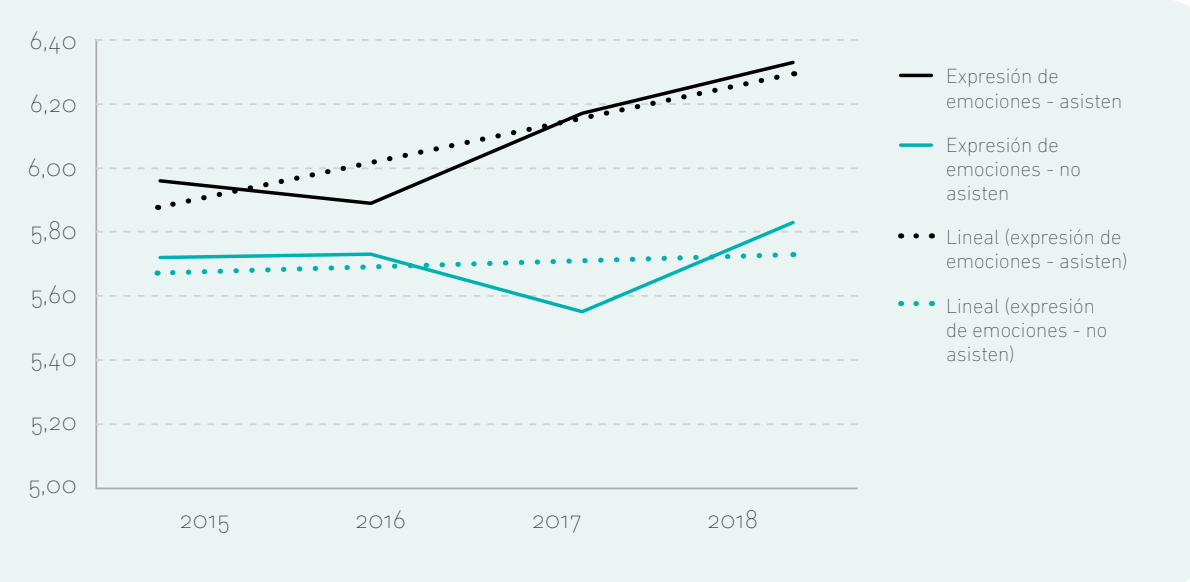

Si bien la competencia de empatía muestra la disminución típica de las competencias en el año 2016, la tendencia, en todo caso, es aumentar su valor, aunque la brecha entre los grupos se mantiene a lo largo del tiempo.

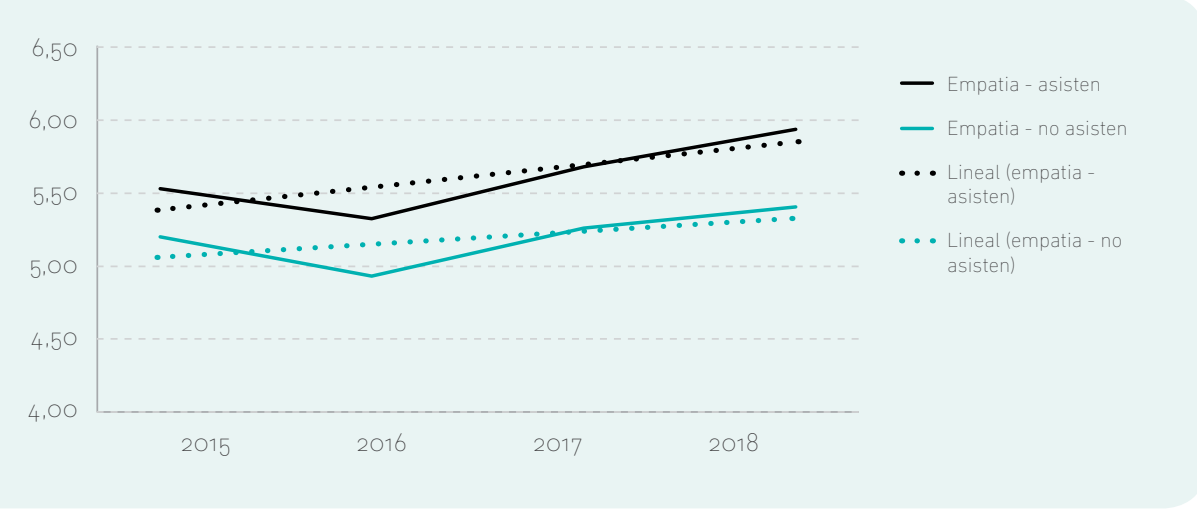

Con respecto a la autorregulación, se observa un comportamiento muy variable en la tendencia, con un comportamiento del grupo de niños que no asisten a la ludoteca por encima del grupo de niños que asisten entre los años 2015 y 2016. Esta tendencia se invierte entre 2017 y 2018, tendiendo a disminuir 
la autorregulación de los niños que no asisten a lo largo de estos últimos años, y a incrementarse, de forma significativa, la brecha entre los dos grupos.

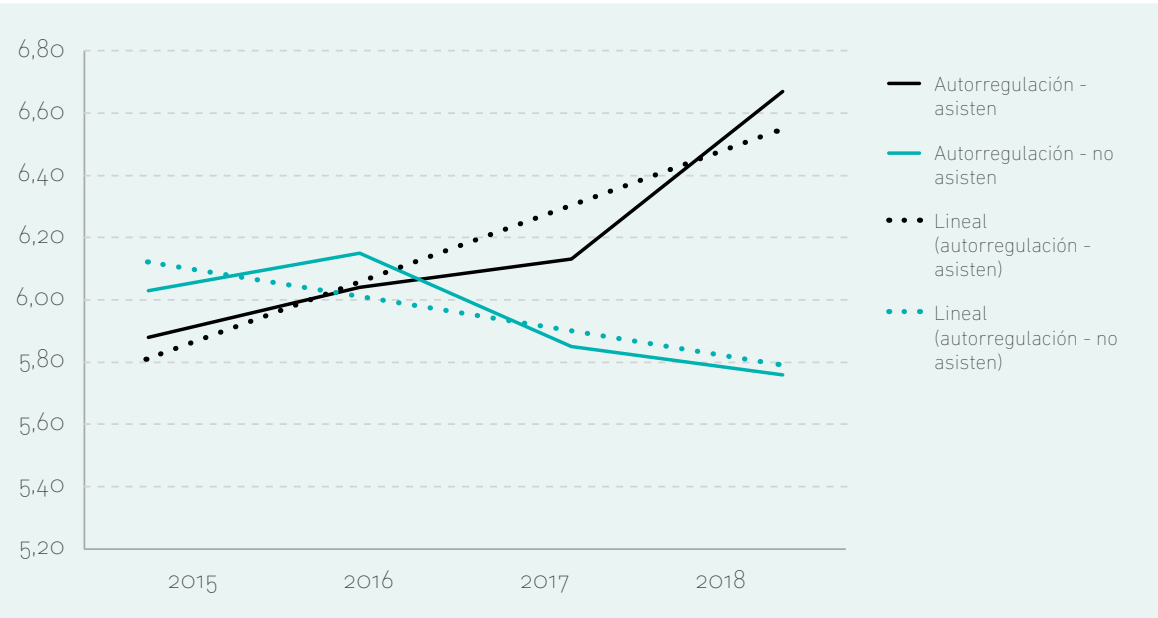

Como se pude apreciar, hay un cambio importante en el comportamiento de la autorregulación a lo largo del tiempo, mostrando un mayor impacto de la asistencia a las ludotecas en esta subcompetencia. Se muestra, bajo esta perspectiva, un impacto relativo en expresión de emociones y, en menor medida, en empatía.

\section{Resultados en la creatividad}

Para la competencia asociada a la creatividad, los valores estimados son los siguientes:

\begin{tabular}{cccc}
\hline G1.CRf & G2.CRf & G1.CRi & G2CRi \\
\hline 17.35 & 15.7 & 15.2 & 13.8
\end{tabular}

\footnotetext{
$\triangle($ Diferencia)

$\Delta f=G_{1} . C R f-G 2 . C R f=17.35-15.7=1.65$
} 
$\underline{\Delta}=G_{1} \cdot C R i-G_{2} \cdot C R i=15 \cdot 2-13.8=1.4$

$\operatorname{ImpCR}=1.65-1.4=0.25$

El puntaje anterior de impacto (0.25), señala que los niños que asisten a las ludotecas tienen una probabilidad de tener 0.25 puntos por encima de los niños que no lo hacen. Como se observa, este puntaje es inferior al estimado para las competencias ciudadanas y emocionales. Esto indica que las ludotecas tienen un impacto, aunque menor, en dicha competencia.

Se observa, para esta competencia, un comportamiento muy parecido al de la empatía, con una disminución de los puntajes de los grupos en el año 2016. y un aumento entre 2017 y 2018 . No se observa un cambio en la brecha entre los dos grupos a lo largo del tiempo.

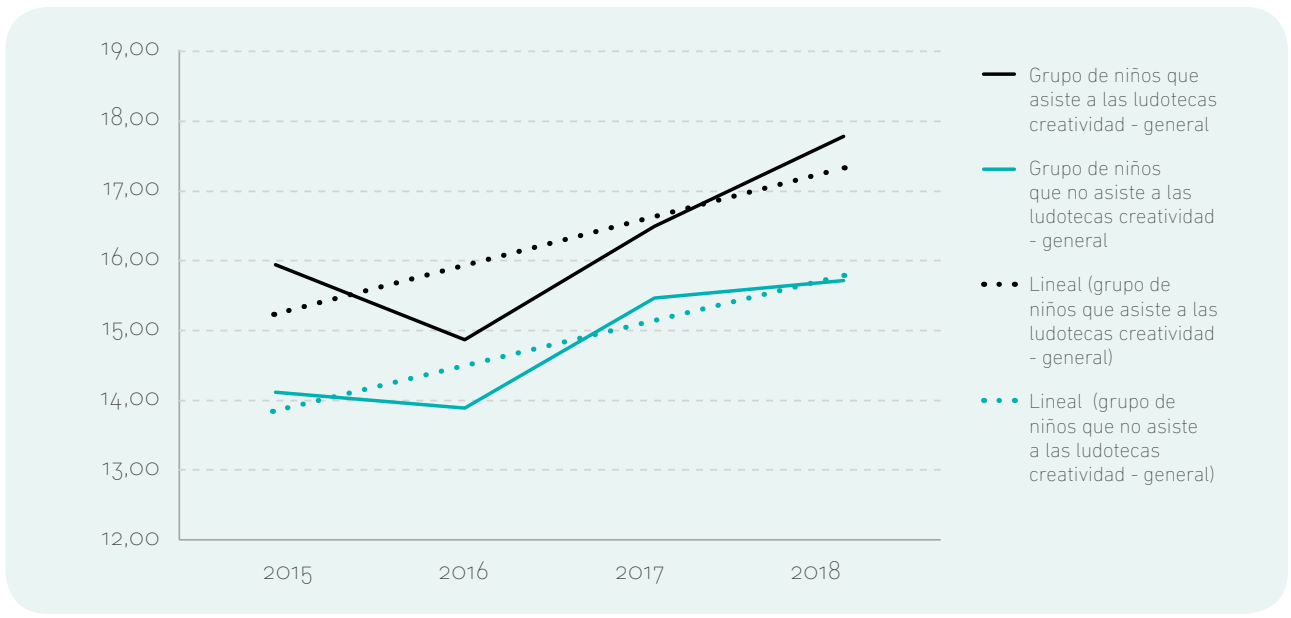

Los comportamientos de cada competencia asociada a la creatividad fueron los siguientes: en pensamiento divergente se muestra el comportamiento típico de descenso en puntajes en 2016, y el aumento entre 2017 y 2018. El análisis de tendencia muestra una disminución de la brecha entre los grupos, lo cual señala un menor impacto de la ludoteca en esta competencia. 


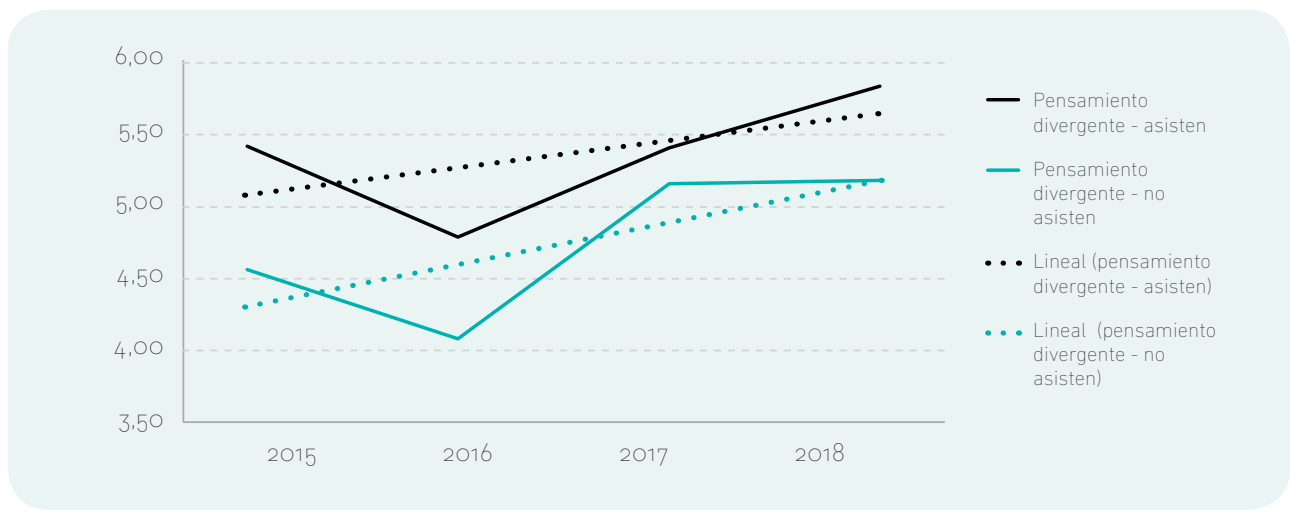

Flexibilidad tiene un comportamiento un tanto distinto a las demás competencias, ya que muestra un ligero aumento, especialmente del grupo de niños que no asiste, durante el año 2016. Si bien, entre 2017 y 2018 los puntajes van en aumento, la brecha entre ambos grupos no es muy grande.

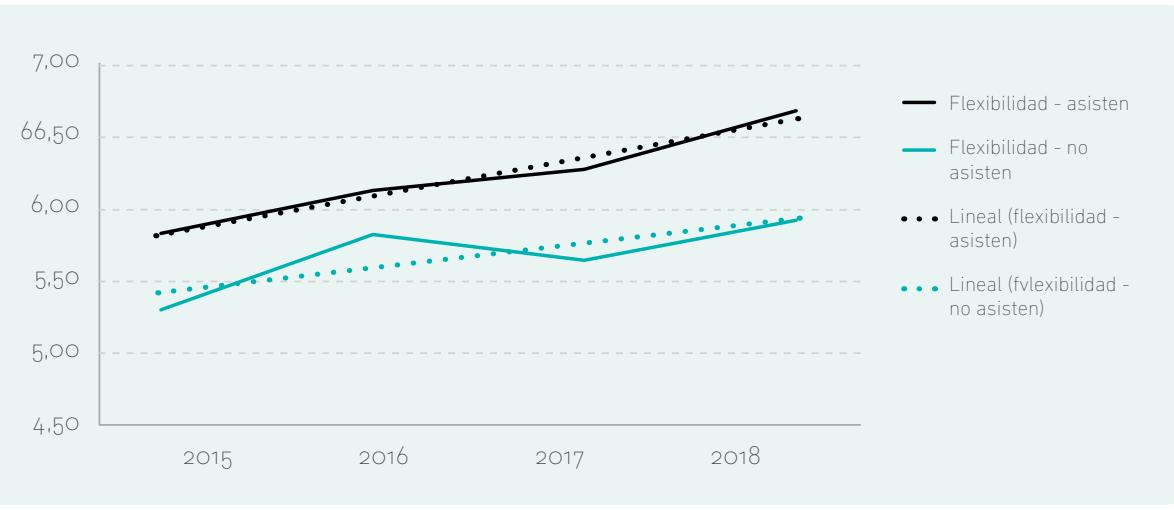

Por su parte, elaboración tiene un comportamiento variable, con un punto de comunión entre grupos en 2016, un aumento de los dos grupos en el año 2017 y una ligera brecha en 2018. La diferencia en la brecha, mostrada en las tendencias a lo largo del tiempo, no es significativa. 


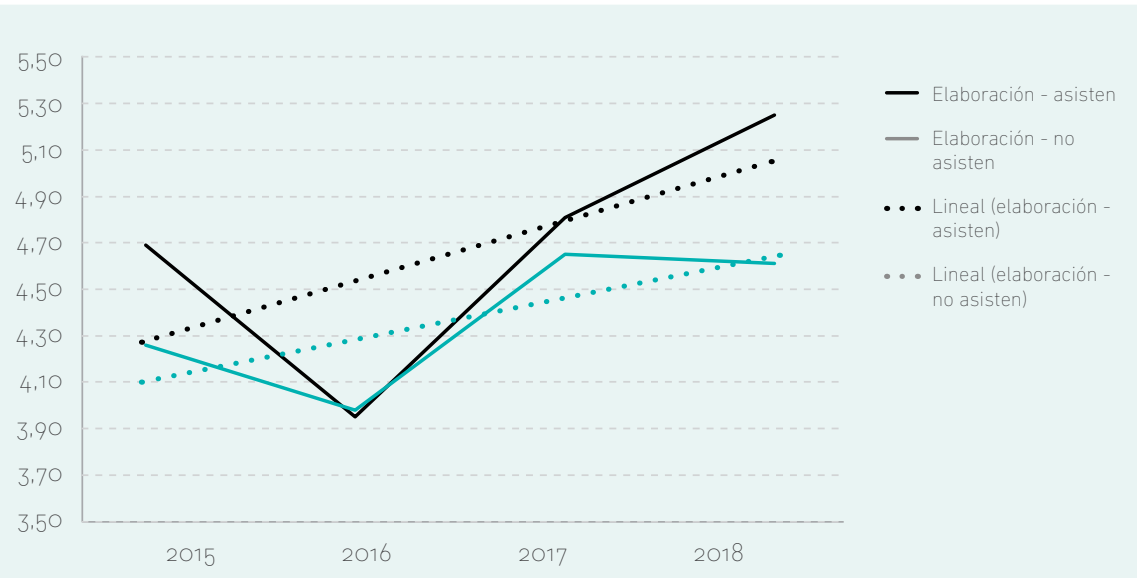

Como se observa, asistir a la ludoteca presenta un impacto relativo en flexibilidad y elaboración a lo largo del tiempo, y un impacto casi nulo en pensamiento divergente.

\section{Resultados de las entrevistas a niños}

En esta sección se presentan los resultados cualitativos del instrumento de caracterización de competencias ciudadanas, emocionales y creativas en niños. Para el análisis de la información se construyeron cuatro categorías: juego, arte y literatura, interacción y comportamiento esperado. Con cada categoría se organizó la información y se presenta a partir de las entrevistas a los niños.

\section{Sobre el juego}

\section{Grupo Intervenido}

Se identifica que en esta categoría algunos niños refieren que los elementos mencionados en la entrevista son usados para una sola finalidad, como "pelota para jugar bolos (Quibdó)", "hojas para dibujar (Quibdó)", "libros para leer (Chinchiná)"... etc.; sin embargo, otro grupo de niños relaciona los elementos con deseos como "me gustaría dibujar carros, motos, con los colores pintarlos (Manaure)", 
"me gustaría dibujar un perrito y una mariposa (Manaure)" y un porcentaje muy pequeño logra asociar los elementos con juegos y actividades que se desarrollen en la ludoteca como "El niño utiliza pelotas para jugar tingo tango y las hojas para dibujar (Quibdó)" o lo asocian con diversidad de gustos por género "a las niñas le gustan los libros y a los niños las pelotas (Bugalagrande)".

\section{Grupo Comparativo}

En el grupo comparativo no se evidencia diferencias significativas en las respuestas de los niños. Algunos responden con la funcionalidad de los objetos "las hojas están en los libros (Bugalagrande)", "en el papel puedo dibujar, escribir y con los libros leer (Quibdó)". Algunos relacionan los objetos con sus gustos o preferencias "no me gustan los libros, pero jugar sí (Bugalagrande)", "cono: jugar como si fuera king Kong. Balón: jugar fútbol. Bloques: armar para jugar bolos. Cubos: armar cosas, muñecos (Sabanagrande)", sin embargo, es muy bajo el porcentaje de niños que relacionan los objetos con juegos o actividades que proporcionan las instituciones educativas.

\section{Sobre el arte y la literatura}

\section{Grupo Intervenido}

Se evidencia que en la mayoría de las ludotecas los niños relacionan los libros solamente con los procesos de lectura y escritura, no hacen referencias de las actividades de lectura que se realizan; en algunos casos mencionan libros representativos o significativos para ellos, a diferencia de la parte artística, donde mencionan intrínsecamente algunas actividades desarrolladas con pintura, crayolas, colores... y los dibujos que ellos han construido con estos elementos; la parte artística está relacionada con lo pictórico, pero no se menciona la música y la expresión corporal. 
"Cubos: haría un castillo. Papel: haría una casita. Libros: leer. Pintura: dibujar una flor (Sabanagrande)".

"Libros: leer y aprender "El principito". Pintura: pintar lo que se me ocurriera en mi imaginación (Sabanagrande)".

“Tijeras para cortar; pinturas para pintar algún trabajo; libros para leer y tener mejor ortografía; lápices para escribir; colores para colorear. (Chinchiná)".

"Los libros tienen cuentos (Bugalagrande)".

"Libros: leo cualesquiera. Ahora estoy leyendo mariposa verde (Chinchiná)".

“Leer 'Los 7 enanitos' y el cuento de 'La bella y la bestia' (Chinchiná)".

\section{Grupo Comparativo}

En el grupo comparativo la información sobre la literatura es muy reducida, ya que asocian los libros solamente a leer, pero no muestra otras actividades que se pueden desarrollar con la lectura o la manera en que las realizan; tampoco mencionan nombres de libros o historias que hayan leído.

"Libros: leer un cuento. Tijeras: recortar un corazón. Pintura: dibujar una princesa (Sabanagrande)".

"Los libros para leer y jugar (Bugalagrande)".

"Libros para leer y aprender; figuras geométricas para armar cosas como casas y animales; pinturas para pintar; crayolas para dibujar y pintar; regla para medir y trazar; papel para escribir, pintar y dibujar (Chinchiná)".

"Con los libros puedo leer y con las pelotas juego quemao (Quibdó)".

\section{Sobre las interacciones}

\section{Grupo Intervenido}

La categoría de interacción está relacionada con el componente de expresión y reconocimiento emocional y resolución de conflictos, ya que se identifica cómo los niños trasversalizan lo aprendido en la ludoteca: al gestionar sus emociones, 
generar empatía con el otro, inferir estados mentales, interpretar y predecir conductas, también se evidencian las relaciones que tienen los niños con sus pares y familia.

"Pedirle perdón y ayudar a limpiar el desastre que ocasionó (Sabanagrande)". "Pedir disculpas a Sara porque ella iba pasando y tumbó sin culpa la pintura (Sabanagrande)".

"Disculparse, darle la mano y abrazarla (Barrancabermeja)".

"Pedir disculpas y ayudarle a conseguir otra pintura para que termine su dibujo (Barrancabermeja)".

"Decirle que todo tiene solución (Quibdó)".

“La niña expresa que, si una amiga encuentra un pájaro muerto, ella le diría que lo recogiera y lo enterrara, y le diría que el pajarito va a estar bien en el lugar donde se encuentre; y en caso de que eso le ocurriera a ella, lo sepultaría y también lloraría porque no le gustan los animales maltratados (Sabanagrande)".

\section{Grupo Comparativo}

Esta categoría en el grupo comparativo está relacionada con las interacciones que realizan los niños solamente con sus pares; las expresiones emocionales son muy limitadas frente a las situaciones que propone la entrevista, responden de manera muy concreta, con palabras cortas como pedir perdón, sin profundizar en la emoción o generar alguna respuesta al problema presentado.

"Disculparse con Sara (Sabanagrande)".

"Juana debe tener más cuidado y no correr para no tropezar la pintura (Sabanagrande)".

"Pedir disculpas (Barrancabermeja)". 

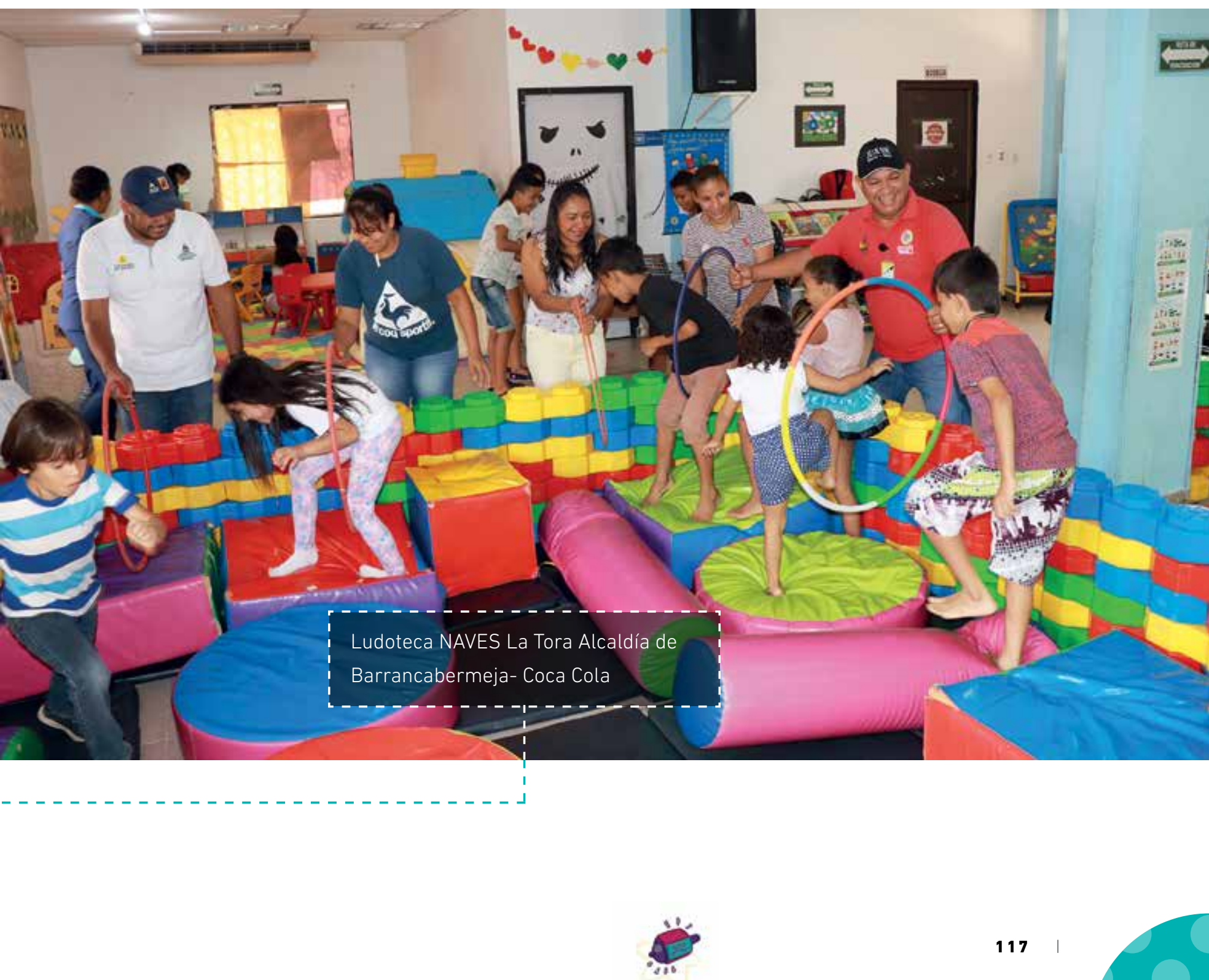


\section{Sobre el comportamiento esperado Grupo Intervenido}

Se identifica que en la competencia ciudadana está relacionada con lo emocional, ya que cuando los niños aprenden a gestionar su propias emociones logran seguir normas y tener mayor conciencia social, como es el caso de la situación problema, en la que los niños identifican que el escenario no es correcto, que no hay una intencionalidad por parte del segundo sujeto y proponen opciones para solucionar la situación, sin embargo, no se evidencia claramente cuáles son las normas que se establecen en la ludoteca y cómo la utilizan los niños.

\section{Grupo Comparativo}

No se identifican comentarios relacionados con el comportamiento esperado.

\section{Resultados de las entrevistas a familias y cuidadores}

Considerando que el programa Ludotecas Naves (acotamos a ludotecas), genera espacios educativos tanto para los niños y niñas como para sus familias, estos espacios deben ser evaluados en todas sus dimensiones. Se presenta a continuación un análisis cualitativo referido al componente de familia, a partir del cual se examina la relevancia de dichos espacios dedicados al juego en los municipios de Sabanagrande, Chinchiná, Bugalagrande, Manaure, Barrancabermeja y Quibdó, a partir de entrevistas realizadas a diversos miembros de familias cuyos hijos asisten regularmente a la ludoteca. Entrevistas que formulan cinco preguntas, las cuales permiten entender cómo son vistas las ludotecas y cómo han aportado en los diferentes ámbitos familiares, sociales y educativos.

Para realizar este análisis, se han escogido cuatro categorías que permiten abordar la información de una manera más precisa y detallada: la concepción de juego, las relaciones familiares, el conocimiento sobre los derechos de los niños y las niñas y los aportes de la ludoteca, que son recurrentes en la percep- 
ción que tienen las familias en cuanto al programa. En consecuencia, con esta categorización, esta sección se encuentra dividida en cuatro partes, una para cada categoría.

\section{Sobre la concepción de juego}

El juego, como elemento central de las ludotecas, es fundamental para entender cómo los niños y las niñas se divierten, aprenden y transforman diferentes prácticas familiares en sus casas. Es así como se ha logrado identificar que el juego permite que cada familia adopte nuevas formas de socializar, aprender y entender el mundo desde un espacio agradable y no convencional. Para poder comprender esto de una mejor manera, se les preguntó a los padres y las madres de familia.

\section{¿Cómo han cambiado las formas en las cuales juega con su hijo, como resultado de la asistencia a las ludotecas?}

Como es de esperarse, las respuestas fueron variadas y apelaron a diferentes aspectos familiares, sin embargo, existen tres asuntos en los que, en términos generales, concuerdan la mayoría de padres y madres de familia: la transformación en algunas prácticas familiares entre padres/madres e hijos/hijas; la apropiación de valores como el respeto, la tolerancia y la obediencia; el interés de padres y madres de familia por el juego; y en contraposición y tensión a este último, la falta de tiempo de muchos padres y madres de familia para poder jugar con sus hijos e hijas.

Se encontró información similar en los municipios de Bugalagrande, Manaure y Quibdó, en la medida en que se destacan respuestas en las que padres y madres de familia ven la necesidad de interesarse por sus hijos e hijas al momento de jugar. No obstante, también se encuentran respuestas que indican que la falta de tiempo de los padres y madres es un limitante para poder compartir 
con los niños y niñas de estos municipios. En la siguiente tabla, se muestran algunas respuestas dadas en los tres municipios.

\section{TABLA 6}

\section{FORMAS DE JUEGO}

\begin{tabular}{|c|c|c|c|}
\hline & BUGALAGRANDE & MANAURE & QUIBDÓ \\
\hline \multirow{3}{*}{ 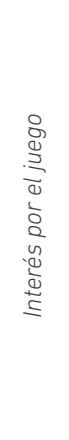 } & $\begin{array}{l}\text { Como que me parece más } \\
\text { importante jugar y esas cosas. }\end{array}$ & $\begin{array}{l}\text { Sí, ahora estoy más pendiente } \\
\text { de sus juguetes, le compro } \\
\text { cosas para jugar, cada vez que } \\
\text { puedo. }\end{array}$ & $\begin{array}{l}\text { Pues ahora le gusta jugar a } \\
\text { rompecabezas y yo le ayudo. }\end{array}$ \\
\hline & $\begin{array}{l}\text { No sé, pero ella siempre llega } \\
\text { a contarme lo que hizo con las } \\
\text { profes, entonces trato de hacer } \\
\text { lo mismo en la casa. }\end{array}$ & $\begin{array}{l}\text { No sé, ahora juego un poquito } \\
\text { más con ella. }\end{array}$ & $\begin{array}{l}\text { A él le gusta enseñarme los } \\
\text { juegos que aprende en la } \\
\text { ludoteca. }\end{array}$ \\
\hline & & $\begin{array}{l}\text { Jugábamos muchos juegos de } \\
\text { mesa, ahora salimos más al } \\
\text { parque para no aburrirnos. }\end{array}$ & \\
\hline \multirow{3}{*}{ 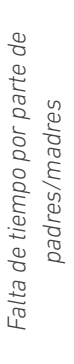 } & $\begin{array}{l}\text { Pues como a uno no le queda } \\
\text { tiempo. }\end{array}$ & $\begin{array}{l}\text { No jugamos, él juega con otros } \\
\text { niños. }\end{array}$ & $\begin{array}{l}\text { La verdad, juego muy poco, por } \\
\text { el empleo. }\end{array}$ \\
\hline & $\begin{array}{l}\text { A veces no tengo muchos } \\
\text { juegos. }\end{array}$ & Casi no jugamos. & $\begin{array}{l}\text { Pues muy poco, jugamos más } \\
\text { que todo lo hace con sus amigos, } \\
\text { porque yo trabajo. Por eso lo } \\
\text { mando a la ludoteca. }\end{array}$ \\
\hline & Es que casi no jugamos. & Ya casi no jugamos. & $\begin{array}{l}\text { Juego muy poco con mi hijo, } \\
\text { por eso lo mando a la ludoteca, } \\
\text { porque no me queda tiempo. }\end{array}$ \\
\hline
\end{tabular}

En el caso particular de Bugalagrande, los padres y madres de familia, reconocen que la presencia de la ludoteca ha incidido de manera positiva en el juego que mantienen con sus hijos e hijas, pues antes de que la ludoteca hiciera presencia en el municipio, los padres no se interesaban por qué o cómo jugaban 
sus hijos e hijas. Respuestas como “(...) antes uno no le sacaba el tiempo por estar cansado, pienso que es eso" o "no, pues creo que ahora jugamos. Antes no me parecía importante", demuestran la transformación que ha sufrido la concepción que tienen sobre el juego y, en consecuencia, las actividades de acompañamiento de los padres y madres hacia sus hijos.

En cuanto a los municipios de Barrancabermeja, Chinchiná y Sabanagrande se nota una actitud bastante positiva frente a la presencia y el trabajo que han logrado las ludotecas en estos lugares. Las respuestas, en general, están dirigidas a reconocer la consolidación de valores por parte de los niños; la preocupación de los padres y madres por compartir más tiempo con sus hijos e hijas a la hora del juego y, en general, una participación de ellos (padres y madres) en las actividades lúdicas de niños y niñas. La siguiente tabla muestra algunos ejemplos de sus respuestas:

TABLA 7

\section{CAMBIOS EN LAS FORMAS DE JUGAR}

\begin{tabular}{|c|c|c|}
\hline B/BERMEJA & CHINCHINÁ & SABANAGRANDE \\
\hline Compartimos sobre sus sueños. & $\begin{array}{l}\text { (...) Ella antes no incluía a los niños; } \\
\text { ahora cuando salen a la calle todos y } \\
\text { llega un niño que no es de la cuadra y } \\
\text { ella dice sí, sí jugamos con él, pero antes } \\
\text { no; si no era de la cuadra, ella no jugaba } \\
\text { (dar juego). Ella cuando la dejaban allá, } \\
\text { ha prestado libros o juguetes para que } \\
\text { cojan la responsabilidad de cuidar en } \\
\text { la casa. }\end{array}$ & $\begin{array}{l}\text { Sí, porque él antes era muy } \\
\text { agresivo, antes quería ser el } \\
\text { ganador en todo, ahora ya si gano, } \\
\text { ganó, y si perdió, perdió. Es más } \\
\text { organizado, comparte ahora, } \\
\text { porque él antes no compartía, era } \\
\text { muy egoísta en ese sentido. }\end{array}$ \\
\hline
\end{tabular}




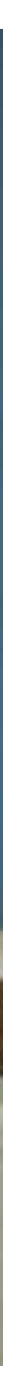


(...) Han aprendido a respetar más a las personas mayores, que han aprendido a respetar más la convivencia con las personas adultas, (...) Si, ahora se aprenden a respetar a símismos y aprenden a respetar el espacio y al otro compañero, a su hermanito, a su primito, a respetarse con su familia,

Está muy atento a su familia. entonces eso siempre los ayuda mucho. Acá simplemente tienen esa libertad de expresión; es la libertad para ellos escoger el juego, qué es lo que les gusta, qué es lo que quieren hacer, pero con su límite también de respeto, de la disciplina, a obedecer, más bien puede ser a lo que tienen derecho y a lo que tienen deberes.
Si ha habido cambios, por ejemplo, la niña ella es aplicada en todo, ella con tal de que uno juegue con ella hace las cosas, es como si el juego fuera el entorno de ella. (...) Es más organizada en el juego, como hay juegos que tienen reglas, ellas las cumple, cede el turno cuando no le toca, ella antes no quería perder y quería jugar siempre.

En general, se entiende que el juego es un mecanismo que potencializa diversos valores y habilidades en los niños. En ese sentido, el juego es adoptado por la mayoría de los padres en estos seis municipios, como una herramienta no solo de diversión, sino de aprendizaje, respeto y como una oportunidad para compartir en familia, en el que tanto niños y niñas como padres y madres de familia se educan.

\section{Sobre las relaciones familiares}

Múltiples pueden ser las causas por las cuales las relaciones familiares pueden verse fragmentadas o debilitadas. En el caso de las familias con niños y niñas es importante tener claro que el diálogo y el constante acompañamiento a los más pequeños es relevante para poder generar lazos de confianza, fraternidad 
y amor. El juego se convierte en herramienta fundamental para los padres y las madres, porque a partir de este aprenden a conocer el mundo infantil y, junto con ello, a entender la manera como se comunican, piensan y sueñan los niños y niñas. De esta manera, los espacios lúdicos abren la posibilidad de que las relaciones familiares no solo se transformen, sino que se fortalezcan desde actividades divertidas y diferentes.

Para poder identificar cómo han colaborado las ludotecas en las relaciones familiares de los niños y niñas que asisten a estos espacios, se acudió a dos preguntas.

\section{¿Cómo ha cambiado la relación con su hijo desde que asisten a la ludoteca? y ¿Qué actividades realiza con su hijo como resultado de la asistencia a las ludotecas?}

Para la primera, las respuestas coincidieron en los municipios de Barrancabermeja, Quibdó, Manaure, Bugalagrande y Sabanagrande, en donde la mayoría de los familiares indicaron que la mejoría en el diálogo y en valores ha sido relevante en los niños y niñas que asisten a las ludotecas. Por ejemplo, para el caso de Manaure, un padre de familia afirma que su hija "ahora [...] cuenta lo que hace, aprende más y lo aplica [...] con sus hermanos", caso similar al de una madre del municipio de Sabanagrande, quien comenta: "digamos que ella no le gusta estar pegada a uno, ahora sí, ahora me abraza y me dice que hagamos cosas con el niño. Ella siempre me habla, me cuenta lo que pasa con las compañeras, los juegos y así". Los valores también son importantes en las respuestas que se brindan; en el municipio de Quibdó, por ejemplo, una de las respuestas afirma: "la relación con mi hija es mucho más armoniosa porque es respetuosa y muy obediente". 
El caso de Chinchiná es diferente, puesto que, en términos generales, las familias no indican que la ludoteca haya transformado la relación de sus hijos con ellos, pero sí consideran que las buenas relaciones se han mantenido. En ese sentido, la ludoteca ha contribuido a mantener un buen diálogo y compartir entre padres y madres de familia con sus hijos e hijas, lo cual, por supuesto, es un factor positivo. Algunas de las respuestas dadas se muestran en la tabla No.8:

TABLA 8

\section{CAMBIOS EN LAS RELACIONES CON LOS HIJOS}

¿Cómo ha cambiado la relación con su hijo desde que asisten a la ludoteca?

(Municipio de Chinchiná)

\begin{tabular}{llll}
\hline La relación siempre & La relación no ha tenido & La relación siempre ha sido & Ella se ha \\
ha sido sincera y de & cambios, siempre ha sido & buena, pero con los cambios que & comunicado siempre \\
confianza, no creo que la & buena. Lo único es que & ha tenido ha hecho que sea más & muy bien con \\
Ludoteca haya influido & antes no jugábamosy & obediente y así tenemos menos & nosotros, no hemos \\
en la relación de la niña & actualmente síjugamos & conflictos a la hora de hacer las & tenido un cambio así. \\
y yo. & más. & cosas. &
\end{tabular}

Ahora bien, en cuanto a la pregunta ¿Qué actividades realiza con su hijo como resultado de la asistencia a las ludotecas?, las respuestas, en general, apuntan a que los padres y madres se ven más comprometidos e interesados por jugar con sus hijos e hijas. También se evidencia una cercanía a la lectura, como efecto de actividades de este tipo que se realizan en las ludotecas. Aunque las particularidades de padres y madres que no tienen tiempo para jugar con sus hijos e hijas son constantes, es en los municipios de Manaure y Bugalagrande es donde más notorias son. Las dos siguientes tablas muestran algunas respuestas de padres y madres en los municipios involucrados en el estudio. 


\section{ACTIVIDADES QUE REALIZA CON EL HIJO}

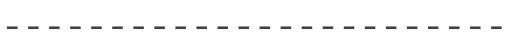

¿Qué actividades realiza con su hijo como resultado de la asistencia a las ludotecas?

\section{RESPUESTAS}

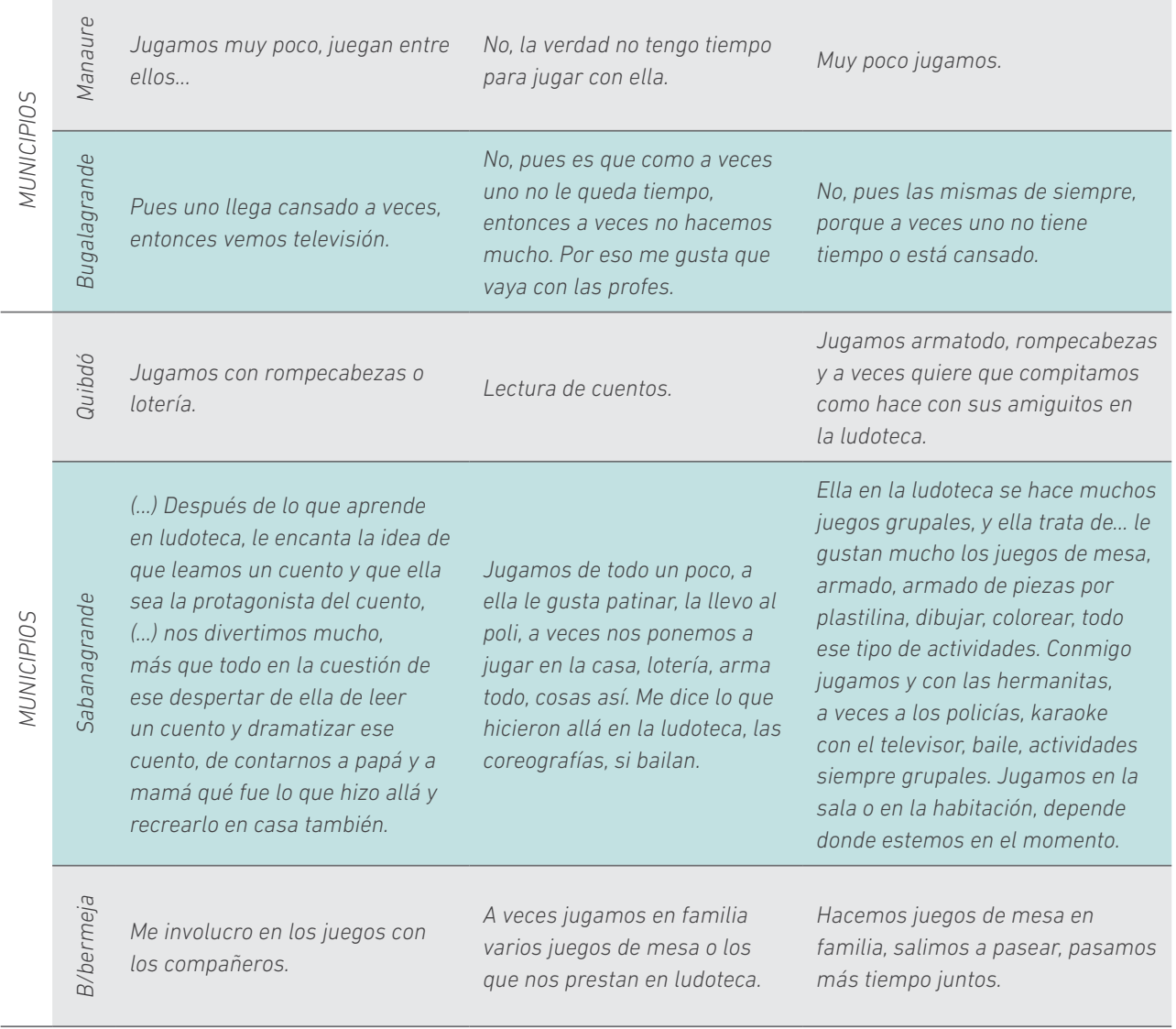


En general, en estos municipios se nota un aporte positivo y significativo en la transformación de las relaciones familiares, lo cual evidencia la importancia de creer en la ludoteca como un espacio que genera condiciones propicias para el bienestar de padres, madres, hijos e hijas.

\section{Conocimientos sobre los derechos de los niños y las niñas}

Los derechos, como herramienta fundamental para construir una sociedad igualitaria, justa y en paz deben permear no solo a toda la población del mundo, sino también todos los ámbitos en los que una persona se desempeña. En el caso de los niños, pensar en sus derechos y en cómo son entendidos y garantizados por padres, madres, niños y niñas, es importante para este programa. En este marco, el derecho al juego es primordial para el desarrollo emocional, físico, social y hasta cultural de un niño o niña, sin embargo, consideramos que este no es el único derecho al que le aportan (y deberían aportar) las ludotecas. Dada la relevancia de los derechos y el impacto de las ludotecas en la cotidianidad de las familias que asisten a estas, se ha decidido tomar en cuenta dos preguntas de las entrevistas realizadas, para así comprender cómo se ha configurado, transformado y/o mantenido el conocimiento sobre los derechos de los niños y niñas en las familias. Las preguntas estudiadas fueron:

\section{¿Cómo siente que la ludoteca promueve el desarrollo de su hijo? y ¿Cómo ha cambiado la relación con su hijo desde que asisten a la ludoteca?}

Así, se puede detectar que en todos los municipios hay una tendencia a notar un cambio en la actitud de los niños y niñas frente a la manera en como comparten con otros niños y niñas, lo cual quiere decir que el derecho propio que tienen estos a compartir y crecer en un ambiente sano, alegre y en compañía de pares se ve enriquecido gracias a la presencia de las ludotecas y las actividades que allí se realizan. Afirmaciones como: 
- "Los niños son el futuro, son alegría, son tranquilidad. Los niños tienen derecho a la recreación. Sarita viene a jugar, a divertirse, a aprender. Al Sarita venir, se da cuenta qué quiere ser cuando esté grande, aprende a compartir, a conocer más gente, más amiguitos. Pues acá los recrean que es un derecho, los respetan, ella se amaña acá, ella es feliz, aprenden, es más expresiva, sociable, habla más, se relaciona más fácil, consigue amigos más fácil" (Chinchiná).

- "Él es un poco callado, ahora interactúa más con nosotros y con sus amigos" (Manaure).

- “(...) ya es una niña más abierta, se relaciona más con los compañeros, ella no se relacionaba casi con los compañeros, se expresa más, pasa con sus hermanos, se relaciona mejor con ellos" (Sabanagrande).

Demuestran un cambio de actitud y cotidianidad de los niños y niñas que asisten a estos espacios, también se nota una actitud positiva de parte de padres y madres de familia al sentir el bienestar de sus hijos e hijas como bienestar propio. Esto último incide en el fortalecimiento de las familias, como derecho esencial de un niño o niña. La familia, como célula central de la sociedad, es un derecho que, por orden jurídico y moral, no debe privársele a ningún niño o niña; de este modo, las ludotecas han visibilizado la necesidad de que los padres y madres de familia comprendan la necesidad de compartir en casa con sus hijos e hijas, haciéndolos sentir parte de una familia. Aunque en todos los municipios esto fue evidente, la siguiente tabla muestra respuestas dadas en algunos de estos. 
TABLA 10

PROMOCIÓN DEL DESARROLLO 1

¿Cómo siente que la ludoteca promueve el desarrollo de su hijo?

\begin{tabular}{|c|c|c|}
\hline MUNICIPIOS & RESPUESTAS & \\
\hline Chinchiná & $\begin{array}{l}\text { El amor familiar, el respeto; pues que siempre } \\
\text { estamos ahi para apoyarlo; la actividad física y } \\
\text { quema tantas energías, porque él viene acá y } \\
\text { juega mucho. }\end{array}$ & $\begin{array}{l}\text { Yo creo que acá les han hablado las cosas; de } \\
\text { abrirles tanto como las emociones a través } \\
\text { de cómo interactúan con los juegos, las cosas } \\
\text { que vienen planeadas para unir las familias; } \\
\text { lo que hacen acá a través de una enseñanza, } \\
\text { un juego, ya los transforman a la vida } \\
\text { habitual; son ambientes muy diferentes. }\end{array}$ \\
\hline Sabanagrande & $\begin{array}{l}\text { (...) Yo veo en ella que los vuelve niños como más } \\
\text { abiertos, más espontáneos, el valor de la familia, } \\
\text { el compartir en familia, el estar unidos, y a ustedes } \\
\text { les gusta promover eso, inclinan a uno a que haya } \\
\text { tiempo para dedicarles tiempo a los niños para su } \\
\text { desarrollo, porque ella es una niña y a los niños } \\
\text { les gusta el juego, es una etapa, el juego le ayuda a } \\
\text { ser una persona segura, madura. }\end{array}$ & $\begin{array}{l}\text { Le ha servido de mucho, ya es una niña } \\
\text { más abierta, se relaciona más con los } \\
\text { compañeros, ella no se relacionaba casi con } \\
\text { los compañeros, se expresa más, pasa con } \\
\text { sus hermanos, se relaciona mejor con ellos. }\end{array}$ \\
\hline
\end{tabular}

¿Cómo ha cambiado la relación con su hijo desde que asisten a la ludoteca?

\begin{tabular}{lll} 
MUNICIPIOS & RESPUESTAS & \\
Quibdó & $\begin{array}{l}\text { Siento que me tiene más confianza, siente gran } \\
\text { interés de contarme todo lo que hizo. }\end{array}$ & $\begin{array}{l}\text { Hemos mejorado la comunicación, yo le hablo } \\
\text { y él me escucha, está más atento a lo que le } \\
\text { digo. }\end{array}$ \\
\hline Bugalagrande & $\begin{array}{l}\text { Ahora el niño está más contento, entonces uno } \\
\text { está más tranquilo. }\end{array}$ & Jugamos más, casi siempre jugamos.
\end{tabular}

\section{Aportes de la ludoteca}

Para terminar esta sección, es necesario hacer una evaluación de los aportes de las ludotecas y el impacto que estas han generado sobre los municipios y las comunidades que atienden; esto permite entender el alcance que tiene el programa y las realidades que logra transformar. Igualmente, permite comprender 
la importancia de los niños y niñas dentro de la sociedad, puesto que, no cabe duda, el futuro de esta depende de los sujetos que se están formando hoy y que vivirán en el mundo que se les entregue mañana.

En ese sentido, se identifican dos subcategorías que buscan especificar cuáles fueron los aportes de las ludotecas. La primera, apoyada en la pregunta:

\section{¿Cómo siente que la ludoteca promueve el desarrollo de su hijo?}

Se encarga de mostrar cómo contribuyeron los espacios lúdicos al desarrollo de los niños y niñas. La segunda, analizada desde la pregunta:

\section{¿Cree que la relación entre la comunidad y la ludoteca ha cambia- do? ¿Cómo?}

Se centra en los aportes a la comunidad. Si bien es cierto que con la primera subcategoría ya se está hablando de una contribución a la comunidad, se considera importante reconocer cuáles fueron los cambios (tanto positivos como negativos), que generó el programa en cada municipio.

En primera medida, se debe tener en cuenta que, en general, los padres y madres de familia tienen una percepción positiva frente al trabajo desarrollado por las ludotecas. Aspectos como la mejoría en la socialización de sus hijos e hijas o la educación en valores, son los que resaltan al momento de preguntarles por el desarrollo de su hijo. De igual manera, se confirma que el juego como estrategia no solo de diversión sino también de aprendizaje, ha contribuido a la mejora de habilidades psicomotrices y cognitivas de los niños y niñas, lo cual los padres observan en el progreso de sus hijos e hijas en la escuela. Por ejemplo, en el municipio de Sabanagrande, un familiar responde: "hasta ahora, bueno, ella llega a la casa y hace sus tareas como organizadita. Le da más concentración en el estudio, porque desarrolla las manos, cambia del colegio al juego, son muchas las 


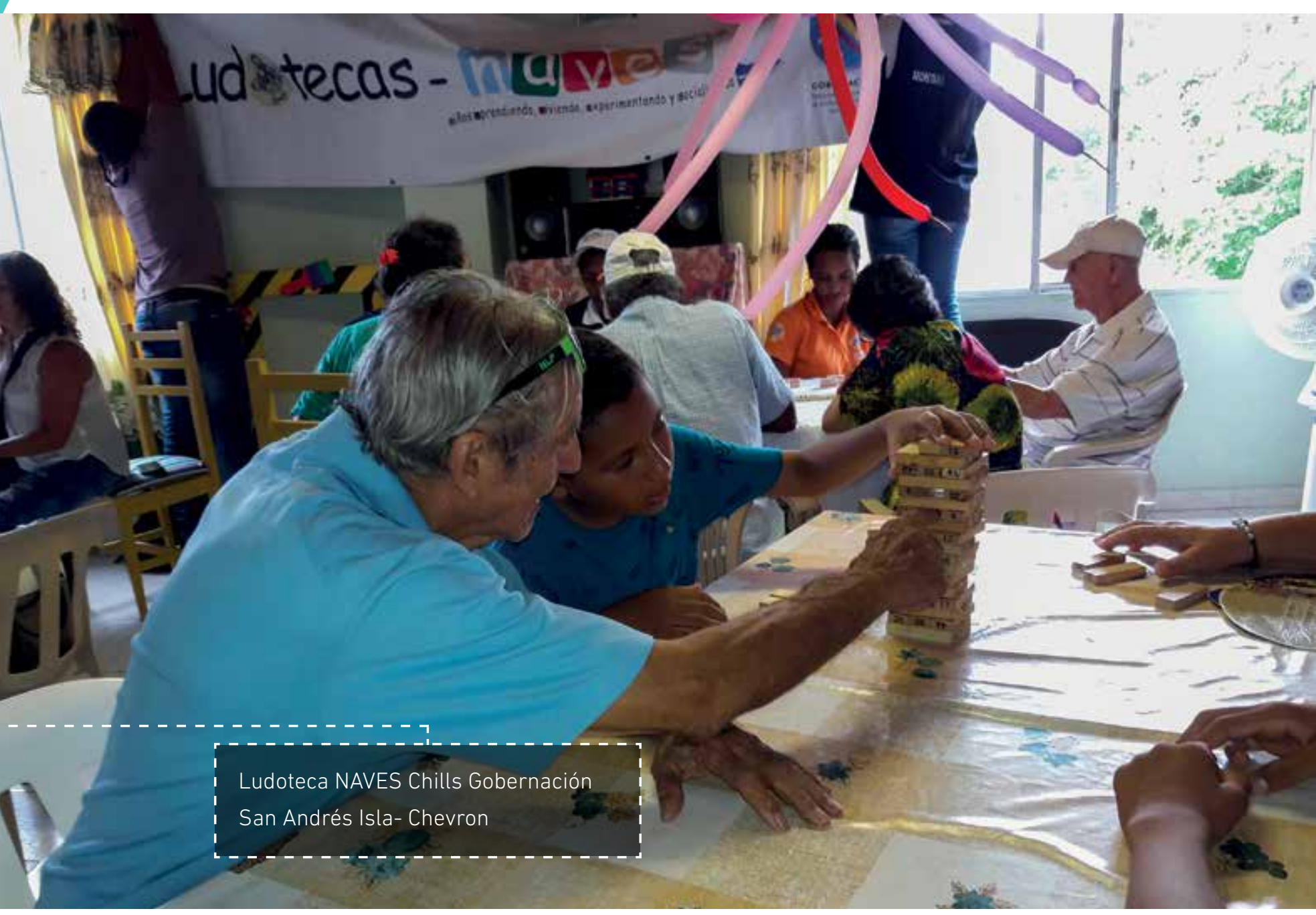


diferencias", logrando así visibilizar que las actividades que desarrolla su hija en la ludoteca permean diferentes espacios de su vida.

Aunque la mayoría de los padres y madres de familia en todos los municipios rescatan la formación en valores, el municipio de Barrancabermeja se destaca por respuestas de este tipo:

TABLA 11

PROMOCIÓN DEL DESARROLLO 2

¿Cómo siente que la ludoteca promueve el desarrollo de su hijo?

(Municipio de Barrancabermeja)

\begin{tabular}{llll}
\hline $\begin{array}{l}\text { Ayudan en el buen trato, } \\
\text { la relación con otros }\end{array}$ & $\begin{array}{l}\text { Conocen de la educación } \\
\text { niños y el respetos y el buen }\end{array}$ & $\begin{array}{l}\text { El compartir con los } \\
\text { demás hace que haya }\end{array}$ & $\begin{array}{l}\text { Le ayuda a mejorar su } \\
\text { comportamiento en la casa y en }\end{array}$ \\
& trato hacia las demás & $\begin{array}{l}\text { respeto y adquieran más } \\
\text { pel colegio, está más pendiente de }\end{array}$ \\
& valores. & colaborar y refuerza los valores. \\
\hline
\end{tabular}

En cuanto a la contribución de las ludotecas a las comunidades que atienden, las respuestas varían entre municipios. En general, se nota un trabajo con los niños y niñas de cada municipio y se entiende cuál es la labor de las ludotecas, pero el trabajo con comunidad aún tiene algunos aspectos que deben considerarse y mejorarse. Se identifican tres municipios en los que las familias conocen y participan de los programas ofertados por las ludotecas: Barrancabermeja, Bugalagrande y Quibdó. En tanto que los municipios de Chinchiná, Manaure y Sabanagrande consideran que las ludotecas podrían tener una mejor comunicación con la comunidad. La siguiente tabla presenta una comparación entre estos municipios: 


\section{TABLA 12}

\section{RELACIÓN COMUNIDAD-LUDOTECA}

\begin{tabular}{|c|c|c|c|}
\hline \multicolumn{4}{|c|}{ ¿Cree que la relación entre la comunidad y la ludoteca ha cambiado? ¿Cómo? } \\
\hline & BARRANCABERMEJA & BUGALAGRANDE & QUIBDÓ \\
\hline \multirow{4}{*}{ 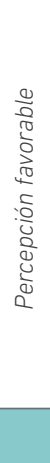 } & $\begin{array}{l}\text { Sí, porque sabemos que allá } \\
\text { recibimos ayuda para poder llevar } \\
\text { a nuestros hijos por mejor camino. }\end{array}$ & $\begin{array}{l}\text { Bien, pues uno habla con las } \\
\text { profes y ellas son muy queridas, } \\
\text { siempre uno pregunta "icómo va } \\
\text { mi hijo?". Uno confía en ellas. }\end{array}$ & $\begin{array}{l}\text { La relación es positiva, porque la } \\
\text { comunidad vive feliz. }\end{array}$ \\
\hline & $\begin{array}{l}\text { Creo que sí, porque estamos } \\
\text { tranquilos cuando ellos están allí. }\end{array}$ & $\begin{array}{l}\text { Yo pienso que nos entendemos con } \\
\text { ellas, las profes. }\end{array}$ & $\begin{array}{l}\text { Siempre ha sido bueno, los } \\
\text { habitantes nos sentimos bien. }\end{array}$ \\
\hline & $\begin{array}{l}\text { Sí estamos contentos por poder } \\
\text { asistir y aprender. }\end{array}$ & $\begin{array}{l}\text { Sí, porque por ejemplo antes yo } \\
\text { creía que era una alcahuetería, } \\
\text { pero no, los niños aprenden y se } \\
\text { relacionan. }\end{array}$ & $\begin{array}{l}\text { La ludoteca le ha brindado a la } \\
\text { comunidad una alternativa de } \\
\text { buena utilización del tiempo libre. }\end{array}$ \\
\hline & CHINCHINÁ & MANAURE & SABANAGRANDE \\
\hline \multirow{3}{*}{$\begin{array}{l}\frac{0}{0} \\
\frac{0}{0} \\
0 \\
0 \\
\frac{0}{0} \\
\frac{0}{0} \\
0 \\
\frac{0}{0} \\
\frac{0}{0} \\
\frac{0}{0} \\
\frac{0}{0} \\
\frac{0}{0}\end{array}$} & $\begin{array}{l}\text { Complicado... pienso que casi no } \\
\text { hay colaboración, la gente conoce } \\
\text { poquito la ludoteca (...) }\end{array}$ & $\begin{array}{l}\text { Sí, no son tan activos ahora, han } \\
\text { perdido visibilidad en el pueblo. }\end{array}$ & $\begin{array}{l}\text { No he escuchado nada. Yo conozco } \\
\text { de acá porque acá había una } \\
\text { biblioteca. No sé qué se hace en la } \\
\text { ludoteca. }\end{array}$ \\
\hline & $\begin{array}{l}\text { Como los procesos no son } \\
\text { continuos, ni con la familia, ni } \\
\text { con los niños y la comunidad; } \\
\text { porque a los ludotecarios los } \\
\text { tienen haciendo otras actividades } \\
\text { y el tiempo que le dedican a la } \\
\text { Ludoteca es muy limitado, tampoco } \\
\text { es posible ver procesos con ellos. }\end{array}$ & $\begin{array}{l}\text { Ya no vienen a los barrios, antes } \\
\text { hacían más cosas. }\end{array}$ & No he escuchado nada. \\
\hline & $\begin{array}{l}\text { La Ludoteca si ha tenido muchos } \\
\text { cambios, antes era mejor porque } \\
\text { los padres veníamos con los niños } \\
\text { a las Ludotecas, hacían actividades } \\
\text { con la comunidad e incluían a } \\
\text { los jóvenes. Hoy en día eso no } \\
\text { se ve porque han cambiado de } \\
\text { ludotecarios (...) }\end{array}$ & $\begin{array}{l}\text { Sí ha cambiado, un cambio porque } \\
\text { ya no se notan en los barrios, } \\
\text { deberían involucrarse más con } \\
\text { la comunidad, es un programa } \\
\text { interesante. }\end{array}$ & $\begin{array}{l}\text { Quizá un poco apartada, porque } \\
\text { si no fuera por las instituciones } \\
\text { no harían grupos con los niños, } \\
\text { porque los de la comunidad no } \\
\text { los llevan, porque si no es por el } \\
\text { colegio, algunos papás no nos } \\
\text { sentimos obligados a llevarlos a la } \\
\text { ludoteca. }\end{array}$ \\
\hline
\end{tabular}

\section{4}

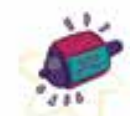


En el municipio de Bugalagrande, las respuestas se centran en la actitud y disposición de las profesoras y el personal que atiende la ludoteca, resaltando de esta manera la importancia de generar un diálogo entre los ludotecarios y los padres de familia. En los municipios de Barrancabermeja, la actitud se dirige hacia el bienestar de los niños y niñas que asisten a la ludoteca y en cómo esto genera lazos de confianza y amabilidad entre la ludoteca y la comunidad. Mientras que en Quibdó, la atención se centra en la sensación de los padres y madres de familia con la presencia de la ludoteca, la cual es bastante favorable porque hace sentir a las familias a gusto y tranquilas.

En los tres municipios restantes, los familiares reconocen que las Ludotecas Naves son un ambiente o espacio de aprendizaje, pero que este debería estar disponible para la comunidad de una manera más notoria y abierta, pues en algunos casos se cree que las ludotecas limitan su trabajo a los espacios escolares, y en otras ocasiones no se tiene información suficiente o clara sobre el trabajo que allí se realiza con padres y madres de familia.

\section{Resultados de la caracterización de las Ludotecas Naves}

En esta sección se presentan los resultados cualitativos del instrumento de caracterización de las interacciones, los recursos y los ambientes para la construcción de ciudadanía, el desarrollo de la competencia emocional y la expresión de la creatividad. Para el análisis de la información se construyeron tres categorías: interacción, recursos y ambiente. Con cada categoría se organizó la información y se presenta a partir de las observaciones de los profesionales de campo. 


\section{Interacción para la construcción de ciudadanía, la expresión y reconocimiento de emociones y la expresión de la creatividad}

El análisis sobre las interacciones de los ludotecarios con los niños y la relación con sus pares se realiza a partir de las siguientes indicaciones:

1. Describa las formas de interacción de los niños (as) con el ludotecario(a), asociadas a la construcción de ciudadanía, a la expresión y reconocimiento de emociones, y a la expresión de la creatividad.

2. Describa las formas de interacción de los niños (as) con otros niños, asociadas a la construcción de ciudadanía, a la expresión y reconocimiento de emociones y a la expresión de la creatividad.

Describa las formas de interacción de los niños (as) con el ludotecario(a), asociadas a la construcción de ciudadanía, a la expresión y reconocimiento de emociones, y a la expresión de la creatividad:

La relación con los ludotecarios es muy favorable y armoniosa en la mayoría de las regiones, hay un reconocimiento de parte y parte. Además, se logra motivar y predecir los gustos de los niños, lo cual fomenta el cumplimiento de reglas.

Se resalta la organización de las ludotecas por grupos de edad para estimular la cooperación y colaboración en el grupo; en algunas ludotecas se realizan diversas actividades, entre ellas canciones, donde los niños cantan y reconocen cada parte de su cuerpo, al igual que juegos por competencias donde se divide el grupo en dos, que deben superar ciertos obstáculos, lo cual permite el trabajo cooperativo y la resolución de problemas. También se han evidenciado cambios 
significativos en la independencia y regulación de emociones, lo que puede estar asociado a la madurez según la edad y grado escolar. En muchos casos, el ludotecario representa una figura de autoridad, respeto y ejemplo a seguir; ven en él una persona en la que han podido confiar y les apoya en su formación.

Las ludotecas se han convertido en escenarios donde se evidencia la construcción de ciudadanía; este se visibiliza cuando los niños participan libremente (hacen preguntas y argumentan sus respuestas), socializan (interactúan con otros niños), el disfrute y goce del juego es otra oportunidad para la construcción de ciudadanía. Se ofrecen entornos protectores de seguridad. Del mismo modo, se tiene en cuenta las opiniones de los niños y a partir de ellas se potencian sus habilidades y se estimulan sus capacidades. También desarrollan encuentros educativos donde se permite el reconocimiento de las emociones (esto lo realiza por medio de la lectura, que incluye temáticas como los valores. Mediante conversaciones amenas, los niños realizan un análisis de la lectura y logran expresar e interiorizar sus emociones) (Sabanagrande). Con relación a la expresión de la creatividad, los encuentros educativos proponen escenarios de baile, los niños disfrutan y comparten libremente. Finalmente, la participación es activa, los niños escuchan las orientaciones y reconocen reglas.

La mayoría de las ludotecas tienen establecidas normas y acuerdos. En el caso de Chinchiná, son planteados por los mismos niños para ser cumplidos por ellos durante la jornada. Sin embargo, en algunas ocasiones no hay un total cumplimento de las reglas por parte de los niños o los ludotecarios no retoman los acuerdos para finalizar las sesiones; a continuación, algunas consideraciones sobre los tipos de interacciones que se desarrollan: 
- La escucha de los niños de manera individual, con sus pares o por subgrupos, para que estos acordaran con anticipación la manera en que jugarían y las reglas para tener en cuenta durante el desarrollo de la actividad.

- La expresión de emociones de los niños y el reconocimiento, atención y reflexión no solo sobre las propias, sino también las expresadas por los otros.

- Reflexiones - preguntas, enmarcadas con claridad en propuestas movilizadoras y motivadoras para la creación y la exploración por parte de los niños.

- La creación de preguntas movilizadoras individuales, a pares o a subgrupos de jugadores, para invitarlos a la reflexión y a transformar desde ellos mismos las situaciones conflictivas y plantear soluciones más centradas en los hechos (además de lo ya acordado al inicio de cada sesión), las diferentes maneras convencionales para el juego, establecer reglas diferentes y / o crear otros juegos con los mismos recursos existentes en la ludoteca.

Describa las formas de interacción de los niños (as) con otros niños, asociadas a la construcción de ciudadanía, a la expresión y reconocimiento de emociones y a la expresión de la creatividad: 
En la mayoría de las ludotecas se percibe buenas relaciones; en cuanto a la construcción de ciudadanía, se puede mencionar el gusto y buen manejo por los juegos en parejas y en en equipos; la cooperación y la creatividad en el manejo de los juegos sustenta una interiorización de las dinámicas de la ludoteca, sin embargo, estas pueden variar a partir del juego que se propone.

Se identifica transformaciones en la socialización, ya que se apoyan y colaboran entre sí; son más autónomos a la hora de elegir y decidir qué quieren hacer y cómo desean realizar sus cosas. Escuchan a sus compañeros, sobre todo del mismo sexo; las niñas se relacionan más entre ellas, son más calmadas y duran un buen rato hablando de sus cosas. En el caso de los niños, prefieren más los juegos de contacto físico.

En la comunicación, los niños se escuchan entre sí, respetan el turno, comparten y en ocasiones tienen diferencias al momento de seleccionar un juguete, sin embargo, buscan la ayuda de los adultos para regular la situación, o le dan solución entre ellos. Seleccionan los juguetes de acuerdo con sus intereses y disfrutan el juego libre. El reconocimiento de las emociones es notable, logran identificar cuando sus amigos están tristes o felices.

\section{Recursos utilizados para la construcción de ciudadanía, la expresión y reconocimiento de emociones, y la expresión de la creatividad}

El análisis sobre los recursos utilizados para la construcción de ciudadanía, la expresión y reconocimiento de emociones y la expresión de la creatividad se realiza a partir de los siguientes ítems: 


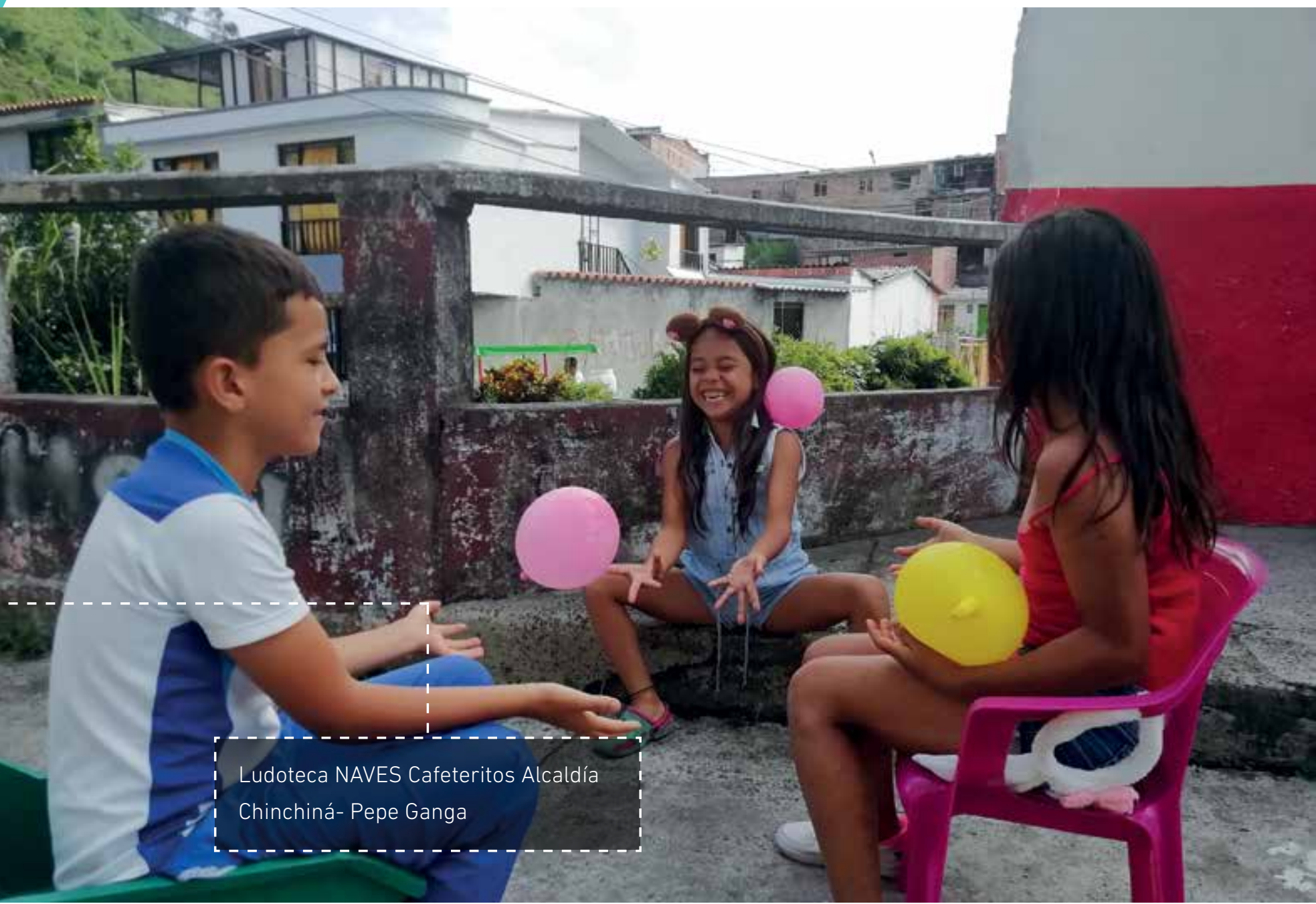




\section{TABLA 13}

\section{RECURSOS UTILIZADOS}

\begin{tabular}{|c|c|c|}
\hline Material & Competencia & Forma de uso en la promoción de las competencias \\
\hline \multirow{3}{*}{ Libros para niños } & Ciudadanía & $\begin{array}{l}\text { En la mayoría de las regiones existen libros que incluyen } \\
\text { información sobre los valores; además se realizan prácticas } \\
\text { que permiten escuchar al otro, participar y asociar a } \\
\text { situaciones reales. }\end{array}$ \\
\hline & $\begin{array}{l}\text { Expresión y } \\
\text { reconocimiento de } \\
\text { emociones }\end{array}$ & $\begin{array}{l}\text { Se han realizado actividades de lectura compartida de } \\
\text { cuentos (de manera colectiva y en parejas), además, se } \\
\text { observó la expresión de emociones relacionadas con sus } \\
\text { contenidos y con las actividades complementarias de la } \\
\text { lectura como intermediaria de otra actividad. }\end{array}$ \\
\hline & Creatividad & $\begin{array}{l}\text { En algunas ludotecas se identifica el uso de los libros para } \\
\text { incentivar el amor por la lectura, desarrollar la creatividad y } \\
\text { enriquecer el vocabulario de los niños y niñas que asisten a la } \\
\text { ludoteca. Además, se realizan actividades complementarias } \\
\text { que promueven la creatividad desde la expresión artística con } \\
\text { dibujos, pinturas, esculturas...etc. }\end{array}$ \\
\hline \multirow{3}{*}{$\begin{array}{l}\text { Elementos de juego para } \\
\text { niños }\end{array}$} & Ciudadanía & $\begin{array}{l}\text { Se ha identificado que en las ludotecas se promueven la } \\
\text { diversidad de juegos, especialmente los que resaltan la } \\
\text { identidad desde lo étnico y cultural. }\end{array}$ \\
\hline & $\begin{array}{l}\text { Expresión y } \\
\text { reconocimiento de } \\
\text { emociones }\end{array}$ & $\begin{array}{l}\text { También se ha identificado diferencias por género, prefieren } \\
\text { los juegos de mesa en el caso de las niñas y los niños los } \\
\text { juegos de competencia y ejercitación, en ocasiones se unen } \\
\text { con las niñas para realizar juegos en común, cediendo un } \\
\text { poco a los juegos de siempre e integrándose en juegos de } \\
\text { roles. }\end{array}$ \\
\hline & Creatividad & $\begin{array}{l}\text { Por género también se identificó que las niñas, por medio } \\
\text { de juego de roles, logran compartir, imaginar, respetar el } \\
\text { espacio de sus pares, dialogar, proponer. Las muñecas: las } \\
\text { niñas pueden crear, generan conversaciones. Sin embargo, a } \\
\text { los niños de g años en adelante les interesan algunos juegos } \\
\text { de mesa, por ejemplo, el Jenga; ellos construyen las reglas y } \\
\text { respetan los turnos, o le dan un uso alternativo a este juego, } \\
\text { por ejemplo, en la elaboración de torres. }\end{array}$ \\
\hline
\end{tabular}




\begin{tabular}{|c|c|c|}
\hline Material & Competencia & Forma de uso en la promoción de las competencias \\
\hline \multirow{4}{*}{$\begin{array}{l}\text { Elementos para el } \\
\text { desarrollo artístico }\end{array}$} & Ciudadanía & \multirow{4}{*}{$\begin{array}{l}\text { Los elementos para el desarrollo artístico son utilizados } \\
\text { para fomentar diferentes formas de expresión corporal, } \\
\text { la manifestación de cualidades artísticas, musicales y el } \\
\text { descubrimiento de potencialidades desconocidas para ellos } \\
\text { mismos. } \\
\text { Por ejemplo: se realizan sesiones para que los niños puedan } \\
\text { dibujar y pintar libremente, también se realizan sesiones } \\
\text { donde se enseñan técnicas de pintado y se asocian a otras } \\
\text { actividades de juego y literatura. } \\
\text { En algunas ludotecas se cuenta con armario de disfraces. } \\
\text { En este espacio se promueve la imaginación, la narración } \\
\text { de historias y el juego libre; en algunos casos, las niñas se } \\
\text { disfrazan de princesas y los niños de diferentes animales, } \\
\text { crean juegos de roles o de imaginación con los mismos, } \\
\text { juegan a los policías, a las princesas y construyen historias } \\
\text { que van desarrollando a medida que pasa el juego. }\end{array}$} \\
\hline & $\begin{array}{l}\text { Expresión y } \\
\text { reconocimiento de } \\
\text { emociones }\end{array}$ & \\
\hline & & \\
\hline & Creatividad & \\
\hline \multirow[b]{3}{*}{$\begin{array}{l}\text { Elementos para explorar } \\
\text { y organizar }\end{array}$} & Ciudadanía & \multirow{3}{*}{$\begin{array}{l}\text { Se identifica que los elementos exploratorios les proveen a los } \\
\text { niños y las niñas el planteamiento de interrogantes, estimular } \\
\text { la atención, la memoria, conocerse a sí mismos, practicar, } \\
\text { manipular y adquirir nuevos saberes guiados por su propia } \\
\text { curiosidad. } \\
\text { Por ejemplo: realizan diversas actividades, ya que es } \\
\text { un espacio abierto donde constantemente se están } \\
\text { realizando distintos eventos que les permiten a los niños } \\
\text { ver y experimentar cada día cosas nuevas y diferentes. Los } \\
\text { elementos de juego de lógica matemática como Tan Gram, } \\
\text { cubos mágicos, laberintos, pirámides, entre otros, han sido } \\
\text { de interés y los obligan a generar diversas estrategias para la } \\
\text { solución de problemas. }\end{array}$} \\
\hline & $\begin{array}{l}\text { Expresión y } \\
\text { reconocimiento de } \\
\text { emociones }\end{array}$ & \\
\hline & Creatividad & \\
\hline
\end{tabular}

\section{Instrumento de caracterización del uso del ambiente para la construcción de ciudadanía, la expresión y reconocimiento de emociones, y la expresión de la creatividad}

El análisis sobre el uso del ambiente para la construcción de ciudadanía, la expresión y reconocimiento de emociones y la expresión de la creatividad se realiza a partir de los tres ítems: espacio interior, espacio exterior y mobiliario. 


\section{Espacio interior}

- Ciudadanía: En el espacio interior de las ludotecas promueven la participación de los niños de manera espontánea. Al inicio, durante el desarrollo de las sesiones y al finalizar, las ludotecarias están recordando las reglas de convivencia y las normas para permanecer en la ludoteca. También se trabaja el tema de valores como el respeto, la escucha, la cooperación y la responsabilidad. En algunas ludotecas se cuenta con espacios para los juegos de mesa, el videojuego, la lectura, rincones de disfraces, la tienda, la cocinita, el hospital, el muñequero, los recorridos con las motos de plástico, el uso de herramientas de trabajo e instrumental de salud y la construcción de objetos y formas con fichas grandes y pequeñas.

- Expresión y reconocimiento de emociones: el espacio interior permite la expresión de emociones libremente; se induce a esto mediante juegos dirigidos, cuando se crean escenarios de juego y se facilitan juguetes para ello. Los niños y niñas expresan emociones con sus pares y adultos. El uso de juguetes, elementos como tapetes con rayuela o parqués dibujados permiten a los niños realizar juegos en los cuales se observa la capacidad de resolución de conflictos, expresar sus emociones cuando algo les desagrada, demostrar capacidad para comprender el comportamiento de sus compañeros y poder hacer algo en consecuencia.

- Creatividad: se identifica que el juego libre es uno de los elementos más importantes para desarrollar la creatividad, además se observa que los niños y ludotecarios hacen uso de los materiales de acuerdo con su intención de juego. En la mayoría de las ludotecas se cuenta con los suficientes elementos didácticos y lúdicos para despertar la 
creatividad e imaginación de los niños, para que creen partiendo de lo que hay y propongan nuevas formas de aplicación y/o utilización.

\section{Espacio exterior}

- Ciudadanía: el espacio exterior en algunas ludotecas no tiene un uso tan relevante, ya que la mayoría de las actividades se realizan dentro de ellas; sin embargo, en otras regiones su uso está dirigido a la organización previa para el ingreso de la ludoteca, donde se establecen acuerdos y normas para el desarrollo del juego libre.

- Expresión y reconocimiento de emociones: en algunas regiones se realizaron juegos por relevos, rondas y juegos libres, los cuales permiten la expresión de sentimientos y emociones de manera autónoma

- Creatividad: se identifica que en los espacios exteriores se realizan actividades como rondas, exploración libre y juegos imaginativos.

\section{Mobiliario}

- Ciudadanía: algunas regiones cuentan con un buen mobiliario que permite acoger cómodamente a los asistentes, les atrae la organización de sus elementos y además les enseña sobre el compañerismo, los valores y el trabajo en equipo para el alcance de metas comunes; sin embargo, en algunas ludotecas el uso de los mobiliarios no es tan recurrente por el interés de otros materiales con lo que cuenta la ludoteca (como juguetes).

- Expresión y reconocimiento de emociones: se identifica que el mobiliario genera una sensación de seguridad, pero al mismo tiempo los invita a controlarse, acatar órdenes, a entender que sus acciones pueden

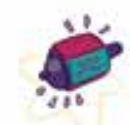


dañar a los demás, asumir pérdida y victoria de forma espontánea y a aceptar que hay cosas en la vida que, aunque se deseen, no se podrán tener; estas acciones se desarrollan en la mayoría de las veces en los juegos de mesa.

- Creatividad: el mobiliario le permite a los niños y niños explorar nuevas formas de diversión haciendo uso de lo que hay, imaginarse qué tan productivo puede ser si se les da un buen uso, identificar que beneficios les suministra e inventar estrategias de uso que ayuden a su conservación.

\section{Conclusiones de los hallazgos del estudio longitudinal}

Este estudio significó un esfuerzo importante, de tiempo y recursos, de las instituciones participantes, para dar cuenta de los comportamientos en distintas competencias de niños que asisten a las Ludotecas Naves. Durante cuatro años se utilizaron distintas estrategias, tanto cuantitativas como cualitativas, para capturar información de dichas competencias.

Los resultados cuantitativos señalan cambios importantes de las competencias entre los grupos a lo largo de los años. Se identificó un impacto importante de las Ludotecas Naves, medido como la diferencia entre las brechas de un primer momento y un último momento, principalmente en competencias emocionales, especialmente en la expresión de emociones y la autorregulación. Estas competencias parecen ser especialmente sensibles a la exposición al contexto de la ludoteca a lo largo del tiempo.

Un comportamiento similar se observa en algunas de las competencias ciudadanas, como interacción en el juego y manejo de reglas, pero especialmen- 


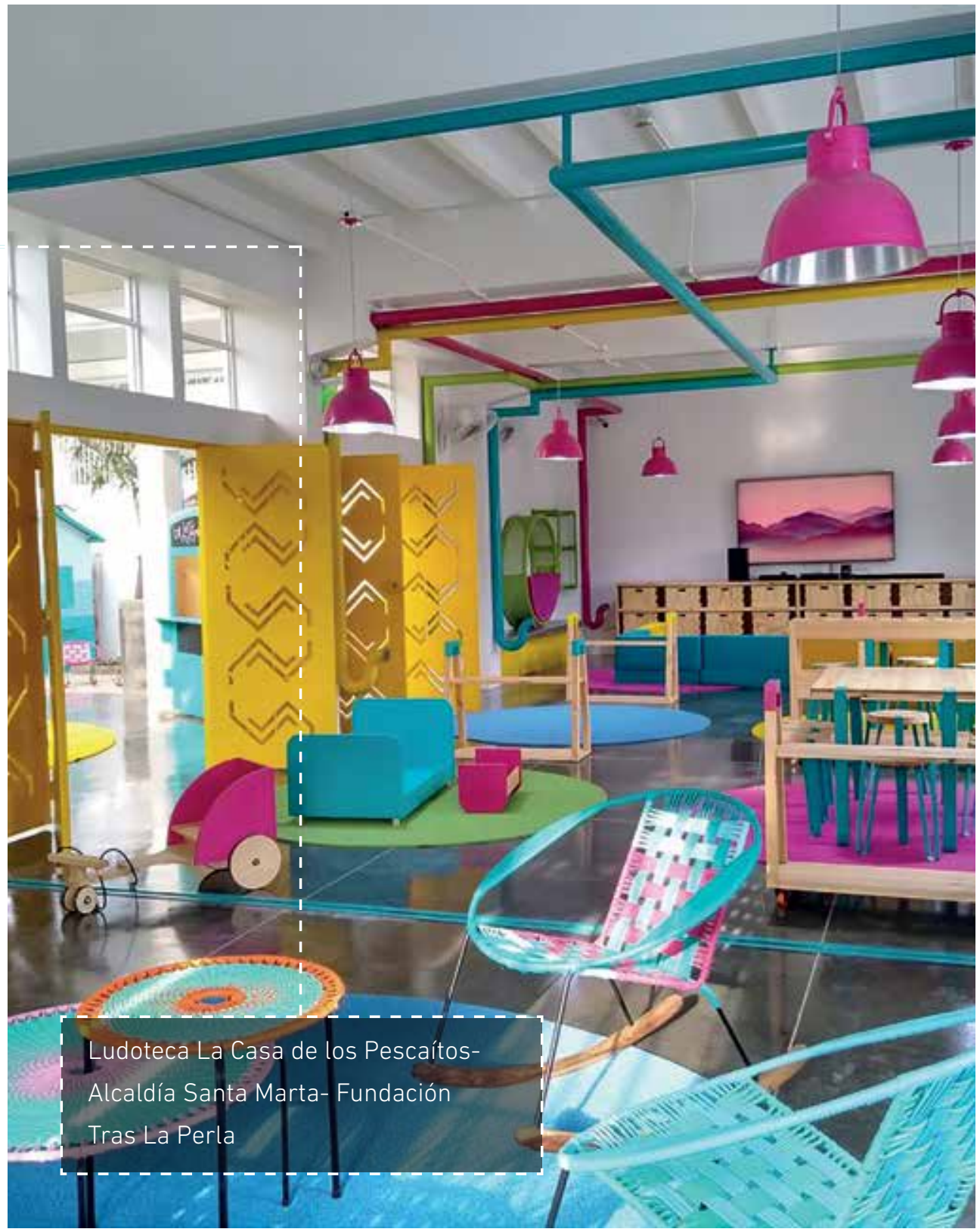

146

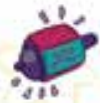


te se observa un impacto importante en el manejo de conflictos, una competencia muy importante para la vida en sociedad.

Lastimosamente, las competencias asociadas a la creatividad no mostraron un indicador de impacto significativo. Los comportamientos de los grupos fueron muy similares a lo largo de los años. Esto señala un lugar de trabajo importante para las ludotecas y su administración. Una dirección en la vía del desarrollo de la creatividad es recomendada, toda vez que esta competencia se ve afectada, de manera importante y directa, por los procesos de escolarización.

Los resultados cualitativos, por su parte, nos muestran algo importante: las Ludotecas Naves generan espacios no solo de diversión para los niños y niñas, sino también espacios de aprendizaje y socialización. Esto también permea en las familias de los niños y niñas que asisten a las ludotecas y quieren replicar en sus casas lo que aprenden en la ludoteca. Por su lado, los padres y madres aplauden la labor que se lleva a cabo con el programa y se notan, en su mayoría, receptivos a las invitaciones que se les hace y al cambio que plantea generar cada ludoteca.

Infortunadamente, existen condiciones externas que no permiten que el programa logre el alcance esperado en toda la comunidad; uno de ellos, por ejemplo, es la poca disponibilidad de tiempo por parte de los padres, debido, en la mayoría de los casos, a situaciones laborales. Sin embargo, la ludoteca se muestra como un espacio que colabora con estas familias que no cuentan con el tiempo suficiente. También se observa que se debe poner especial atención a los casos en los que las familias no sienten una cercanía entre la ludoteca y la comunidad, puesto que esto influye no solo en el ejercicio de la ludoteca, sino en el desarrollo de los niños y niñas que asisten con regularidad a esta. 
Por último, se celebra el trabajo desarrollado por el programa de Ludotecas Naves asistido técnicamente por la Corporación Juego y Niñez en cuanto al fomento del juego, el aprendizaje, el fortalecimiento de las relaciones familiares, el conocimiento de los derechos de niños y niñas, y los aportes de las ludotecas en el desarrollo de los niños y niñas, así como de la comunidad. En general, el balance es positivo e invita a que estos espacios se sigan desarrollando y promoviendo en diferentes regiones del país. 


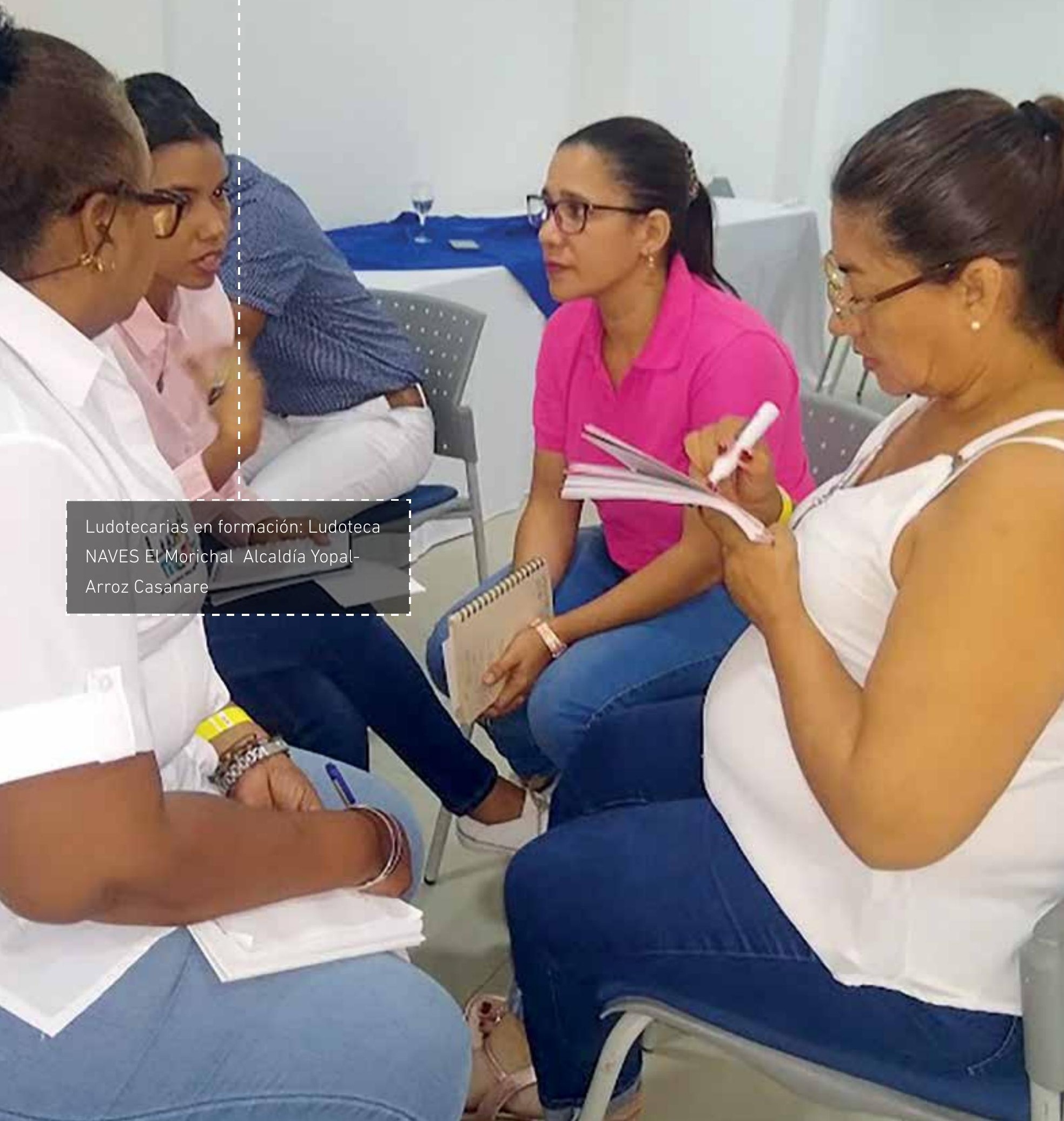




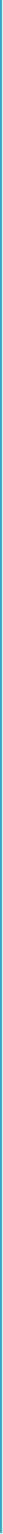


Conclusiones y

Recomendaciones

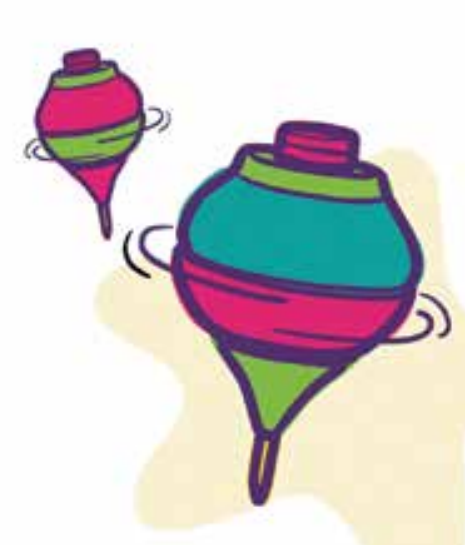

151 
Como se ha señalado a lo largo del libro, y a manera de resumen, este estudio nace de la necesidad de indagar los efectos de las ludotecas, y particularmente aquellas que hacen parte del programa ludotecas NAVES de infancia, en el desarrollo de una serie de competencias en niños y niñas de seis regiones de Colombia. Para esto se propuso un programa de evaluación de impacto con un seguimiento longitudinal a cuatro años (2015-2018), el más grande realizado en el país y en la región. Se contó con la participación de 540 niños y niñas de estas regiones, los cuales, por consideraciones de diseño del estudio, fueron distribuidos en dos grupos: uno, de niños que asistían a las ludotecas, y otro, de niños que no asistían. El criterio de selección de las ludotecas fue el tiempo de funcionamiento de esta (mayor a dos años). Se coordinó con las autoridades locales y ludotecarios de las distintas ciudades para ubicar la muestra de niños del grupo comparación.

Para esta investigación se diseñó un instrumento de observación dividido en tres dimensiones de análisis: competencias ciudadanas, competencias emocionales y creatividad. Cada dimensión, a su vez, evaluaba distintos componentes: en la dimensión de competencia ciudadana se valoraba participación y autonomía (PA), convivencia (CV), interacción en el juego (IJ), manejo de conflictos (MC) y manejo de reglas (MR); en la dimensión de competencia emocional se valoraba la expresión de emociones (EE), empatía (EM) y autorregulación (AR); y en la dimensión de creatividad se valoraba pensamiento divergente (PD), flexibilidad (FX) y elaboración (EB). Cada componente podía ser caracterizado en uno de cuatro niveles, que iban de un nivel bajo de expresión del componente (Valor 1) hasta un nivel alto (Valor 4). Además, el instrumento se diseñó para recoger información en dos situaciones distintas de observación: una, en un escenario de juego natural (espacio de descanso de los niños en ludoteca, jardín o colegio); y otra, en un escenario de juego en situación artificial (juego dirigido o propuesto por el observador).

| 152

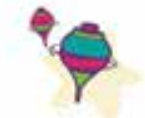


Luego de identificadas las ludotecas, jardines y colegios en los que se harían las observaciones, y luego de obtenidos los consentimientos de los padres, los observadores de campo (dos en cada ciudad), asistieron durante mes y medio a cada escenario de observación. Se realizaron observaciones de 15 niños durante una semana, ya fuese en la ludoteca (grupo de intervención), en colegios o jardines (grupo de comparación), dependiendo de la disponibilidad de los niños en las instituciones. Estas observaciones fueron repetidas durante la semana. Las observaciones de los profesionales que recolectaron la información se hicieron en parejas, como estrategia de triangulación de la información recabada. En promedio, se realizaron tres visitas por semana a cada institución, para tener consistencia en las valoraciones. Este análisis se complementó con información cualitativa, mediante entrevistas a estudiantes, a quienes se les indagó por las competencias señaladas; y a padres de familia, a quienes se les interrogó por los efectos de la asistencia a las ludotecas en las dinámicas y prácticas familiares.

Este proyecto longitudinal nos permite plantear las siguientes conclusiones:

- El juego como forma de manifestar nuestra humanidad, de expresarnos y de ser en el mundo, ha mostrado una serie de efectos positivos en una gama amplia de habilidades, capacidades y destrezas en el niño (Marín, 2009; Sicart, 2014). Por ejemplo, el juego es importante para el desarrollo motor (Park, Jeong, \& Bornman, 2011); el desarrollo de múltiples inteligencias (Eberle, 2011); la estimulación de procesos cognitivos y afectivos, importantes para el desarrollo de la creatividad (Russ \& Kaugars, 2001); el desarrollo social (Lancy \& Grove, 2011); la promoción del desarrollo moral (Davis \& Bergen, 2014); la construcción de un sentido de mayor comprensión de la existencia de reglas sociales (Benedet \& Zanella, 2011); el fomento del desarrollo de habilidades

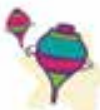


para la convivencia (Mejía \& Londoño, 2011) y la adaptación del niño al mundo (Önder, 2018).

- Gracias a la interacción con otros niños en escenarios lúdicos, el juego promueve el desarrollo del lenguaje y la solución de problemas (Gértrudix y Gértrudix, 2013; Holmes, Romeo, Ciraola, y Grushko, 2015). Por su parte, las ludotecas, como espacios privilegiados para la promoción del juego y que nacen de la voluntad de favorecer el derecho de los niños y niñas a este (Marín, 2009), han mostrado un sinnúmero de efectos importantes sobre el desarrollo infantil, especialmente cuando son entendidas como medio, mas no como fin, ya que promueven el desarrollo integral y facilitan la interacción entre pares (Ringoot et al., 2013), permiten cambios individuales, familiares y sociales importantes (Nicholson, 2013), fomentan el desarrollo de la imaginación, la creatividad y la autonomía (Managers, 2005) y favorecen el desarrollo cognitivo, psicomotor y socioafectivo (Rosas et al., 2015). En general, en las ludotecas, se aprovecha el juego como un factor que estimula el aprendizaje significativo, con el objetivo de que los niños que participan en ellas desplieguen una gama más amplia de habilidades (Fleisher, 2015).

- En el primer año del estudio (2015), se encontraron diferencias entre los grupos comparados en competencias como convivencia, manejo de reglas, expresión emocional, empatía, pensamiento divergente y flexibilidad, a favor de los niños que asisten a las ludotecas. También se identificaron aumentos significativos de los grupos en cada una de las competencias (ciudadanas, emocionales y de creatividad), a medida que aumentaba el rango de edad, en comparación con el grupo contraste, cuyos valores en las competencias disminuía. En cuanto a la competencia ciudadana, se observó una mejora en el promedio de la medición

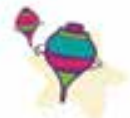


para el grupo intervenido. En cuanto a la competencia emocional y a la creatividad, también se observó un impacto positivo, aunque aparentemente con una variación más pequeña. Es muy importante resaltar que los resultados estadísticos muestran que las competencias que más se fortalecen en los niños mediante el programa de ludotecas Naves, en esta fase, son las relacionadas con la creatividad.

- El segundo año (2016), mostró diferencias específicas en manejo de conflictos, manejo de reglas, expresión de emociones, empatía, pensamiento divergente y flexibilidad, siendo mayor, para todos los casos, en el grupo de niños que asiste a la ludoteca. Al igual que con el año anterior, se observó un incremento de las competencias por rango de edad. Al comparar los desempeños de forma longitudinal, entre el primer año y el segundo, entre niños que asisten y que no, la competencia que más se ve impactada por las ludotecas es la empatía. Manejo de conflictos y autorregulación parecen ser competencias que se ven afectadas por el tiempo de permanencia en las ludotecas. La interacción en el juego y elaboración no muestran cambios entre los grupos.

- El tercer año del estudio (2017), mostró diferencias significativas en competencias como participación, convivencia, manejo de reglas, expresión de emociones, empatía, y flexibilidad. Comparativamente con años anteriores, la competencia ciudadana muestra un incremento significativo en el tercer año, la competencia emocional muestra una disminución en el grupo comparación a lo largo de los años, lo que contrasta con el desempeño de los niños que asisten a las ludotecas, mientras que el comportamiento de la creatividad es parecido entre los grupos. Se reconoce, en comparación con los resultados de los años anteriores, que las competencias de empatía, como competen-

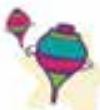


cia emocional, y flexibilidad, en creatividad, se mantienen en diferencias, lo que señala el efecto a largo plazo de las ludotecas sobre estas competencias específicas. Los resultados en la comparación por edad señalan las diferencias en cada una de las competencias analizadas entre los grupos etarios, siendo mayor la competencia a mayor edad. Sin embargo, la comparación con el grupo contraste parece señalar que el verdadero efecto de las ludotecas sobre las competencias está en el grupo de los 6 a los 9 años.

- En el cuarto año del estudio (2018), se identificaron diferencias estadísticamente significativas en todas las competencias entre los grupos. En análisis longitudinal confirma lo observado en 2016, respecto a que competencias como manejo de conflicto y autorregulación dependen del tiempo, y se ven incrementadas en los niños que asisten a las ludotecas. El análisis longitudinal señala impactos significativos en competencias como manejo de conflictos, manejo de reglas, expresión de emociones, y autorregulación. No se comprueban efectos a largo plazo en las competencias relacionadas con la creatividad.

- Estos hallazgos señalan la importancia de las ludotecas para el desarrollo de competencias, especialmente aquellas relacionadas con las competencias ciudadanas y emocionales. Este estudio muestra un efecto importante de las ludotecas en el desarrollo de las emociones, importantes para la interacción social, lo que concuerda con lo señalado por Lancy y Grove (2011), sobre el efecto del juego, elemento característico de estos espacios en el desarrollo de las emociones.

- Es evidente que las ludotecas generan espacios no solo de diversión para los niños y niñas, sino también espacios de aprendizaje y socia- 
lización. Esto también permea en las familias de los niños y niñas que asisten a las ludotecas y quieren replicar en sus casas lo que aprenden en la ludoteca. Por su lado, los padres y madres aplauden la labor que se lleva a cabo con el programa y se notan, en su mayoría, receptivos a las invitaciones que se les hace y al cambio que plantea.

- Para futuros estudios, es importante comprender las dinámicas que ocurren en otros escenarios lúdicos (por ejemplo, en instituciones educativas), para reconocer qué promueve las competencias en estos espacios formales y realizar nuevos estudios en otros escenarios (como hospitales o cárceles). También es importante comprender más a fondo el efecto de la cultura y de los contextos en las prácticas lúdicas, especialmente en comunidades indígenas y en comunidades campesinas.

\section{Recomendaciones}

1. Las ludotecas en Colombia deben trascender los espacios físicos. Deben contemplar un componente técnico que asegure una operación con perfiles formados que asuman el juego con sentido; un componente administrativo que gestione su sostenibilidad dentro de las políticas públicas locales y un componente de sistematización y gestión del conocimiento que ayude a aprender de las expresiones y sentires de los participantes.

2. Las ludotecas, como programas sociales que contribuyen enla formaciónde los niños, las niñas y sus familias, deben ser implementadas por las administraciones locales, asegurando su sostenibilidadconcriteriosde calidad y pertinencia. Uno delos factores que debegarantizarse es la vinculación de un talento humano que responda con compromiso, conocimiento y actituda la responsabilidad de serfacilitadores de

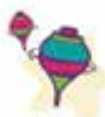


procesos desde y con el juego, para que los participantesavancen en sudesarrollo. Por ejemplo, cuando las alcaldías comprenden que las ludotecas son entornos protectores, el programa aporta grandes resultados en el desarrollo de la infancia y adolescencia.

3. Al ser un programa social, la ludoteca requiere de la vinculación de la comunidad, tanto en la planeación de sus ofertas como en el desarrollo y evaluación de estas. El programa es de la comunidad y esta lo debe usar, disfrutar y apropiar con el más alto sentido de bien común. Es decir, si bien las administraciones municipales son responsables de garantizar su implementación, la apropiación que la comunidad realice de la misma es un factor de sostenibilidad. Las comunidades están llamadas a participar de manera activa de estos procesos, para lo cual las ludotecarias y ludotecarios deben ser agentes articuladores que muestren el potencial de la ludoteca.

4. La ludoteca debe ofrecer a todos los niños y niñas, adolescentes, jóvenes y adultos una gama de alternativas de juego que reten y movilicen su dimensión lúdica para lograr que su potencial creativo, socioemocional y ciudadano tenga un piso de ricas experiencias, las cuales les permitirán encontrar en los conflictos, oportunidades, y en los riesgos, aprendizajes.

5. Uno de los factores centrales en los logros, resultados e impactos que las Ludotecas Naves tienen en las comunidades, en las familias, y en especial en los niños, las niñas y los adolescentes, es la ludotecaria o ludotecario, por lo cual es imprescindible una formación especializada en y con el juego. Debe ser un profesional coherente con el juego, para lo cual lo debe vivir, disfrutar, estudiar, profundizar, proponer y reinventarse siempre, enfocado en la construcción de nuevas experiencias 
que incorporen los elementos de su comunidad, pero también que abra la posibilidad a nuevas alternativas que viabilicen un verdadero desarrollo humano. Sería recomendable, entonces, que las instituciones de educación superior diseñen programas de formación de profesionales en el campo lúdico, para que incidan, por ejemplo, en el desarrollo de las habilidades socioemocionales, ciudadanas y de creatividad en las nuevas generaciones. En la medida en que se logre promover los niveles de profesionalización de los ludotecarios, se hará necesario el reconocimiento y creación de este cargo.

6. Es importante fortalecer las alianzas o asociaciones público-privadas para garantizar una inversión sostenida y significativa en programas sociales que hayan demostrado tener impacto en el desarrollo integral de los niños, niñas, adolescentes y sus familias. Se sugiere, por ejemplo, presentar a la confederación de cámaras de comercio y asociaciones empresariales las virtudes del desarrollo de las habilidades socioemocionales, ciudadanas y creativas en las nuevas generaciones, como necesarias para el buen desempeño empresarial y factor clave en el desarrollo del país.

7. Se recomienda estrechar los vínculos entre las ludotecas, las diferentes modalidades de atención integral a la primera infancia (AIPI), el Ministerio de Educación Nacional y las Secretarías de Educación para promover un diálogo sobre la importancia del juego y de la actitud lúdica en todo el ciclo vital y en todos los niveles educativos. Además, para reflexionar sobre la relación entre el juego, el desarrollo integral y el aprendizaje en todas las áreas o dominios del currículo, incluyendo el conocimiento social. Desde la perspectiva pedagógica, se comprende que la escuela tiene una gran responsabilidad, no solo frente a los

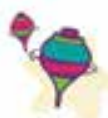


procesos de enseñanza-aprendizaje -relacionados con diferentes áreas del currículo-, sino en aquellos procesos que tienen que ver con el conocimiento social: conocimiento sobre uno mismo, sobre los otros, sobre las relaciones con otros, sobre los roles y las instituciones sociales, sobre los sistemas de valores y creencias y, en fin, sobre nuestro mundo social. La cognición social brinda los fundamentos para una educación que promueve el desarrollo sociomoral.

8. Un programa como las Ludotecas Naves puede ser fuente de conocimiento en el país para otros ambientes y espacios lúdicos porque sus lineamientos y estándares se validan con estudios como esta investigación.

9. Por último, se invita a extender el alcance de las ludotecas a otros escenarios que la requieren, por ejemplo, hospitales con pabellón de atención pediátrica, centros de salud que velan por el desarrollo y crecimiento de los menores de 5 años, jardines infantiles anexos a centros penitenciarios, centros de reclusión para menores de edad, entre otros. 
<smiles>C1CCCCC1</smiles> 


\section{Referencias bibliográficas}


Abuhatoum, S., \& Howe, N. (2013). Power in sibling conflict during early and middle childhood. Social Development, 22(4), 738-754. https://doi.org/10.1111/ sode.12021

Beck, L., Kumschick, I., Eid, M., \& Klann-Delius, G. (2012). Relationship between language competence and emotional competence in middle childhood. Emotion, 12(3), 503-514. https://doi.org/10.1037/a0026320

Benedet, M. C., \& Zanella, A. V. (2011). Brinquedoteca na escola: Tempos/espaços e sentidos do brincar. Arquivos Brasileiros de Psicologia, 63(2), 1-121.

Bisquerra, R., \& Pérez-Escoda, N. (2007). Las competencias emocionales. Educación $X X_{1}, 10,61-82$. https://doi.org/10.5944/educxX1.1.10.297

Borja, M. de. (1994). Las ludotecas como instituciones educativas. Enfoque sincrónico y diacrónico. Revista Interuniversitaria de Formación Del Profesorado, (19), 19-41. Recuperado de: https://dialnet-unirioja-es.biblioremot.uvic.cat/ servlet/articulo?codigo $=117809$

Bourdieu, P. (1999). La miseria del mundo. Buenos Aires: Fondo de Cultura Económica de Argentina.

Brougere, G. (2013). El niño en la cultura lúdica. Ludicamente, 2(4), 1-11.

Bruner, J. (1983). Juego, pensamiento y lenguaje. Madrid: Editorial Morata.

Bustillo, L., \& Martínez, J. (2008). Los enfoques del desarrollo sustentable. Revista Interciencia, 33(5), 389-395. 
Caillois, R. (1986). Los Juegos y los hombres: la máscara y el vértigo. México: Fondo de Cultura Económica.

Chaux, E. (2004). Formar para la ciudadanía... isí es posible!. Serie Guías Nº6. Estándares Básicos de Competencias Ciudadanas. Bogotá, Colombia: Ministerio de Educación Nacional.

Corporación Día de la Niñez. (2009). Ludotecas NAVES, jno solo juguetes! Orígenes, organización y metodología. Bogotá, Colombia: Divergráficas.

Corporación Día de la Niñez. (2014). Metodología NAVES. Su ser y su hacer. Bogotá: Divergráficas.

Corporación Juego y Niñez. (2017). Ludotecas Naves. Recuperado de: http://www. juegoyninez.org/ludotecas-naves

Davidson, A., Walton, M., \& Cohen, R. (2013). Patterns of conflict experience that emerge in peer reports and personal narratives during middle childhood. Applied Developmental Science, 17(3), 109-122. https://doi.org/10.1080/108 88691.2013 .804374

De Puig, I., \& Sátiro, A. (2011). Jugar a pensar. Recursos para aprender a pensar en educación infantil (4-5 años). Barcelona: Editorial Octaedro.

Denham, S. (2007). Dealing with feelings: how children negotiate the worlds of emotions and social relationships. Cognition, Brain, Behavior, 9(1), 1-48.

Donolo, D., \& Elisondo, R. (2007). Creatividad para todos. Consideraciones sobre un grupo particular. Anales de Psicología, 23(1), 147-151. 
Duek, C. (2016). El juego contemporáneo y las nuevas plataformas: la construcción de nuevos espacios de juego y de interacción. Intercom: Revista Brasileira de Ciências Da Comunicação, 39(1), 193-210. https://doi.org/10.1590/180958442016111

Duvignaud, J. (1982). El juego del juego. México: Fondo de Cultura Económica.

Enriz, N. (2011). Antropología y juego: apuntes para la reflexión. Cuadernos de Antropología Social, (34), 93-114.

Fayne, M., García, B., Montero, M., \& Valencia, A. (2013). Regulación materna y esfuerzo de control emocional en niños pequeños. International Journal of Psychological Research, 6(1), 30-40.

Fink, E. (1993). El juego como símbolo del mundo. París: Les Éditions de Minuit.

Fleisher, S. (2015). Where and how the child plays. American Academy of Political and Social Science, 121, 137-140.

Fragoso-Luzuriaga, R. (2015). Inteligencia emocional y competencias emocionales en educación superior, ¿un mismo concepto? Revista Iberoamericana de Educación Superior, 6(16), 110-125. https://doi.org/10.1016/j. rides.2015.02.001

Fredricks, J., \& Eccles, J. (2002). Children's competence and value beliefs from childhood through adolescence: Growth trajectories in two male-sextyped domains. Developmental Psychology, 38(4), 519-533. https://doi. org/10.1037/0012-1649.38.4.519 
Gadamer, H.-G. (1991). La actualidad de lo bello. Barcelona: Paidós.

Gadamer, H.-G. (2001). Verdad y método. Salamanca: Ediciones Sígueme.

Gaeta, M., \& López, C. (2013). Competencias emocionales y rendimiento académico en estudiantes universitarios. Revista Electrónica Interuniversitaria de Formación Del Profesorado, 16(2), 13-25. https://doi.org/10.6018/reifop.16.2.181031

García Márquez, G. (2014). La Proclama: por un país al alcance de los niños. Recuperado de: https://www.mineducacion.gov.co/cvn/1665/w3-article-340541.html

Garoz-Puerta, I. (2005). El desarrollo de la conciencia de regla en los juegos y deportes. Revista Internacional de Medicina y Ciencias de La Actividad Física y El Deporte, 5(19), 238-269.

Goleman, D. (2008). Inteligencia emocional (7a ed.). Barcelona: Editorial Kairós.

Guichot-Reina, V. (2015). El «enfoque de las capacidades» de Martha Nussbaum y sus consecuencias educativas: hacia una pedagogía socrática y pluralista. Teoría de La Educación. Revista Interuniversitaria, 27(2), 45-70. https://doi. org/10.14201/teoredu20152724570

Han, H. (2014). Supporting early childhood teachers to promote children's social competence: Components for best professional development practices. Early Childhood Education Journal, 42(3), 171-179. https://doi.org/10.1007/ s10643-013-0584-7 
Heckman, J. (2000). Policies to foster human capital. Research in Economics, 54(1), 3-56. https://doi.org/10.1006/reec.1999.0225

Herrera, M. (2004). Las nuevas tecnologías en el aprendizaje constructivo. Revista Iberoamericana de Educación, 34(3), 1-20.

Holmes, R., Romeo, L., Ciraola, S., \& Grushko, M. (2015). The relationship between creativity, social play, and children's language abilities. Early Child Development and Care, 185(7), 1180-1197. https://doi.org/10.1080/03004430.20 14.983916

Huizinga, J. (1972). Homo ludens. Madrid: Alianza Editorial.

Invernizzi, A., \& Williams, J. (2008). Children and citizenship. Londres: SAGE Publications.

Ireland, A., Sayers, A., Deere, K., Emond, A., \& Tobias, J. (2016). Motor competence in early childhood is positively associated with bone strength in late adolescence. Journal of Bone \& Mineral Research, 31(5), 1089-1098.

Johnson, J. (2007). Play and creativity. In Play and Creativity Conference. Tainan, Republic of China.

Kahneman, D. (2012). Pensar rápido, pensar despacio. Barcelona: Editorial Debate.

Kalinowski, M. (2010). A program showcase: Lu Nistou, Beaulieu sur Mer, France. Exchange, (800), 82-83. Recuperado de: https://ccie-catalog.s3.amazonaws.com/library/5019582.pdf 
Kapeleris, A., \& Paivio, S. (2011). Identity and emotional competence as mediators of the relation between childhood psychological maltreatment and adult love relationships. Journal of Aggression, Maltreatment and Trauma, 20(6), 617-635. https://doi.org/10.1080/10926771.2011.595764

Kishimoto, T. (2011). Jogo, brinquedo, brincadeira e a educação. São Paulo: Cortez Editora.

Lado, A., Ismach, L., \& Rossi, I. (2002). La mediación del aprendizaje hoy por hoy y el derecho a aprender. Recuperado de: http://www.delasallesuperior.edu. ar/biblioteca/mediacion_\%2oderecho_aprender.pdf

LaFreniere, P. (2013). Children's play as a context for managing physiological arousal and learning emotion regulation. Psychological Topics, 22(2), 183-204.

López, M., Arán-Filippetti, V., \& Richaud, M. (2014). Empatía: desde la percepción automática hasta los procesos controlados. Avances En Psicología Latinoamericana, 32(1), 37-51. https://doi.org/10.12804/apl32.1.2014.03

Managers, S. (2005). Toy libraries. Every Child, 11(3), 1-32.

Mantilla, L. (1991). El juego y el jugar ¿Un camino unilineal y sin retorno? Estudios Sobre Las Culturas Contemporáneas, 4(12), 101-123.

Marín, I. (2009). Jugar, una necesidad y un derecho. Revista de Psicologia, Ciències de l'Educació I de l'Esport, 25, 233-249.

Masten, A. (2006). Developmental psychopathology: Pathways to the future. International Journal of Behavioral Development, 31, 47-54. 
Masten, A., Coatsworth, J., Neemann, J., Gest, S., Tellegen, A., \& Garmezy, N. (1995). The structure and coherence of competence from childhood through adolescence. Child Development, 66(6), 1635-1659. https://doi.or$\mathrm{g} / 10.1111 / \mathrm{j} .1467-8624.1995 . t b 00956 . x$

Masten, A., Desjardins, C., McCormick, C., Kuo, S., \& Long, J. (2010). The significance of childhood competence and problems for adult success in work: a developmental cascade analysis. Development and Psychopathology, 22(3), 679-694. https://doi.org/10.1017/So954579410000362

Masten, A., Morison, P., \& Pellegrini, D. (1985). A revised class play method of peer assessment. Developmental Psychology, 21(3), 523-533. https://doi. org/10.1037/0012-1649.21.3.523

Matsumoto, D., Hwang, H., López, R., \& Pérez-Nieto, M. (2013). Lectura de la expresión facial de las emociones: Investigación básica en la mejora del reconocimiento de emociones. Ansiedad y Estrés, 19(2-3), 121-129.

Maturana, H. (2001). Formación humana y capacitación. Buenos Aires: Dolmen Editores.

Max-Neef, M., Elizalde, A., \& Hopenhayn, M. (1986). Desarrollo a escala humana: Una opción para el futuro. Santiago de Chile: CEPAUR/Fundación Dag Hammarskjöld.

Mejía, R., \& Londoño, L. (2011). Diseño de juegos para el cambio social. Revista Kepes, 8(7), 135-158. 
MEN. (2009). Desarrollo infantil y competencias en la Primera Infancia. Documento $n^{\circ}$ 10. Bogotá: Ministerio de Educación Nacional.

Moreno, G. (2000). Espacio para la infancia. La Haya, Países Bajos: Bernard van Leer Foundation.

Nicholson, S. (2013). Playing in the past: A history of games, toys, and puzzles in North American Libraries. Chicago Journals, 83(4), 341-361.

Niec, L., \& Russ, S. (2002). Children's internal representations, empathy, and fantasy play: A validity study of the SCORS-Q. Psychological Assessment, 14(3), 331-338. https://doi.org/10.1037//1040-3590.14.3.331

Nussbaum, M. (2010). Sin fines de lucro. Por qué la democracia necesita de las humanidades. Buenos Aires: Katz Editores.

Nussbaum, M. (2014). Las emociones políticas. ¿Por qué el amor es importante para la justicia? Barcelona: Paidós.

Ochman, M., \& Escalante, J. (2013). Sistematización y evaluación de las competencias ciudadanas para sociedades democráticas. Revista Mexicana de Investigacion Educativa, 18(56), 63-89.

Ochsner, K., \& Gross, J. (2005). The cognitive control of emotion. Trends in Cognitive Sciences, 9(5), 242-249.

Ortega, R. (2006). La convivencia: Un modelo de prevención de la violencia. In A. Moreno \& M. P. Soler (Eds.), La convivencia en las aulas: Problemas y soluciones. Madrid: Ministerio de Educación y Ciencia. 
Pavia, V. (2018). Relatos en juego. Neuquén, Argentina: Editorial Universidad Nacional de Comahue.

Penela, E., Walker, O., Degnan, K., Fox, N., \& Henderson, H. (2015). Early behavioral inhibition and emotion regulation: Pathways toward social competence in middle childhood. Child Development, 86(4), 1227-1240. https://doi. org/10.1111/cdev.12384

Pérez-Escoda, N., Velar, K., \& Ruiz-Bueno, A. (2014). Competencias emocionales y depresión en cuidadores familiares de personas mayores dependientes. Ansiedad y Estrés, 20(2-3), 181-191.

Piaget, J. (1979). La formación del símbolo en el niño. México: Fondo de Cultura Económica.

Piaget, J. (1991). Seis estudios de psicología. Barcelona: Editorial Labor.

Power, T. (2011). Social play. In P. Smith \& C. Hart (Eds.), The Wiley-Blackwell Handbook of Childhood Social Development (2nd ed., pp. 455-471). Malden, MA: Blackwell Publishing Ltd.

Ramírez, M. (2009). La mediación en el proceso de enseñanza-aprendizaje. Innovación y Experiencias Educativas, (14), 1-9.

Reed, T., \& Brown, M. (2000). The expression of care in the Rough and Tumble play of boys. Journal of Research in Childhood Education, 15(1), 104-116. https:// doi.org/10.1080/02568540009594779 
Rendón, M. (2007). Regulación emocional y competencia social en la infancia. Revista Diversitas, 3(2), 349-363.

Reyes, N. (2012). Las ludotecas: orígenes, modelos educativos y nuevos espacios de socialización infantil. Universidad de Granada. Recuperado de: http:// digibug.ugr.es/bitstream/10481/21771/1/20959370.pdf

Ringoot, A., Jansen, P., Steenweg-de Graaff, J., Measelle, J., van der Ende, J., Raat, H., ... Tiemeier, H. (2013). Young children's self-reported emotional, behavioral, and peer problems: The Berkeley Puppet Interview. Psychological Assessment, 25(4), 1273-1285. https://doi.org/10.1037/aoo33976

Riquelme, E., Munita, F., Jara, E., \& Montero, I. (2013). Reconocimiento facial de emociones y desarrollo de la empatía mediante la Lectura Mediada de literatura infantil. Cultura y Educación, 25(3), 375-388. https://doi. org/10.1174/113564013807749704

Rodríguez, L., Russián, G., \& Moreno, J. (2009). Autorregulación emocional y actitudes ante situaciones de agravio. Revista de Psicología UCA, 5(10), 25-44.

Root, A., \& Denham, S. (2010). Focus on gender, parent and child contributions to the socialization of emotional competence. New Directions for Child and Adolescent Development, 128, 29-49.

Rosas, R., Ceric, F., Aparicio, A., Arango, P., Arroyo, R., Benavente, C., ... Véliz, S. (2015). ¿Pruebas tradicionales o evaluación invisible a través del juego? Nuevas fronteras de la evaluación cognitiva. Psykhe, 24(1), 1-11. https://doi. org/10.7764/psykhe.23.2.724 
Ruiz, A., \& Chaux, E. (2005). La formación de competencias ciudadanas. Bogotá, Colombia: ASCOFADE.

Saarni, C. (1999). The development of emotional competence (1st ed.). New York, NY: Guilford Press.

Salazar, C., \& Chiang, M. (2007). Competencias y educacion superior. Un estudio empírico. Horizontes Educacionales, 12(2), 23-35. Recuperado de: http:// wWw.redalyc.org/articulo.oa?id=97917592003

Salazar, I., \& Flórez, A. (2019). El juego como factor protector de los niños y las niñas. Revista 70, 62-63.

Sánchez-Aragón, R., \& Díaz-Loving, R. (2009). Reglas y preceptos culturales de la expresión emocional en México: su medición. Universitas Psychologica, 8(3), 793-805.

Santos, A., \& Salgado, J. (2006). ¿Para que sirve una ludoteca? Psicología Educativa, 12(2), 123-132.

Saracho, 0. (2002). Young children's creativity and pretend play. Early Child Development and Care, 172(5), 431-438. https://doi.org/10.1080/03004430214553

Sarlé, P. (2010). Lo importante es jugar: ¿Cómo entra el juego en la escuela? Santa Fe, Argentina: Homo Sapiens Ediciones.

Sátiro, A. (2006). Jugar a pensar con mitos (8-9 años): Guía para educadores. Barcelona: Editorial Octaedro. 
Scheines, G. (1998). Juegos inocentes, juegos terribles. Buenos Aires: Editorial Universitaria de Buenos Aires.

Seargeant, L. (2011). Play power: how to turn around our creativity crisis. The Atlantic, 1. Retrieved from https://www.theatlantic.com/business/archive/2011/05/play-power-how-to-turn-around-our-creativity-crisis/238167/

Sen, A. (1987). On ethics and economics. Oxford: Basil Blackwell.

Sen, A. (1999). Development as freedom. Oxford, UK: Oxford University Press.

Shiner, R., \& Masten, A. (2012). Childhood personality as a harbinger of competence and resilience in adulthood. Development and Psychopathology, 24(2), 507-528.

Sutton-Smith, B. (2009). La ambigüedad del juego. In D. Aranda \& J. Sánchez-Navarro (Eds.), Aprovecha el tiempo y juega (pp. 37-59). Barcelona: Editorial UOC.

Tirado, M. (1998). El juego y el arte de ser... humano. Medellín, Colombia: Universidad de Antioquia.

Tonucci, F. (2015). La ciudad de los niños. Barcelona: Editorial Graó.

UNESCO-OCDE. (2016). Habilidades para el progreso social. El poder de las habilidades sociales y emocionales. París: Autor.

van der Wilt, F., van Kruistum, C., van der Veen, C., \& van Oers, B. (2015). Gender differences in the relationship between oral communicative competence and peer rejection: an explorative study in early childhood education. 
European Early Childhood Education Research Journal, 1-11. https://doi.org/10.1080/1350293X.2015.1073507

Vidart, D. (1995). El juego y la condición humana: Notas para una antropología de la libertad en la necesidad. Montevideo, Uruguay: Ediciones de la Banda Oriental.

Weaver, C., Shaw, D., Crossan, J., Dishion, T., \& Wilson, M. (2015). Parent-child conflict and early childhood adjustment in two-parent low-income families: Parallel developmental processes. Child Psychiatry and Human Development, 46, 94-107. https://doi.org/10.1007/s10578-014-0455-5

Wilson, E. (1982). Sociobiology. The new synthesis. Cambridge, MA: Harvard University Press.

Winnicott, D. (1982). Realidad y juego. Barcelona: Gedisa.

Yogman, M., Garner, A., Hutchinson, J., Hirsh-Pasek, K., \& Golinkoff, R. (2018). The power of play: a pediatric role in enhancing development in young children. Pediatrics, 142(3), 1-16. 

Este libro se terminó de imprimir en septiembre de 2019

Todas las fotografías son tomadas de unsplash.com 

Este libro presenta los resultados de la primera investigación longitudinal que se ha realizado en el mundo en ludotecas sobre el impacto en el comportamiento de los niñas y las niñas cuando juegan con una metodología específica, como es la Metodología Naves(niños, niñas aprendiendo, viviendo, experimentando y socializando) de la Corporación Juego y Niñez. Este estudio consignó durante 4 años, observaciones, mediciones, y pruebas que el grupo de investigación Cognición y Lenguaje de la Universidad Nacional realizaron bajo la batuta de la profesora Titular de este claustro, la doctora Rita Flórez, de la mano del docente investigador Jaime Castro y con la activa participación de colaboradores de la Corporación y ludotecarios de los territorios focalizados.

El presente trabajo se hace desde la perspectiva de que el juego es el recurso natural más importante en una economía creativa ya que es uno de los lenguajes naturales del ser humano indispensable en el desarrollo de las personas y sus comunidades y por supuesto, un derecho.

Esta perspectiva del juego, es fundamental para La Corporación Juego y Niñez y por ello es que impulsa la Celebración Día de la Niñez en 1999 y El Estado la eleva a ley de la República -724 de 2001 con la certeza que los niños, niñas, adolescentes y jóvenes de Colombia cuando juegan como parte de su ser, se empoderan para influir en su realidad y fortalecen sus habilidades socioemocionales, ciudadanas, creativas y en general para la vida.

Estos resultados son un aporte para que los tomadores de decisiones sobre espacios y ambientes lúdicos y culturales como las ludotecas, encuentren en metodologías como Naves, un camino a seguir para implementar políticas públicas de niñez y adolescencia con alto impacto y gran calidad. 